SAND95-0331

Unlimited Release

Printed June 1996

\title{
Advanced Drilling Systems Study
}

\author{
K. G. Pierce \\ Strategic Studies Center \\ Sandia National Laboratories \\ Albuquerque, NM 87185-0419
}

\author{
B. J. Livesay \\ Livesay Consultants \\ 126 Countrywood Lane \\ Encinitas, CA 92024
}

\author{
J. T. Finger \\ Geothermal Research Department \\ Sandia National Laboratories \\ Albuquerque, NM 87185-1033
}

\begin{abstract}
This report documents the results of a study of advanced drilling concepts conducted jointly for the Natural Gas Technology Branch and the Geothermal Division of the U.S. Department of Energy. A number of alternative rock cutting concepts and drilling systems are examined. The systems cover the range from current technology, through ongoing efforts in drilling research, to highly speculative concepts. Cutting mechanisms that induce stress mechanically, hydraulically, and thermally are included. All functions necessary to drill and case a well are considered. Capital and operating costs are estimated and performance requirements, based on comparisons of the costs for alternative systems to conventional drilling technology, are developed. A number of problems common to several alternatives and to current technology are identified and discussed.
\end{abstract}




\section{ACKNOWLEDGMENTS}

Through the course of this study, the authors have discussed advanced-drilling concepts and systems with a large number of people closely involved with drilling, drilling operations, and drilling research. Some of these people we have known and been associated with for some time; others we met only in the course of this effort. Almost without exception, these individuals were completely open in discussing their knowledge and experience with drilling systems and in providing the authors with data and documentation on both current and past efforts. Without this cooperation and courtesy, this study would not have been possible.

Work performed at Sandia National Laboratories is supported by the U.S. Department of Energy under contract DE-AC04-94AL8500. 


\section{CONTENTS}

Section I: Executive Summary

Section II: Introduction

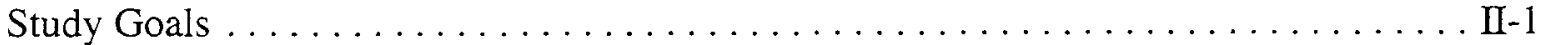

Methodology . . . . . . . . . . . . . . . . . .

Section III: Functional Descriptions

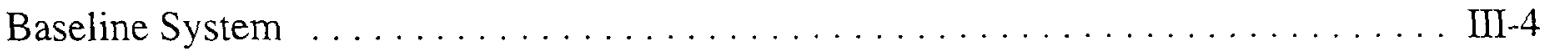

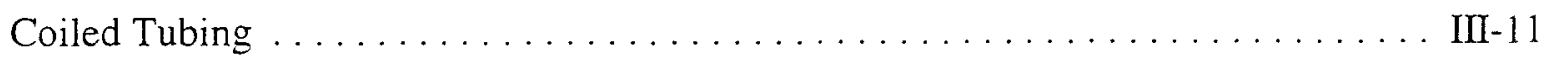

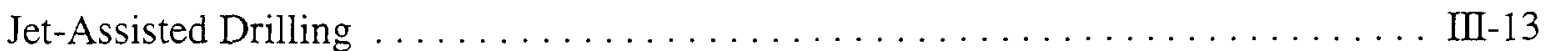

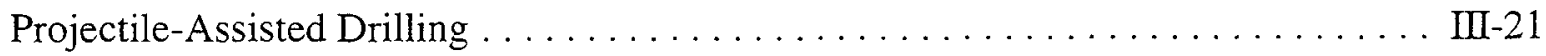

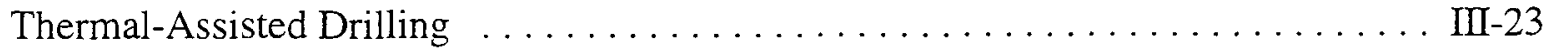

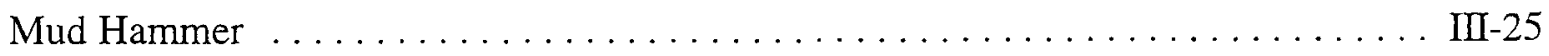

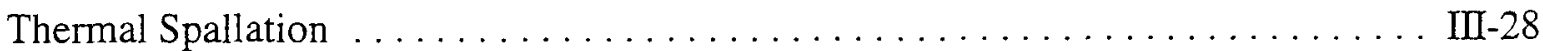

Spark Drill . . . . . . . . . . . . . . . . . . . . . . . . . III-32

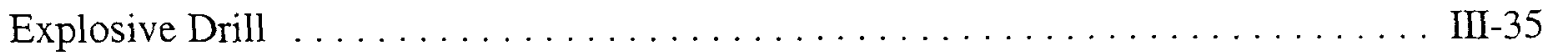

Rock Melters . . . . . . . . . . . . . . . . . . . . . . . III-38

Pulsed-Laser Water-Jet . . . . . . . . . . . . . . . . . . . . . III-43

Impact of Advanced Systems . . . . . . . . . . . . . . . . . . . III-45

Section IV: System Limitations, Needs, and Common Problems

System Limitations and Technology Needs $\ldots \ldots \ldots \ldots \ldots \ldots \ldots \ldots \ldots \ldots \ldots$ IV -2

Common Problems . . . . . . . . . . . . . . . . . . . . . . . IV -9

Section V: Cost and Performance

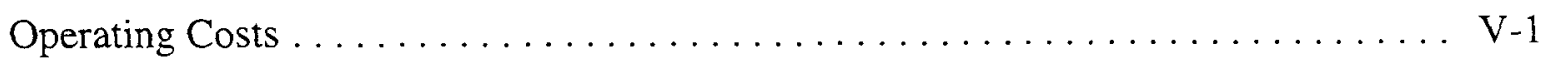

Conventional Rotary Performance $\ldots \ldots \ldots \ldots \ldots \ldots \ldots \ldots \ldots \ldots \ldots \ldots \ldots \ldots$

Performance Requirements . . . . . . . . . . . . . . . . . . . . . .

Coiled Tubing Rig . . . . . . . . . . . . . . . . . . . . . . . V

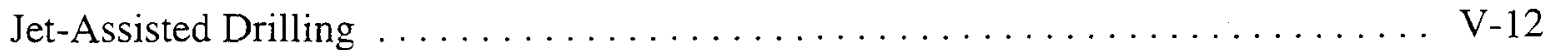

Projectile-Assisted Drilling $\ldots \ldots \ldots \ldots \ldots \ldots \ldots \ldots \ldots \ldots \ldots \ldots \ldots \ldots \ldots \ldots \ldots$

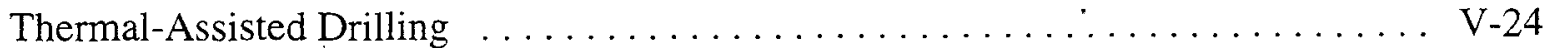

Mud Hammer $\ldots \ldots \ldots \ldots \ldots \ldots \ldots \ldots \ldots \ldots \ldots \ldots \ldots \ldots \ldots \ldots \ldots . \ldots \ldots \ldots$

Thermal Spallation - Downhole Separator . . . . . . . . . . . . . . . . V V-29

Spark Drill - Tetra Cost Estimates . . . . . . . . . . . . . . . . . V-33

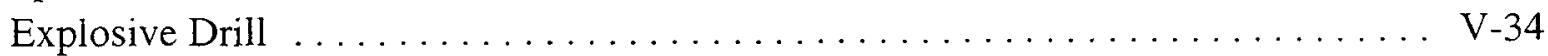

Rock Melters ................................. . V-35

Pulsed-Laser Water-Jet . . . . . . . . . . . . . . . . . . . . . . V-41

Section VI: Development Status

Section VII: Conclusions

Section VIII: References

Section IX: Appendices

A: Drilling Performance Curves $\ldots \ldots \ldots \ldots \ldots \ldots \ldots \ldots \ldots \ldots \ldots \ldots \ldots \ldots \ldots$

B: Interval Definition and Costs $\ldots \ldots \ldots \ldots \ldots \ldots \ldots \ldots \ldots \ldots \ldots$ VIII-7

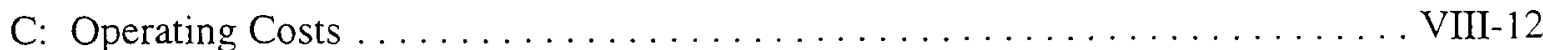

D: Rental Rates . . . . . . . . . . . . . . . . . . . . . . . . . VIII-24 



\section{EXECUTIVE SUMMARY}

Because drilling is ubiquitous in the oil, gas, geothermal, minerals, water well, and mining industries, there is great interest in reducing its cost. Areas for improvement, however, are not obvious. Both government laboratories and industry maintain ongoing research projects, but these are typically aimed at incremental changes in performance and cost. Although the U. S. Department of Energy's Geothermal Division funds some investigation of revolutionary drilling and excavation methods, the generally declining state of U. S. oil and gas activity over the past 15 years has greatly decreased industry support for revolutionary technology. This report describes the present situation in advanced drilling research and provides background and guidance to government and industry policy-makers responsible for that research.

The report is divided into two major sections: a functional description of alternative drilling systems, with emphasis on how each system differs from the baseline technology called "conventional rotary drilling"; and a cost/performance analysis of each system which estimates what performance it must achieve to be economically viable. We have been careful, in both the functional descriptions and the cost/performance analyses, to examine the complete system; that is, to look at all functions required to make and preserve a hole, not just at the rock-breaking mechanism.

Data have been collected from published and unpublished drilling research, existing texts on alternative drilling systems, and extensive interviews with workers in industry, academia, and government laboratories. We have considered systems which break rock mechanically, hydraulically, thermally, and by combinations of these methods. Some systems use gaseous drilling fluid and some use mud. Some systems described as "alternative" are commercially available and cost-competitive in limited cases, while others are little more than laboratory curiosities. After thorough examination of this great accumulation of drilling research, however, certain conclusions are clear.

- Except in hard rock, completion dominates well cost -- If penetration rate is 20 feet-perhour, the time cost of cutting rock is less than $20 \%$ of total well cost, while the casing and cement may be more than half the well cost. This proportion is somewhat dependent on hole diameter, but it is generally true that improving, even doubling or tripling, penetration rate in soft rock does not bring revolutionary improvement to drilling economics. Because lower penetration rates in hard rock increase the amount of time spent drilling, and because most drilling costs are time-related, the potential savings from improved performance in hard rock are much greater. Increasing national attention to geothermal and deep natural gas reservoirs may expand hard-rock drilling's market share, even in the short term. 
- Changing the rock cutting mechanism may have little effect on drill rig cost -- The size of the rig's mast and substructure is usually determined by the weight of the casing to be run into the well, and capacity of the mud pumps and mud cleaning system is based on the quantity of chips to be produced, not on the way the chips are produced. Size and complexity of the surface system is largely independent of the rock-reduction method.

- Today's drilling industry is not conducive to radically new technology -- Rigs are stacked, out of service, all over the world and profit margins are thin for the ones that are working. Early trials of any advanced drilling system would almost certainly take place on an existing rig, but even so, the cost of modifying the rig and training the crews could be significant. These costs, and the risk of unproved technology, tend to discourage a drilling contractor from experimentation. In some cases the contractor may even believe that his interest is not served by improving performance, if that shortens the job and reduces the amount of time for which he is paid. We believe this view is wrong and discuss it in more detail on page IV-1.

The drilling systems examined for this report vary widely in principle, promise and technical maturity. In considering whether a particular technology merits further development, it is important to maintain a systems approach and examine all aspects of drilling operations, not just the rock-breakage mechanism. With this methodology, it is very speculative to extrapolate performance of a complete system from limited laboratory data, so we have approached this problem by comparing estimated costs and service lives of the alternative systems to conventional rotary drilling. This allows an analysis of what performance is necessary for each system to be cost-competitive with conventional technology. These analyses indicate that alternative systems can be competitive if their rates of penetration are better than rotary drilling by ratios ranging from five down to slightly more than one, depending on the formation being drilled. These calculations, which also include assumptions of service life, are encouraging in that the required performance improvements appear to be within reach of a reasonable development effort.

In evaluating a particular technology's potential acceptance by the drilling industry, it is also crucial to recognize that risk-avoidance is at least as important as direct cost savings. With these factors in mind, we believe that the identification in this report of strengths and weaknesses in alternative drilling systems will aid in directing further drilling research. 


\section{INTRODUCTION}

Because drilling is ubiquitous in the oil, gas, geothermal, minerals, water well, and mining industries, there is great interest in reducing its cost. Areas for improvement, however, are not obvious. Both government laboratories and industry maintain ongoing research projects, but these are typically aimed at incremental changes in performance and cost. Although the U. S. Department of Energy's Geothermal Division funds some investigation of revolutionary drilling and excavation methods, the generally declining state of U. S. oil and gas activity over the past 15 years has greatly decreased industry support for revolutionary technology. This report describes the present situation in advanced drilling research and provides background and guidance to government and industry policy-makers responsible for that research.

Interest in revolutionary drilling systems is driven by the possibility of very large cost benefits. Because the industry is so large (oil and gas worldwide drilling expenditures approach $\$ 75$ billion per year), saving small percentages of drilling cost can translate into large dollar amounts. Reduced drilling cost might also enable economic developments which presently aren't done at all -- many depleted and relatively low yield oil and gas reservoirs could become economically viable with cheaper drilling. For the development of geothermally-produced electric power, drilling and well completion account for $25 \%$ to $50 \%$ of the cost of producing electricity.

Attempts to improve or replace rotary drilling technology date back to at least the 1930's. Many novel and even exotic concepts were examined in the 1960s and 1970s, with some continued development through the 1980s. The breadth of this effort -- documented in Novel Drilling Techniques (Maurer 1968) and Advanced Drilling Techniques (Maurer 1980) -- means that new work on advanced drilling systems is likely to build on an idea or a variation of an idea that has already been investigated. Although this may save a great deal of work toward establishing a foundation for an alternative technology, it may also be a disincentive for truly revolutionary work. We believe, therefore, that a review of these previous concepts, coupled with estimates of their technical maturity and the performance which would be required to make them viable drilling systems, will be a valuable tool in directing future work. That concept provides the basis for this study.

\section{STUDY GOALS}

The goals of this study are to update the history and current status of research in advanced drilling and to identify promising concepts for further development, thus providing the guidance described above. This will require the following tasks: 


\section{Introduction}

- Provide system descriptions

- Identify the strengths and weaknesses of various concepts

- Identify common needs and problems among systems

- Estimate capital and operating costs for each system

- Assess system performance required for viability

The principal difficulty in performing these tasks across the broad spectrum of past work is a radical difference in the amount of data available about various research projects. Some systems and components have reached limited commercialization, while other concepts have been only bench-scale experiments in the laboratory. Nevertheless, we have attempted to describe and evaluate each of the systems in a standard format, with the results appearing in the report in the order shown above.

\section{METHODOLOGY}

The first step in the study, primarily a literature search, established a list of advanced concepts. This search also produced a list of people now or previously involved in drilling research. Using a combination of published and unpublished data, interviews, and contact with companies engaged in on-going research, the list of advanced drilling concepts was refined. In an attempt to describe these systems in a standard format, the drilling process was subdivided into the following six functions which are necessary to provide a useful hole:

- Transmission of energy to the system-rock interface

- Reduction of the rock

- Removal of the rock

- Maintenance of the borehole (formation stability) while drilling

- Control of formation fluids (well control)

- Preservation of the borehole (completion)

The last function, completion, includes casing and cement. Since a well can be drilled without setting casing, completion is not required to make the hole, but it is included because it is a significant well cost and is necessary for the well to be useful.

In addition to the drilling functions, any system must also operate under at least the following technical or institutional constraints:

- Environmental impact

- Operational safety

- Government regulations

- Directional drilling and control

- Sensing and communication 
For example, regulatory restrictions on environmental impacts such as system footprint, emissions to the local environment, and control and disposal of hazardous materials, must be satisfied. Similarly, operational safety features must not only meet state and OSHA requirements, but often the operator's individual safety program as well. Most systems must be capable of directional control and must have some capability for sensing and communication with the operator (these last two constraints are not considered functions because they are not universal in all wells).

Having defined these criteria, each of the alternative systems is described in terms of how it performs the six functions and how that performance compares with what we call "conventional rotary drilling." The functional descriptions of the systems -- along with what we believe to be their advantages and disadvantages -- appear in Section III. A discussion of the variation in data availability for the different systems and its consequences is also in this section. Because many of the advanced systems share functional similarities, some of the technology needs overlap among several systems. These common problems are described in Section IV.

Once a system is functionally defined, and a detailed list of its capital and operating costs is derived, an ideal approach would be to compare the alternative system's performance at that cost with conventional rotary drilling. For many of the advanced systems, however, extrapolation of laboratory performance (the only data available) to actual field use is highly speculative. To allow for this uncertainty, we used the related strategy of calculating the performance that would be required from an alternative system to be cost-competitive with conventional rotary drilling. This comparison required several different activities: collection of cost data for current drilling practices; estimation of costs for the advanced system; modeling rigs and drilling operations; modeling rental rates for equipment; and selecting reasonable business approaches for cost generation. These tasks are described in detail in the appendices, and the cost/performance conclusions are given in Section $\mathrm{V}$.

In both the descriptions and the cost/performance analyses, we have been careful to consider the complete drilling system. Many studies of advanced systems concentrate on methods of reducing rock with little or no discussion of how these methods would fit into a comprehensive system necessary to drill, provide well control, and line the wellbore. Unless the entire system is considered, much effort and money could be spent improving specific aspects of drilling technology only to discover that other facets of the problem prevent successful deployment of the system. Consequently, this study has not just investigated novel methods for reducing rock, but has attempted to examine all aspects of drilling systems necessary to make and complete a well. 
Introduction

This page intentionally left blank

page $I I-4$ 


\section{FUNCTIONAL DESCRIPTIONS OF DRILLING SYSTEMS}

The process of drilling, rather than digging, holes in the ground has been under development for thousands of years, but the techniques we now know as "conventional rotary drilling" began to be developed around the end of the nineteenth century. This technology, with only minor variations, is ubiquitous in the oil, gas, geothermal, minerals, water well, and mining industries. There is an extensive literature on the principles and practices of this kind of drilling (Bourgoyne, et al; Gatlin; Moore), and what we describe as the baseline system -- a tall, steel derrick supporting a string of pipe which turns a bit to drill the hole - is at least superficially familiar to almost everyone.

Because the drilling industry, in all its manifestations, is very large, there have been

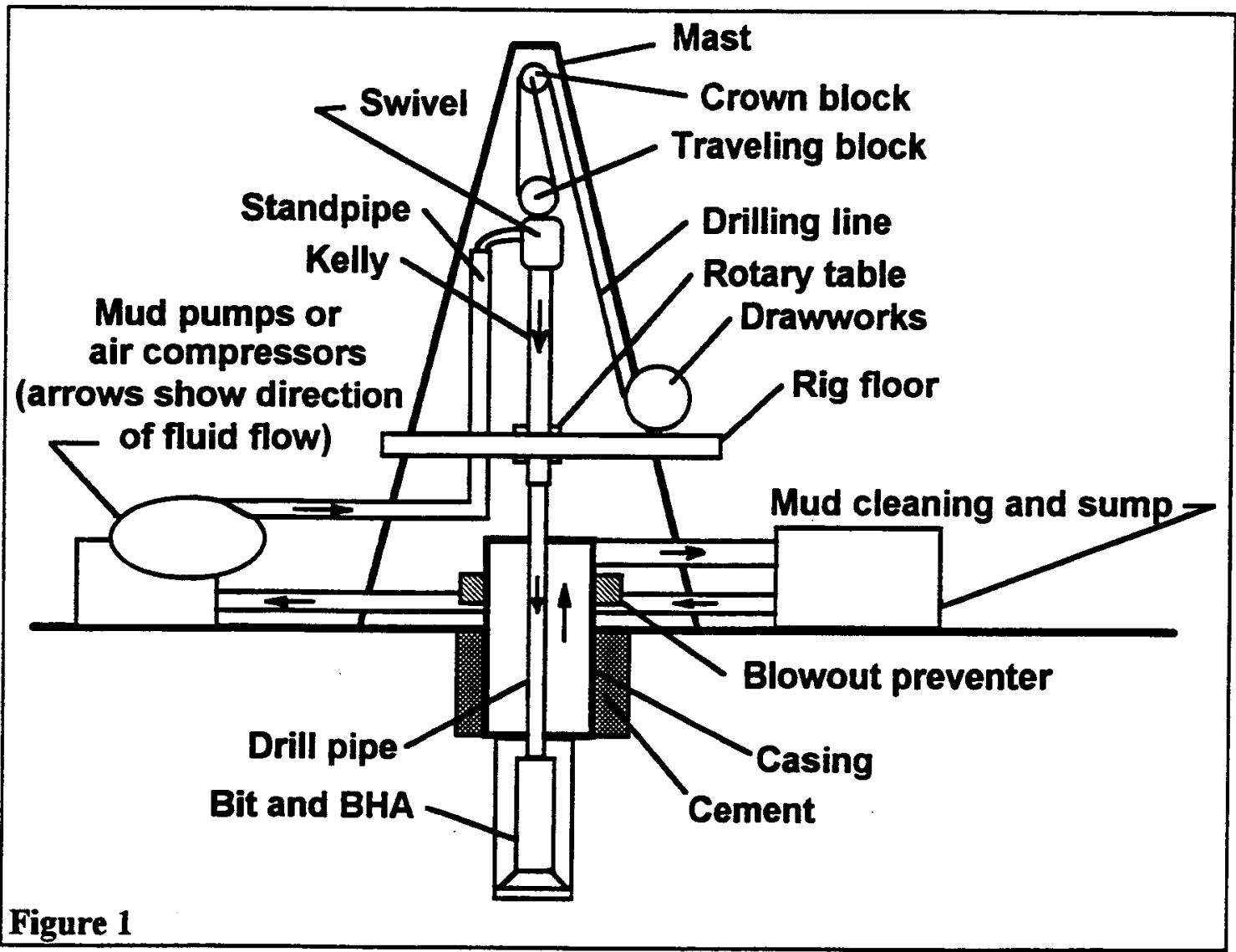

many attempts to develop new ways of breaking rock more cheaply and/or quickly, but most of these new concepts share similarities. In this section of the report, functional aspects of the novel or alternative drilling systems considered in the study are examined with respect to their differences from a baseline system, similar to that shown schematically in Figure 1. Differences 
are generally described in terms of how the alternative concepts perform the six major functions necessary for any drilling system:

1. Transmit energy from the surface to the rock face,

2. Reduce rock from its more-or-less monolithic state,

3. Remove the reduced rock from the wellbore,

4. Maintain control of any pressures encountered in the wellbore,

5. Keep the hole open, stable at some minimum diameter, and on the desired trajectory while drilling, and

6. Preserve and control the well for some indefinite, but relatively long, time.

Each system description defines these functional differences in some detail (a summary for all systems is collected in Table 1 on the following page) and each description also contains a list of advantages and disadvantages for that system, as well as technology items needed for the system to become operational. The technology needs are sometimes overlapping among systems; common problems are discussed further in Section IV. In the description of the baseline system below, the basic drilling functions are numbered as in the list above.

Because technical maturity differs greatly among the systems, the amounts of research data and the researchers' attitudes toward the systems displayed in those data, are quite variable. A surprisingly difficult task was to determine why development was stopped on some projects. Many times a project's progress reports were optimistic, reflecting proven and potential benefits of that technology, but then the project was dropped by the company with no recorded explanation. This difference in data availability affects the lists of positive and negative attributes for the individual systems, since the evaluation of those attributes often reflects the authors' opinions. Drafts of these descriptions have been submitted to previous or current researchers for review wherever possible. 


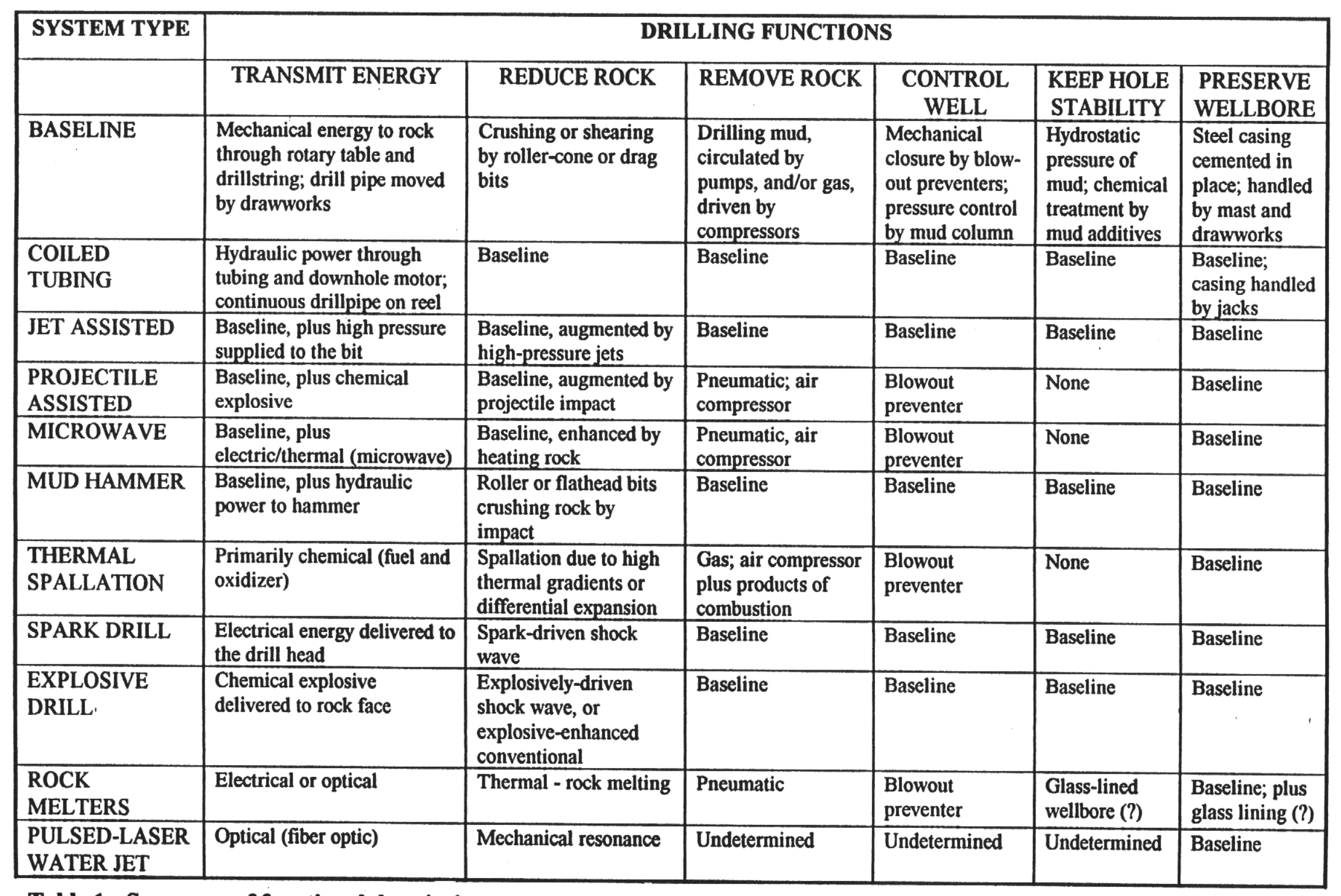

Table 1 - Summary of functional descriptions 
BASELINE SYSTEM:

\begin{tabular}{|c|l|l|l|l|l|l|}
\hline $\begin{array}{c}\text { SYSTEM } \\
\text { TYPE }\end{array}$ & \multicolumn{6}{|c|}{ DRILLING FUNCTIONS } \\
\hline & $\begin{array}{c}\text { TRANSMIT } \\
\text { ENERGY }\end{array}$ & $\begin{array}{l}\text { REDUCE } \\
\text { ROCK }\end{array}$ & $\begin{array}{l}\text { REMOVE } \\
\text { ROCK }\end{array}$ & $\begin{array}{l}\text { CONTROL } \\
\text { WELL }\end{array}$ & $\begin{array}{l}\text { MAINTAIN } \\
\text { HOLE } \\
\text { STABIITY }\end{array}$ & $\begin{array}{l}\text { PRESERVE } \\
\text { WELIBORE }\end{array}$ \\
\hline BASELINE & $\begin{array}{l}\text { Mechanical } \\
\text { energy to rock } \\
\text { through rotary } \\
\text { table and } \\
\text { drillstring, drill } \\
\text { pipe moved by } \\
\text { drawworks }\end{array}$ & $\begin{array}{l}\text { Crushing or } \\
\text { shearing by } \\
\text { roller-cone } \\
\text { or drag bits }\end{array}$ & $\begin{array}{l}\text { Drilling } \\
\text { mud, } \\
\text { circulated } \\
\text { by pumps, } \\
\text { and/or gas, } \\
\text { driven by } \\
\text { compressors }\end{array}$ & $\begin{array}{l}\text { Mechanical } \\
\text { closure by } \\
\text { blow-out } \\
\text { preventers; } \\
\text { pressure } \\
\text { control by } \\
\text { mud column }\end{array}$ & $\begin{array}{l}\text { Hydrostatic } \\
\text { pressure of } \\
\text { mud; } \\
\text { chemical } \\
\text { treatment by } \\
\text { mud } \\
\text { additives }\end{array}$ & $\begin{array}{l}\text { Steel casing } \\
\text { cemented in } \\
\text { place; handled } \\
\text { by mast and } \\
\text { drawworks }\end{array}$ \\
\hline
\end{tabular}

In the baseline system, all of the equipment necessary for the drilling operation is organized around the derrick, or mast. This is a steel tower (see Figure 2), ranging from 50' to $180^{\prime}$ in height, which supports the drill pipe with the bit and all the other downhole equipment, and which provides a platform for much of the other equipment necessary to drill the hole. Every rig, except

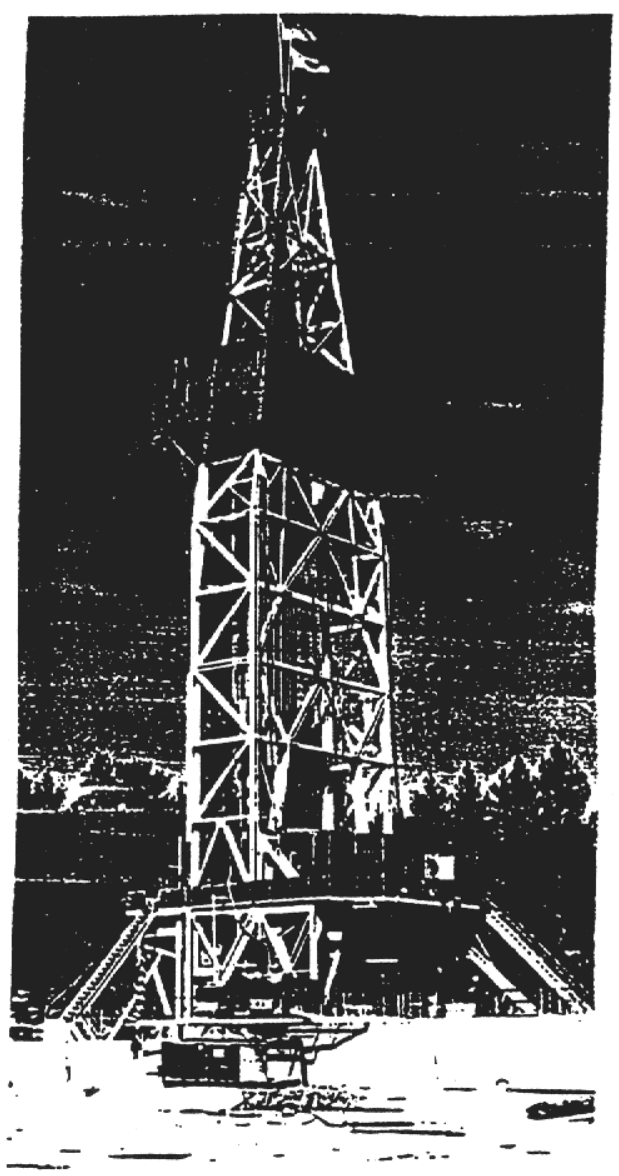
for the smallest ones, has a floor just above ground level where most activity required to operate the rig takes place. The driller, who has minute-by-minute control of the rig's operation, has a console here and most pipe handling (adding a new piece of pipe, making and breaking drill string connections, changing bits, etc.) takes place on the floor. In smaller rigs, the mast and the floor are a unit and are simply raised into position in preparation for drilling. Bigger rigs, which may require 50 to 60 large truck loads for transportation, are usually assembled at the drill site, a job which may take several days, even in accessible locations on land. Offshore, or in locations with difficult access, this assembly is much more complex and time-consuming. Eventually the mast will be erected, the power generation system on-line, the fluidhandling equipment plumbed together, and the myriad other smaller components in place; only then is the rig ready to begin drilling a hole by performing the six essential functions listed above.

Figure 2 - Drill rig 
(1) To make the hole, energy must be transmitted from the surface to the rock face at the end of the wellbore. Power supply for drilling has evolved from the early days of steam-driven, mechanically coupled rigs to the current standard of diesel-electric drive. In this configuration, two to four diesel engines (up to 2,000 horsepower each) drive electric generators, which supply power to individual electric motors driving the rotary table, drawworks, mud pumps, and other equipment. The rotary table is a mechanism, usually inset into the rig floor, which turns the drill string to break rock and advance the hole. (A "drill string" comprises the drill pipe plus the bottom-hole-assembly, or BHA. The BHA includes drill collars, stabilizers, bit, and any other specialized tools below the drill pipe).

Hole diameters in oil and gas drilling usually range from 4 to 26 inches, while geothermal holes generally have a minimum production size of $8-1 / 2$ inches. To drill these holes, torque is applied to the kelly, which is at the top of the drill string. The kelly is a section of pipe with a square or hexagonal outside cross-section which engages a matching bushing in the rotary table. This bushing lets the rotary table continuously turn the kelly and drill string while they slide downward as the hole advances.

The upper end of the kelly is attached to a "swivel", which is a rotating pressure fitting that allows the drilling fluid to flow from the mud pumps, up the standpipe, through the kelly hose, into the swivel, and finally down the drill pipe as it rotates. The swivel is carried by the hook on the traveling block (see below) and it suspends most of the weight of the drill string while drilling.

Moving the drill string or the casing into and out of the hole is called tripping. Trips are usually required because the bit or some other piece of downhole equipment must be replaced, or because of some activity such as logging, testing, or running casing, and of course trips take longer as the hole grows deeper. Raising or lowering the drill string for a trip is done by the drawworks, which is basically a large winch. (The swivel and kelly are almost always handled as a unit, and are set aside in the "rat hole" while tripping.) The drawworks reels in or pays out a wire rope (drilling line) which passes over the crown block at the top of the rig's mast and then down to the traveling block which carries the hook, which in turn suspends the drill string or casing. Depending on what mechanical advantage is required, the drilling line is reeved several times between the crown and traveling blocks, as in a block and tackle.

(2) Attached to the bottom of the drill string, the bit rotates to break (reduce) the rock and advance the hole. The bit is usually either a roller-cone (see Figure 3 ), which crushes the rock as the cones turn and their teeth successively come in contact with unbroken areas, or a drag bit (see Figure 4), which shears the rock in the same way that a machine tool cuts metal. Because of this shearing action, drag bits are inherently more efficient than roller-cone bits. Drag bits with polycrystalline-diamond-compact (PDC) cutters began to be widely used in the early 1980 's for their ability to drill faster and last longer in soft to medium formations. They usually do not have 
acceptable life in hard or fractured formations, and extension of their use to harder rocks would be a significant technology advance. Roller-cone technology is very mature (over 80 years since the first patent) and, although bit companies still do constant research, improvements in the last 20 years have been incremental, but significant. Since the 1950 s, $R \& D$ for roller-cone bits has

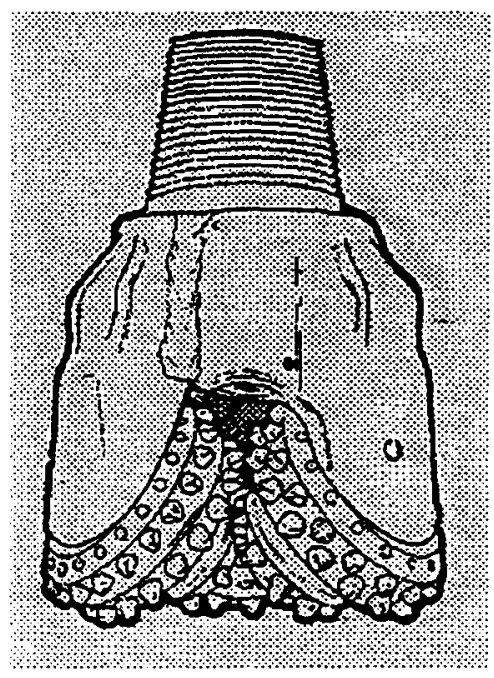

Figure 3 - Roller-cone bit

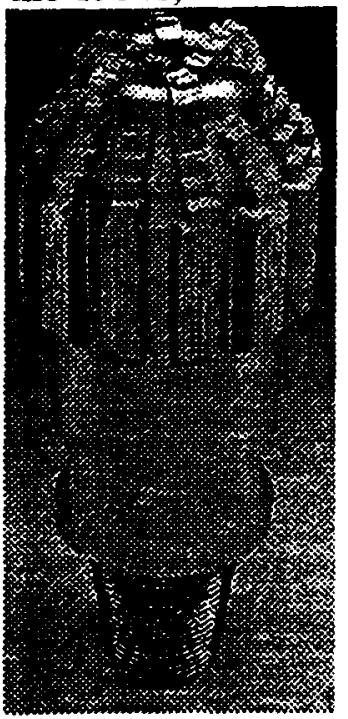

Figure 4 - Drag bit (PDC cutters)

alternated between better bearings and more durable cutting structures, depending on which is the dominant failure mode at the time.

(3) Once the rock has been reduced to chips and fines, it must be removed from the hole bottom to expose fresh rock surface and to avoid wasting energy by re-grinding these same cuttings. This cleaning is done by a stream of fluid which circulates down the drill pipe, passes through ports (called "jets") in the bit, and returns up the annulus between the wellbore wall and the outside of the drill string, carrying the rock cuttings back to the surface. This fluid is sometimes a gas (air, nitrogen, natural gas), but is most often a liquid, universally known as "mud" from its origin as a mixture of water and clay.

Air drilling, in which the hole is cleaned by a compressor-driven air-stream, generally makes hole faster than with mud, but suffers severe problems of well control, hole stability, drill-pipe erosion, and inability to handle water influx. Mud drilling uses pumps to circulate the liquid, which not only carries cuttings but stabilizes the weilbore and lubricates the bit and drill string. The mud can be either oil- or water-based, depending on the formations to be drilled and the regulatory restrictions at the site, but functionally the two are essentially identical.

When mud returns to the surface, it is cleaned to remove most of the rock cuttings and is then re-circulated. Pumping mud, while drilling, at typical flow rates of 200 to 800 gallons per minute, 
with pressures up to several thousand pounds per square inch, can represent more than $75 \%$ of the rig's total power consumption.

(4) During drilling, the personnel and equipment must be protected against unexpected pressure surges in the wellbore. In oil and gas drilling, these surges can come from hydrocarbon fluids trapped under impermeable rock which holds them at pressures higher than the static head of the fluid column in the wellbore, and in geothermal operations the surges come from hot formations which heat the pore or wellbore fluids above the saturation temperature at the static wellbore pressure. In either case, the first line of control is the weight of the fluid column in the wellbore. With a gas column, this weight is negligible, but with mud the liquid density will range from slightly greater than water ( $>8.5$ pounds per gallon) to almost three times that. In addition to the clays and additives which raise the viscosity of the mud to improve hole cleaning, weighting materials such as barite are often added to increase the mud's density and enable it to control higher downhole pressures.

If a pressure surge cannot immediately be controlled with fluid weight, the wellbore can be mechanically sealed at the surface with BOPs, or blow-out preventers. There are three principal types of BOP: blind rams, which are sliding plates that come together across the wellbore when the drill string is not in the hole; pipe rams, which are like blind rams except that the sliding plates are cut out in the center so the rams can seal around the drill pipe; and an annular preventer, which is an inflatable bladder that seals around drill collars, stabilizers, or other off-size or irregularly shaped tools.

(5) After drilling through some kinds of rock, the formation may tend to swell (because it absorbs water) or squeeze (extrude into the wellbore because of overburden pressure), reducing the hole diameter, or chunks of the wellbore wall may cave or slough into the hole. These phenomena can cause problems ranging from minor (the necessity to clean out fill or to ream part of the hole) to major (stuck drill string). With gas drilling, there is no liquid to cause swelling, but there is no fluid pressure to counteract squeezing. With mud these problems can often be eliminated or mitigated by the pressure of the fluid column or by the mud's chemical composition.

There are two important aspects of hole trajectory: direction (inclination and azimuth) and straightness. Historically, most wells have been designed as vertical holes, although the technology for directional drilling has existed for decades. Vertical holes depend mostly on the pendulum effect of gravity to keep the drill string pointed downward, but sometimes the combination of BHA design and formation properties will drive the hole away from verticality. Changes to the BHA configuration can often correct the direction of the hole, but in some cases it is necessary to force the hole into the correct trajectory with directional drilling. (See the discussion of directional drilling on page III-9). Hole direction is usually measured by lowering into the drillpipe a camera which photographs a compass and level. The photograph shows the 
bubble of the level, giving inclination, and the direction of the compass tilt, giving azimuth. To record azimuth, the camera must be in a non-magnetic section of the drill string, so a monel drill collar is usually placed just above the bit.

Proper BHA design is also essential in keeping the hole straight. Sudden changes in hole direction (called "dog-legs") are highly detrimental to drilling performance: they cause excessive wear on the drill string and casing, create high torque on the drill string, limit the weight on bit, thus slowing hole advance, and can even prevent getting the next casing string into the hole.

(6) Once the hole is drilled to the target depth, it must be kept open for testing or production. This is conventionally done by putting steel pipe, or casing, into the hole and cementing it in place. Casing is not done all at once, at the end of drilling, but is placed sequentially in the hole as it reaches increasingly greater depths (see Figure 5). As each casing string is placed and cemented, the hole interval below that string must be smaller than the one above, since the new drill bit must pass through the casing just set. The completed hole, then, will usually have two to four concentric strings of casing cemented in place with an open-hole section at the bottom for production of the desired fluids.

To complete any given interval of the well, casing (which is several inches smaller than the hole diameter at that point) is lowered almost to the bottom of the hole; then cement is pumped down the inside of the casing and displaced with mud up the annulus between the casing and the wellbore wall. Because large volumes of cement must be pumped quickly, and at high pressure because of the density

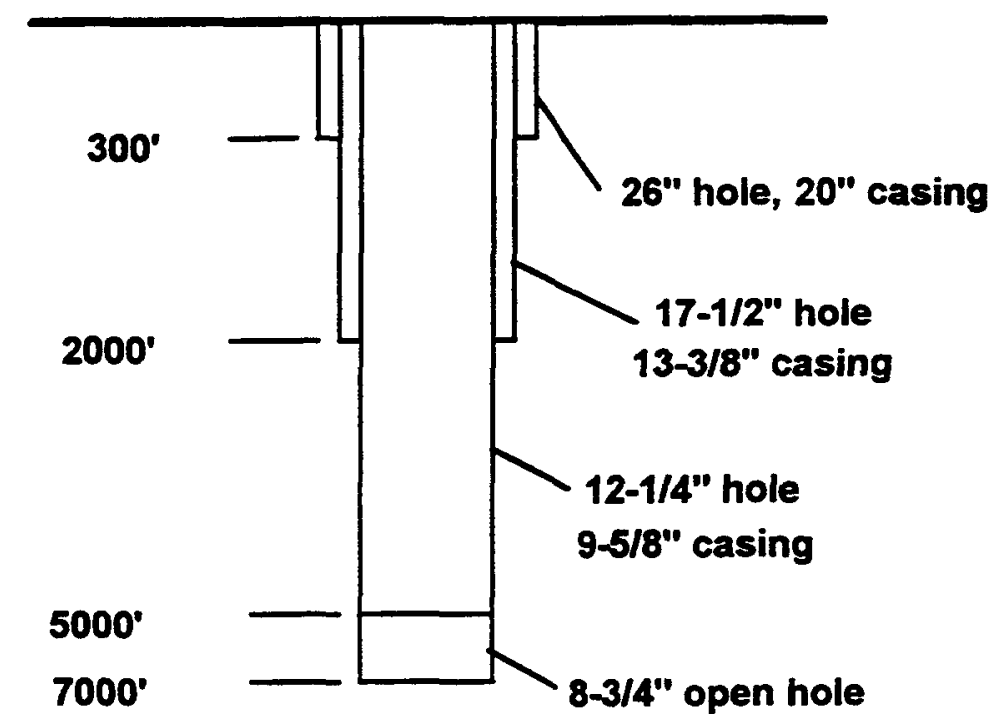
Figure 5 - Typical casing program difference between the mud and cement, specialized cementing equipment is used for this job. It is not uncommon for the cost of casing and cement to approach half the total well cost.

Other available equipment: Several pieces of drilling technology are relatively mature but are not widely used, either because they are not broadly applicable or because of their cost. These are briefly described below as (a) alternative energy transmission/rock reduction, or (b) improved hole-trajectory control. 
Alternative energy transmission/rock reduction: Instead of turning the drill string with a conventional kelly/rotary-table drive, some rigs use an electric or hydraulic motor, suspended in the derrick and integrated with the swivel, to rotate the drilling assembly. These "top-drive" rigs require other non-standard components - some structure to withstand reaction torque from the drive motor, and power tongs below the drive motor to make and break cornections far above the rig floor - but they offer time savings in their ability to drill with stands of pipe (approximately 90') instead of adding individual $30^{\prime}$ joints, and there are operational advantages (well control and avoiding stuck pipe) in the ability to circulate drilling fluid while tripping the drill string.

It is also possible to use the hydraulic power of the drilling fluid to drive a motor at the bottom of the drill string, rotating only the bit and eliminating the requirement to turn the drill string at all. These motors are either turbines or advancing-cavity (Moineau) types and are generally driven by mud. Air-driven motors of each type have been demonstrated, and Moineau motors with misted air are sometimes used in the field; there are no active air-turbine projects.

For directional drilling, or actively controlling direction of the hole's advance, these motors will have a "bent sub" attached to either the upper or lower end. This drill-string component aligns the motor and/or bit at a small angle $\left(1 / 4-2^{\circ}\right)$ relative to the drill string, and the motor and bit are then oriented in the direction of the corrected trajectory. Now the hole can be advanced in that direction with the motor's rotation, since the drill string is not turning. If the driller wishes to drill a straight section without tripping to remove the bent sub, the drill string can be rotated at the same time the motor is also turning the bit. This causes the hole to advance along its existing trajectory; if the direction must be altered again the driller can stop drill string rotation and resume building angle in the hole. Downhole motors, without bent subs, can also give good performance in straight-hole drilling, reducing drill pipe and casing wear and frequently producing high rates of penetration, but they are very expensive. The hourly charges for a motor can be over $\$ 200 /$ hour, approaching the hourly charge for the drill rig.

Another variant in rock reduction is the use of air-powered downhole hammers. In these tools, a reciprocating piston applies an impulse to the bit instead of depending on the weight of drill collars to load the rock in compression. Hammers can be used on either conventional rollercone bits or on solid-head bits with tungsten-carbide inserts (see Figure 6). Compared to the baseline system, a hammer's high-frequency impulses, coupled with the lack of fluid-column pressure, gives high rates of penetration, especially in brittle rock and especially at shallow depths where little drill collar weight could be carried. Downhole hammers are relatively inexpensive to use, but require an air-drilling scenario (a prototype mud hammer is described on page III-25), need precise weight-on-bit control, and often suffer severe gauge wear with solid-head bits. 
Improved hole-trajectory control: In directional drilling, described above, the drilling assembly must advance the hole in the proper direction and its azimuth and inclination must be surveyed and controlled frequently. This can be done by lowering a single- or multi-shot survey camera into the drill string, but it is time-consuming to stop drilling for each survey. A more efficient way to do this is measurement-while-drilling (MWD), or steering tool, which sends continuous signals from a downhole sensor package back to instruments at the surface. These signals most commonly are pressure pulses in the mud column (which have a low data rate of $\sim 1$ $\mathrm{bit} / \mathrm{sec}$ ) but electrical MWD with special drill pipe or hard-wire connections has also been used.

MWD is expensive (up to several hundred dollars per hour), so its use is limited. A cheap MWD system with high data-rate would have valuable applications to drilling, such as improved well control by immediately sensing influx of fluids, continuous survey of hole trajectory for identification of deviation in straight holes, and immediate knowledge of formation changes by logging-while-drilling. Real-time knowledge of the near-bit environment (temperature, true weight-on-bit, shock and vibration, etc.) would also be extremely useful in drilling optimization and protection of downhole tools. 


\section{COILED TUBING:}

\begin{tabular}{|c|c|c|c|c|c|c|}
\hline \multirow{2}{*}{$\begin{array}{c}\text { SYSTEM } \\
\text { JYPE }\end{array}$} & \multicolumn{6}{|c|}{ DRILING FUNCTIONS } \\
\hline & $\begin{array}{l}\text { TRANSMIT } \\
\text { ENERGY }\end{array}$ & $\begin{array}{l}\text { REDUCE } \\
\text { ROCK }\end{array}$ & $\begin{array}{l}\text { REMOVE } \\
\text { ROCK }\end{array}$ & $\begin{array}{l}\text { CONTROL } \\
\text { WELLL }\end{array}$ & $\begin{array}{l}\text { MAINTAIN } \\
\text { HOLE } \\
\text { STABIITY }\end{array}$ & $\begin{array}{l}\text { PRESERVE } \\
\text { WELLBORE }\end{array}$ \\
\hline BASELINE & $\begin{array}{l}\text { Mechanical } \\
\text { energy to rock } \\
\text { through rotary } \\
\text { table and } \\
\text { drillstring; drill } \\
\text { pipe moved by } \\
\text { drawworks }\end{array}$ & $\begin{array}{l}\text { Crushing or } \\
\text { shearing by } \\
\text { roller-cone } \\
\text { or drag bits }\end{array}$ & $\begin{array}{l}\text { Drilling } \\
\text { mud, } \\
\text { circulated } \\
\text { by pumps, } \\
\text { or gas, } \\
\text { driven by } \\
\text { compressors }\end{array}$ & $\begin{array}{l}\text { Mechanical } \\
\text { closure by } \\
\text { blow-out } \\
\text { preventers, } \\
\text { pressure } \\
\text { control by } \\
\text { mud column }\end{array}$ & $\begin{array}{l}\text { Hydrostatic } \\
\text { pressure of } \\
\text { mud; } \\
\text { chemical } \\
\text { treatment by } \\
\text { mud } \\
\text { additives } \\
\end{array}$ & $\begin{array}{l}\text { Steel casing } \\
\text { cemented in } \\
\text { place; handled } \\
\text { by mast and } \\
\text { drawworks }\end{array}$ \\
\hline $\begin{array}{l}\text { COILED } \\
\text { TUBING }\end{array}$ & $\begin{array}{l}\text { Hydraulic power } \\
\text { through tubing } \\
\text { and motor, } \\
\text { continuous } \\
\text { drillpipe on reel }\end{array}$ & Baseline & Baseline & Baseline & Baseline & $\begin{array}{l}\text { Baseline, but } \\
\text { casing } \\
\text { possibly } \\
\text { handled by } \\
\text { jacks }\end{array}$ \\
\hline
\end{tabular}

Instead of a conventional drill string - 30' lengths of rigid drill pipe screwed together - a coiled-tubing rig uses continuous steel tube wrapped around a large reel. To trip into or out of the hole, an injector applies traction to the tubing to insert or extract it and the reel turns in the appropriate direction to keep the tubing wound tightly on it. There are several important consequences, both positive and negative, of this configuration:

Pro - Tripping is much - up to 2.5 times - faster than with drill pipe.

- Drilling fluid can be pumped while tripping, improving well control and reducing the possibility of stuck pipe.

- Underbalanced drilling is easier because of continuous pumping.

- A massive derrick is not required for handling drill pipe, so surface equipment and its footprint can be reduced. Some method is still necessary for handling casing and making up BHAs, but these functions can be fulfilled with casing jacks.

- It would be relatively simple to incorporate an electrical conductor into coiled tubing. This would open many options: drilling with electric motors, using active downhole steering tools, and collecting real-time, high-bit-rate downhole data.

Con - Since the tubing does not rotate, a downhole motor (which is expensive) must be used for drilling. Lack of pipe rotation also increases the possibility of differential sticking.

- Hole size and downhole hydraulics are limited by currently available tubing sizes.

- Weight-on-bit and torque may be limited.

- The tubing is deformed plastically in bending it around a relatively small radius, so pipe fatigue limits the number of trips for any piece of tubing. 
The coiled-tubing industry is substantial ( $\$ 650 \mathrm{M} /$ year worldwide), but drilling is expensive. Day-rates for a tubing unit, excluding any other surface equipment, are frequently higher than for a medium-size drill rig, so coiled-tubing is now used primarily (85\%) for workover applications where time savings from its rapid mobilization and speed in tripping can make it economically attractive. One of largest obstacles to greater use of coiled tubing in drilling operations is the inability to rotate, thus requiring the use of downhole drilling motors. A lower cost alternative to currently available motor technology will be necessary before coiled tubing captures more than a niche in the drilling market.

The layout and preliminary design have been completed on a hybrid coiled tubing rig capable of drilling the upper hole with conventional drill pipe and employing coiled tubing in the smaller diameter sections of the well (Newman and Doremus). A logical follow-on to a hybrid rig would be a fully-integrated coiled tubing drill rig, which would be significantly different from a conventional rig. The mast and substructure would be much smaller. The drawworks could be removed and replaced by the tubing drive unit in drilling operations and by hydraulic jacks in running casing. An integrated CT rig would require development of hydraulic jacks for running casing and larger diameter tubing to provide higher flow capacity than currently possible. There would be no rotating equipment on the rig floor. Pipe handling and traveling equipment would be modified. The drill string would be replaced by the tubing. Finally, the bottom-hole assembly (BHA) would include a motor for rotary drilling. 
JET ASSISTED DRULLNG:

\begin{tabular}{|l|l|l|l|l|l|l|}
\hline \multicolumn{1}{|c|}{$\begin{array}{c}\text { SYSTEM } \\
\text { TYRE }\end{array}$} & $\begin{array}{c}\text { TRANSMII } \\
\text { ENERGY }\end{array}$ & $\begin{array}{l}\text { REDUCE } \\
\text { ROCK }\end{array}$ & $\begin{array}{l}\text { REMOVE } \\
\text { ROCK }\end{array}$ & $\begin{array}{l}\text { CONIROL } \\
\text { WELL }\end{array}$ & $\begin{array}{l}\text { MAINTAN } \\
\text { HOLE } \\
\text { STABLITY }\end{array}$ & $\begin{array}{l}\text { PRESERVE } \\
\text { WELLBORE }\end{array}$ \\
\hline BASELINE & $\begin{array}{l}\text { Mechanical } \\
\text { energy to rock } \\
\text { through rotary } \\
\text { table and } \\
\text { drillstring, drill } \\
\text { pipe moved by } \\
\text { drawworks }\end{array}$ & $\begin{array}{l}\text { Crushing or } \\
\text { shearing by } \\
\text { roller-cone } \\
\text { or drag bits }\end{array}$ & $\begin{array}{l}\text { Drilling } \\
\text { mud, } \\
\text { circulated } \\
\text { by pumps, } \\
\text { or gas, } \\
\text { driven by } \\
\text { compressors }\end{array}$ & $\begin{array}{l}\text { Mechanical } \\
\text { closure by } \\
\text { blow-out } \\
\text { preventers; } \\
\text { pressure } \\
\text { control by } \\
\text { mud column }\end{array}$ & $\begin{array}{l}\text { Hydrostatic } \\
\text { pressure of } \\
\text { mud; } \\
\text { chemical } \\
\text { treatment by } \\
\text { mud } \\
\text { additives }\end{array}$ & $\begin{array}{l}\text { Steel casing } \\
\text { cemented in } \\
\text { place; handled } \\
\text { by mast and } \\
\text { drawworks }\end{array}$ \\
\hline $\begin{array}{l}\text { JET } \\
\text { ASSISTED }\end{array}$ & $\begin{array}{l}\text { Baseline, plus } \\
\text { high pressure } \\
\text { supplied to the } \\
\text { bit }\end{array}$ & $\begin{array}{l}\text { Baseline, } \\
\text { augmented } \\
\text { by high- } \\
\text { pressure jets }\end{array}$ & Baseline & Baseline & Baseline & Baseline \\
\hline
\end{tabular}

Although a fluid jet driven with sufficient pressure can cut rock directly, most drilling research has focused on jets which enhance or augment rock breakage by conventional bits. Early efforts in high-pressure jet drilling were described in two books, Novel Drilling Techniques and Advanced Drilling Techniques (Maurer 1968, Maurer 1980), and the recently published Waterjetting Technology (Summers 1995), is a comprehensive volume on the use of highpressure water jets. Jets can enhance rock reduction by either weakening and partially breaking the rock or by improving bottom-hole cleaning.

In considering jet-assisted drilling systems from a functional viewpoint, we must address two questions: (a) what performance improvements are possible? and (b) how can pressures much higher than conventional drilling practice be delivered to the bit?

(a) During the late 1950's and 1960's, the benefits of fluid dynamics in cleaning the hole bottom were recognized and the use of jet bits grew rapidly (Kendall). Many technical papers, based both on research and field demonstration, described the increased rate-of-penetration achieved by increases in hydraulic horsepower (HHP) at the bit. These relatively high-pressure jets do not cut rock, but they clean away debris created by a conventional bit so that the bit teeth contact fresh rock instead of re-grinding cuttings. Cleaning efficiency depends on volume and pressure of the flow and on placement and aim of the nozzles with respect to the cutters, but there is a limit to this effect. "Perfect cleaning" is described as the condition when the bit design and hydraulics are so effective that no debris remains to interfere with the bit's curting action (Maurer, 1962). Flow rate increases past this point do not improve ROP. Maurer derived a drilling-rate equation, supported by field and experimental data, which indicates that with perfect cleaning the rate of penetration increases linearly with rotary speed and as the square of weight- 
on-bit. Once perfect cleaning is achieved, then further penetration-rate improvements with increased HHP must come from the jets' cutting or weakening the rock. Because these separate phenomena, cleaning and cutting, improve performance by different mechanisms, it may be very difficult to decide which effect is dominant when increased HHP improves penetration rate. Generally, jets are most effective augmenting rock-breakage methods which produce many fractures, probably because the jet extends the fractures and aids rock-breakage by loading the rock in tension.

If hole-cleaning is actually near optimum and jet-assisted cutting is to be the method for improved performance, drilling fluid must be delivered to the bit jets at high pressure (at least $10,000 \mathrm{psi}$, and possibly more than $30,000 \mathrm{psi}$, depending on the rock) well above that used in conventional drilling. The rock's failure mechanism may be erosion, hydraulic fracturing, spallation, or some combination of these, but under any given set of drilling conditions, a specific rock type will have a threshold pressure which must be exceeded for cutting to begin. This threshold pressure is related in some general way to the tensile and compressive strength of the rock, but it cannot be reliably predicted only from knowledge of the rock properties.

Once reaching the threshold, however, increasing the jets' flow rate is more effective than further increases in pressure. In summary, the choice of how to implement jet-assisted drilling follows this rationale:

1. For given drilling conditions, there is a maximum benefit to be obtained from improved cleaning;

2. For performance improvement beyond "perfect cleaning", rock cutting must begin;

3. For rock cutting to begin, the jet pressure must exceed the rock's threshold pressure; and

4. Once the threshold pressure is exceeded, any additional power should go into increased flow rate, not further increases in pressure.

These points indicate that an assessment of current state-of-the-art in bottomhole cleaning is an important research task.

(b) If higher-than-normal pressures are to be delivered to the bit jets, either for cutting or improved cleaning, there are three principal methods: (1) surface pressure generation with a single flow channel (Figure 7a); (2) surface pressure generation with multiple flow channels (Figure 7b); and (3) a downhole intensifier (Figure 7c). Table 2 summarizes the advantages and disadvantages of each method. 


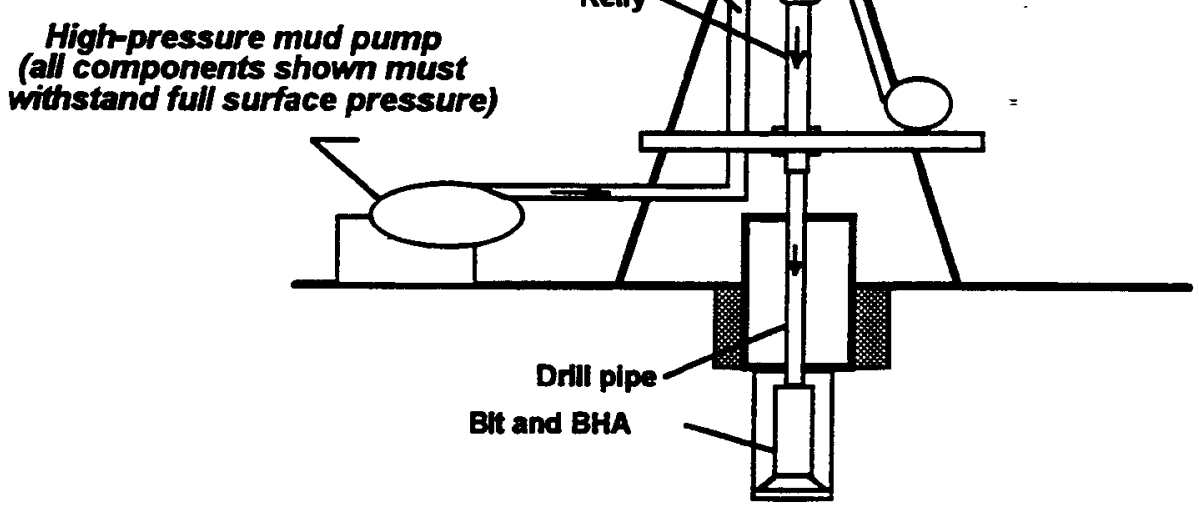

Fig $7 \mathrm{a}$ - Jet assist with full surface pressure

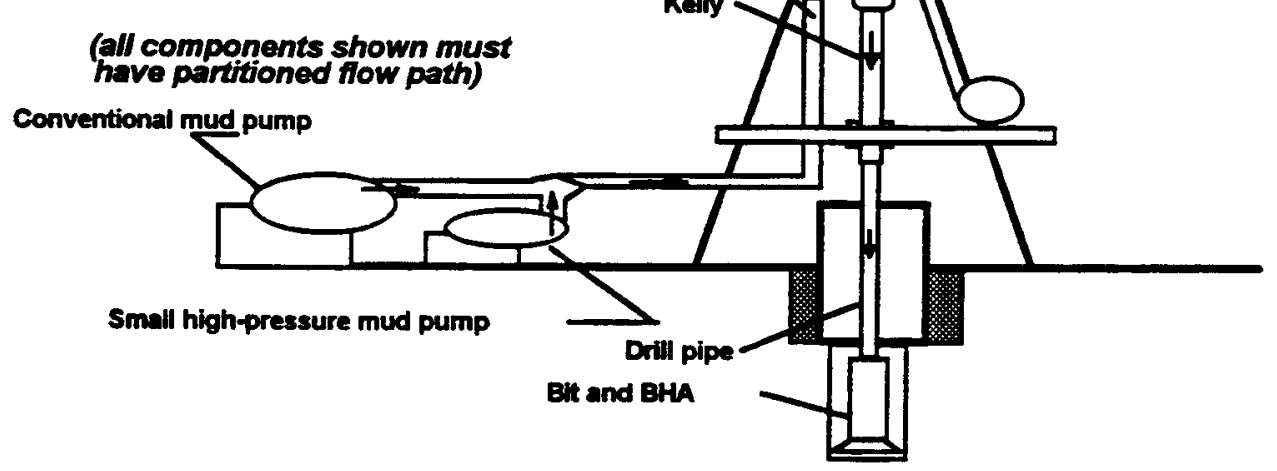

Fig $7 \mathrm{~b}$ - Jet assist with partitioned surface pressure

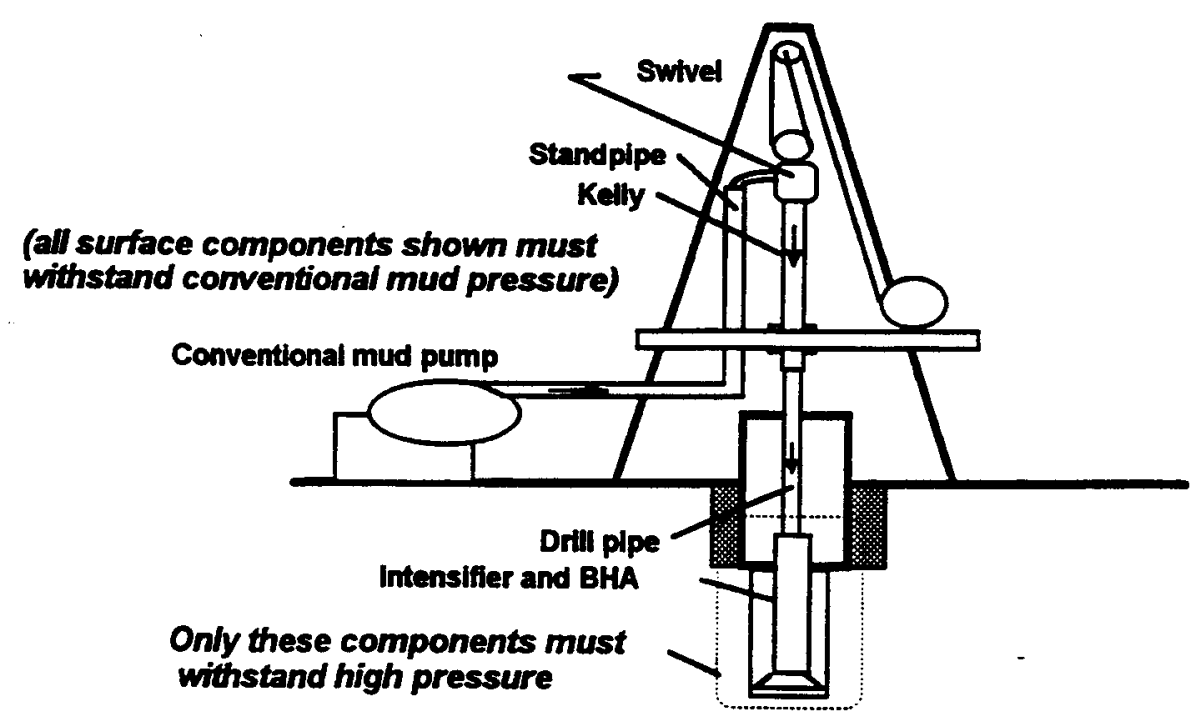

Fig 7c - Jet assist with downhole intensifier 


\begin{tabular}{|c|c|}
\hline Advantages & Disadvantages \\
\hline \multicolumn{2}{|c|}{ (1) Surface Pressure Generation/Single-channel flow } \\
\hline $\begin{array}{l}\text { - } \quad \text { shortest development time } \\
\text { - } \quad \text { easily implemented } \\
\text { - lowest development cost }\end{array}$ & $\begin{array}{l}\text { - } \quad \text { requires special pumps, hoses, swivels, } \\
\text { pipe } \\
\text { - difficult to seal } \\
\text { - } \quad \text { working fluid pH critical for pipe life } \\
\text { - highest operating costs } \\
\text { - greatest pressure-safety hazard }\end{array}$ \\
\hline \multicolumn{2}{|c|}{ (2) Surface Pressure Generation/Multi-channel flow } \\
\hline $\begin{array}{l}\text { - } \text { easily developed } \\
\text { - low development costs } \\
\text { - failure of high-pressure conduit or nozzles } \\
\text { will not stop operations }\end{array}$ & $\begin{array}{l}\text { - high pressure losses } \\
\text { - } \quad \text { time-consuming joint make-up } \\
\text { - dual pumping systems required } \\
\text { - dual flow channel from swivel to bit } \\
\text { required } \\
\text { - high-pressure safety hazards } \\
\end{array}$ \\
\hline \multicolumn{2}{|c|}{ (3) Downhole Intensifier } \\
\hline $\begin{array}{l}\text { - } \text { safest design } \\
\text { standard components except downhole } \\
\text { pump }\end{array}$ & $\begin{array}{l}\text { - highest development costs } \\
\text { - long development time } \\
\text { - cleanliness of working fluid critical } \\
\text { - limited high-pressure flow rate }\end{array}$ \\
\hline
\end{tabular}

Table 2 - Comparison of jet-assisted drilling techniques

Surface Pressure Generation: Early efforts in high-pressure jet and jet-assisted drilling concentrated on pressurizing the entire mud flow. This approach had a number of problems:

- The abrasive nature of drilling mud increases at higher pressure, accelerating wear on mud pump valves, seats, and seals and resulting in reduced pump life.

- The abrasiveness of the mud causes increased wear in the bit jets.

- Leaks develop at connections, especially in the drill string, leading to washouts, rapid erosion of the drill pipe, and failure.

- Surface generation requires high-pressure lines around the drill rig. Possible failure of these lines is a safety concern.

In the early 1970s, a major program in high-pressure, pure-jet drilling was conducted at Exxon Production Research (EPR) (Maurer 1973). High-pressure pumps and piping to deliver 15,000-psi fluid at the bit were developed. There were major problems with pump life and highpressure safety around the rig, but these problems were not considered unsolvable and the EPR program demonstrated increases in penetration rate greater than $50 \%$ in both sand and shale sections at depths of 3,000 feet to 6,000 feet (Deily). In spite of these successes, the program was canceled, partly because their tests also indicated that as the hole depth increased, performance improvement decreased until, at a depth of 6,000 feet to 8,000 feet, there was no improvement in penetration rate (Summers and El-Saie). The most plausible explanation for this 
apparent reduction in capability is that increased plastic behavior and reduced permeability of the rock diminished the effectiveness of high-pressure jets as a cutting mechanism. There are no known current efforts to develop a full-hole drilling system using high-pressure-jets with full mud pressurization.

Surface pressure generation/partitioned flow: A jet-assisted drilling system in which only a part of the fluid stream is raised to high pressure would have advantages. Since there is a lower volume of high-pressure flow around the rig, safety concerns are reduced, but not completely eliminated. By running clean water in the high-pressure (jet) flow section, the valves, seats, and seals in the high-pressure pump are not exposed to the abrasive mud, and erosion problems at joints and nozzles are mitigated. This technique, however, requires a continuous supply of clean water and dilutes the drilling mud.

Running only a portion of the flow at high pressure adds complexity to the overall system. This concept requires redesigning the entire fluid circulation system to provide a parallel flow path from the pumps through the swivel, kelly, drill pipe, drill collars, stabilizers, and bit.

Two companies, FlowDril of Kent, WA and TeleJet Technologies of Dallas, TX, have worked toward development of multi-channel drill strings for partitioned

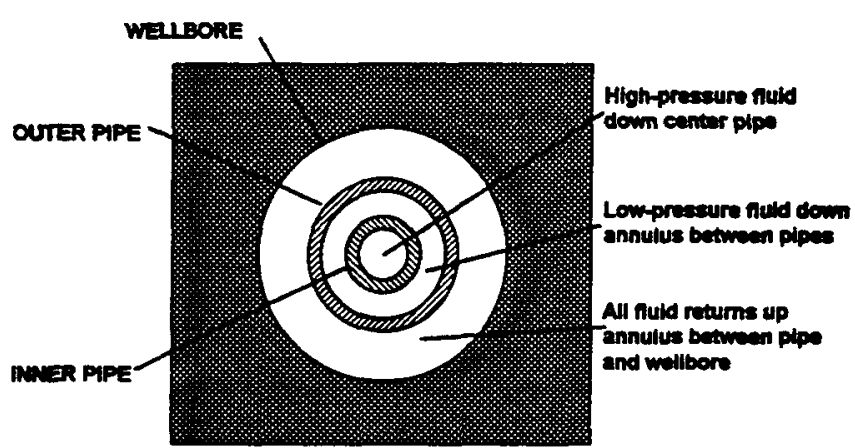

Figure 8 - Concentric, multi-channel drill pipe (high/low pressure) flow: FlowDril developed a system with parallel flow paths (see Figure 8) for the high- and low-pressure fluids through double-walled, concentric drill pipe (Littleton, McNally, Killalea, Butler, Cure, Kolle). Approximately 30 to 40 gallons per minute (gpm) of fluid at about 34,000 psi flows through the center conduit and the balance of several hundred gpm passes down the annulus between the pipe walls. The high-pressure pumps are isolated from drilling mud to reduce erosion problems, but in early development there were still leaks and erosion at drill string connections. These leakage problems were mostly solved, but details remain proprietary. Toward the end of development the FlowDril system operated nearly seven-hundred hours without a leak and demonstrated improved performance (up to twice normal penetration rate), particularly in hard-rock drilling.

TeleJet Technologies, Inc. is currently designing a system to deliver high pressure fluids to the bit through multiple conduit (MultiCon ${ }^{\text {TM}}$ ) pipe (Schuh 1994, Schuh 1995). TeleJet's design is aimed at improved cleaning, since perfect cleaning may not often be achieved in actual drilling. Specifically, some field data indicate that the penetration rate does not increase as rapidly with 


\section{Functional description/jet-assisted}

rotary speed and weight-on-bit as Maurer's equation predicts. Based on this idea, TeleJet's objective is to increase hydraulic horsepower at the bit without regard to achieving a specific threshold pressure necessary to cut rock.

The TeleJet drill pipe is a more elaborate version of the dual-wall pipe system described above, with two high-pressure lines, a fluid return line, and an electrical conduit inside a 7-5/8" OD pipe. The high-pressure lines are 2-3/8" each, while the fluid return line, used for reverse circulation, is 3-1/2". Additional drilling mud will be pumped down the annulus to provide a filter cake (coating on the wellbore wall) for formation stabilization and well control. This mud will mix with the high-pressure fluid to lift cuttings up the return line with a velocity of approximately $500 \mathrm{ft} / \mathrm{min}$. Although not directly related to jet-assist, the electrical conductor may be the most important feature of this drill string, since it can enable logging and downhole measurement while drilling, active control of downhole tools, and even electric drilling motors.

Since configuration of the MultiCon ${ }^{\mathrm{TM}}$ drill pipe is asymmetric, it will not be dynamically balanced. Asymmetry of the high-pressure conduits may cause bending of the pipe while rotating, with subsequent contact between the pipe and the hole wall. This would cause some increase in drag and torque, along with accelerated wear on the pipe. These effects may be small - Schuh estimates the increased torque will be less than $40 \mathrm{ft}-\mathrm{lb}$ (Schuh correspondence) - but it is possible for the dynamic unbalance to cause bit whirl or other downhole instabilities.

The multiple channeis and reverse circulation will require development of motors, subs, and bits. (Design of a reverse-circulation bit is not a trivial problem.) In addition, the sleeve-type connection, which should significantly reduce leakage and erosion problems at the joints, cannot be made up with conventional tools or methods.

TeleJet Technologies has performed detailed design and analyses of the drill pipe and connections, and has defined rig requirements to use this drilling system. FlowDril took a dualchannel system through field tests demonstrating improved performance as well as feasibility. TeleJet Technology is currently funding engineering efforts to define the specifications and perform the preliminary design analysis on the MultiCon ${ }^{\mathrm{TM}}$ system. The bottom-hole assembly, drilling tools, and bits have yet to be defined.

Downhole intensifier: A downhole intensifier is a pump, integrated into the drill string and driven by the hydraulic power in the drilling fluid. Inserted into the flow stream, it raises the normal mud pressure to the value required for jet-assisted drilling and does this downhole, thus eliminating all problems of high pressures generated at the surface. An intensifier has several advantages $(+)$ and disadvantages $(-)$, compared to surface generation of high pressure:

- (+) Safety concerns related to high-pressure flow lines at the surface are eliminated. 
- (+) By placing the intensifier near the bit, much less of the system is exposed to abrasive, high-pressure drilling mud.

- $(+)$ The reduced length of high-pressure flow minimizes head losses, giving higher efficiency in delivering high-pressure liquid to the bit.

- ( $+/-)$ Dual-conduit flow path is limited to the length between the intensifier and the bit, but will still require dual flow channels through the BHA and the bit.

- (-) A downhole intensifier is relatively complex and has to survive abrasive drilling mud.

- (-) Since intensifiers extract hydraulic power from the mud to drive the pump, HHP at the bit is diminished.

- (-) Downhole intensifiers cannot generate as large a volume of high-pressure fluids as surface pumps.

In considering the use of an intensifier, we should return to the question of which performance-enhancement mechanism, cutting or cleaning, is to be emphasized. If cleaning is not yet optimum, then just getting maximum HHP to the bottom of the hole will be effective. In that case, an intensifier may be a handicap because some of the hydraulic horsepower is consumed in driving its mechanical operation. If cleaning is near enough "perfect", then jet-created rock damage is needed and the intensifier is an effective way to get downhole pressures above the cutting threshold.

A downhole intensifier can operate on the principle of either a positive-displacement pump or a centrifugal pump. The pressure differential across a positive-displacement pump is dependent primarily on the ratio of the areas of the pistons. The pressure differential across a centrifugal pump is dependent on pump diameter and rotary speed.

Two companies are currently engaged in development of downhole intensifiers: FlowDril in Kent, WA, has tested prototype intensifiers, and Maurer Engineering in Houston, TX has a design for an intensifier operating on a different principle. The FlowDril devices are positive displacement hydraulic pumps with a length of about 30 feet, sized to operate in 8-3/4" and 7-7/8" holes. The FlowDril intensifiers will pump approximately $20 \mathrm{gpm}$ at $30,000 \mathrm{psi}$. The intensifier system uses partitioned-flow bits, with a claimed nozzle life of 100 hours in mud, which were previously designed and tested during development of the dual-channel system.

The Maurer device is a centrifugal pump which is being designed as two separate units: a pump section and a motor section, each based largely on currently available pumps and motors. Output pressure depends on pump diameter and speed, with anticipated flow rates of about 15 to $25 \mathrm{gpm}$ at pressures exceeding $12,000 \mathrm{psi}$ (Cohen).

We estimate lower initial cost and lower repair cost for the centrifugal device, for two main reasons: the centrifugal pump does not require the high pressure valves of the positivedisplacement pump; and it is more difficult to maintain the seals in a positive-displacement pump than in a centrifugal pump. The abrasive nature of drilling mud will cause accelerated wear in any 
downhole intensifier. In a positive displacement pump, high-pressure valves, seats, and seals will be particularly susceptible. In a centrifugal pump, solids in the mud will cause accelerated wear on the blades. Since these devices pressurize only a portion of the mud stream, it may be possible to develop a downhole screen or filter to clean the mud to acceptable standards, but it may also be necessary to use a centrifuge in the surface mud system.

To summarize the principal considerations in jet-assisted drilling, it is still necessary to define expected performance improvements and to focus on the mechanism by which they will be achieved. There are conflicting data on the effects of jet-assist at depth. Later work suggests that the benefits of jet-assisted drilling can extend to greater depths: FlowDril has published data indicating that jet-assisted drilling doubled the rate-of-penetration down to a depth of nearly 10,000 feet (Cure) and a second FlowDril publication documents a 50\% increase in penetration rate at 10,000 feet (Veenhuizen 1993). These data imply that whatever the cause of reduced cutting capability in earlier efforts, it is possible to contend with these problems to rather significant depths.

Further research into jet-assisted drilling could also take advantage of existing facilities which can independently simulate pore pressure, borehole fluid pressure, and rock stress. Before committing significant resources to this work, these laboratory facilities could be used to assess the ability of fluid jets to cut and/or clean at depth.

Two other jet concepts deserve mention: pulsating or cavitating jets appear to increase the jets' effectiveness for a given jet pressure (Chahine), and deliberate addition of abrasives to the high-pressure stream could increase the cutting action while complicating the mud cleaning equipment and process and adding the requirement for another conduit to carry the abrasive at low pressure.

Finally, almost all previous work on the effects of jet-assist has been devoted to drilling with roller-cone bits -- it may well be that the benefits are significantly different for PDC bits. For example, instead of aiming a jet at the borehole circumference to cut a kerf and relieve compressive stress so that a roller bit can crush rock more efficiently, an optimum strategy for PDC bits may be to point the jet directly at a cutter face, improving the cleaning and cooling at a critical point. Laboratory experiments (Glowka) have shown that jets aimed at a cutter reduce cutting force by $10-40 \%$ under atmospheric pressure, but it is unclear whether this effect extends to cutting under a liquid column. 


\section{PROJECTILE ASSISTED:}

\begin{tabular}{|c|c|c|c|c|c|c|}
\hline \multirow{2}{*}{$\begin{array}{c}\text { SYSTEM } \\
\text { TYRE }\end{array}$} & \multicolumn{6}{|c|}{ DRLLING FUNCTIONS } \\
\hline & $\begin{array}{l}\text { TRANSMIT } \\
\text { ENERGY }\end{array}$ & $\begin{array}{l}\text { REDUCE } \\
\text { ROCK }\end{array}$ & $\begin{array}{l}\text { REMOVE } \\
\text { ROCK }\end{array}$ & $\begin{array}{l}\text { CONTROL } \\
\text { WELL }\end{array}$ & $\begin{array}{l}\text { MAINTAIN } \\
\text { HOLE = } \\
\text { STABIITY }\end{array}$ & $\begin{array}{l}\text { PRESERVE } \\
\text { WELLBORE }\end{array}$ \\
\hline BASELINE & $\begin{array}{l}\text { Mechanical } \\
\text { energy to rock } \\
\text { through rotary } \\
\text { table and } \\
\text { drillstring; drill } \\
\text { pipe moved by } \\
\text { drawworks }\end{array}$ & $\begin{array}{l}\text { Crushing or } \\
\text { shearing by } \\
\text { roller-cone } \\
\text { or drag bits }\end{array}$ & $\begin{array}{l}\text { Drilling } \\
\text { mud, } \\
\text { circulated } \\
\text { by pumps, } \\
\text { or gas, } \\
\text { driven by } \\
\text { compressors }\end{array}$ & $\begin{array}{l}\text { Mechanical } \\
\text { closure by } \\
\text { blow-out } \\
\text { preventers; } \\
\text { pressure } \\
\text { control by } \\
\text { mud column }\end{array}$ & $\begin{array}{l}\text { Hydrostatic } \\
\text { pressure of } \\
\text { mud; } \\
\text { chemical } \\
\text { treatment by } \\
\text { mud } \\
\text { additives }\end{array}$ & $\begin{array}{l}\text { Steel casing } \\
\text { cemented in } \\
\text { place; handled } \\
\text { by mast and } \\
\text { drawworks }\end{array}$ \\
\hline $\begin{array}{l}\text { PROJECTILE } \\
\text { ASSISTED }\end{array}$ & $\begin{array}{l}\text { Baseline, plus } \\
\text { chemical } \\
\text { explosive }\end{array}$ & $\begin{array}{l}\text { Baseline, } \\
\text { augmented } \\
\text { by projectile } \\
\text { impact }\end{array}$ & $\begin{array}{l}\text { Pneumatic; } \\
\text { air } \\
\text { compressor }\end{array}$ & $\begin{array}{l}\text { Blowout } \\
\text { preventer }\end{array}$ & None & Baseline \\
\hline
\end{tabular}

This system uses projectiles fired downhole to fracture rock ahead of the bit, speeding penetration and reducing wear on the bit. Sandia Laboratories worked on a projectile-assisted drilling system in the 1970s (Newsom) and, after Sandia terminated effort on the project, it was commercially developed through the 1980s under the name Tround (Regan, Hill, Howland, McClintock).

The Tround system fires projectiles sequentially through three passages, or barrels, in the bit to produce stress waves and fractures in the rock. These projectiles are made of ceramic to minimize damage to the bit when it drills their residue. Tround's design for an operational system has been extensively tested and has demonstrated significantly increased drilling rates, two to five times as fast as conventional technology (see Table 3 ) Significant effort has been expended in development of the Tround system, so it is relatively mature when compared to other novel concepts. Finally, the Tround system is designed to fit into a conventional drill string and supplement current technology. This allows minimal perturbation of current practices and enhances the chance for acceptance of this technology. 


\begin{tabular}{|c|l|c|c|c|}
\hline Date & Lithography & Hole Size & \multicolumn{2}{c|}{ Penetration Rates (ft/hr) } \\
\hline \multicolumn{2}{|l}{} & (inches) & Tround & Conventional \\
\hline $1 / 82$ & Barre Granite & $97 / 8$ & 19 & 5.5 \\
& Limestone & $97 / 8$ & 220 & 48 \\
\hline $8 / 82$ & Basalt & $97 / 8$ & 32.5 & 14 \\
\hline $10 / 82$ & Basalt & $97 / 8$ & 120 & 28 \\
\hline $6 / 83$ & Taconite & 15 & 100 & 51 \\
\hline $11 / 83$ & Taconite & 15 & 80 & 40 \\
\hline $2 / 84$ & Basalt & 15 & 39 & 18 \\
\hline $4 / 84$ & Barre Granite & $97 / 8$ & 45 & 13 \\
\hline $7 / 84$ & Taconite & 15 & 108 & 53 \\
\hline $6 / 87$ & Taconite & 16 & 70 & 32 \\
\hline Data supplied by James N. Juliana, President/CEO, Tround International \\
\hline
\end{tabular}

Table 3 - Performance of projectile-assisted drilling system

The system does, however, have disadvantages. The magazine and firing mechanism are fairly complex and it is not certain how well they would survive either the downhole environment or just the stress induced during normal handling around a drill rig. It is likely that only deployment of a prototype will determine life of the system under realistic operating conditions. The system also employs propellants to fire the rounds, and this will require special considerations for handling safety. When using projectile-assisted drilling, all components of the drill string and bottom-hole assembly below the firing unit must incorporate barrels to provide a path for the projectiles.

A major drawback for the current system is its inability to fire the projectiles in a liquid environment, but Tround has proposed a valve design which would allow the system to operate under a full column of drilling mud. The valves, normally closed to prevent drilling mud from entering the barrels, would be driven by firing-chamber gases to open and allow the projectiles to exit, closing again before mud could enter the barrels. This valve system exists in concept only, no hardware has been developed or demonstrated.

If the system can be made to work in a liquid environment, it could be further enhanced by the addition of high-pressure jets, which would extend the fractures created by the projectiles and would augment the rotary bit (roller-cone or PDC) as discussed under "jet-assisted drilling". 


\section{THERMALLY-ASSISTED DRILLING:}

\begin{tabular}{|c|c|c|c|c|c|c|}
\hline \multirow{2}{*}{$\begin{array}{c}\text { SYSTEM } \\
\text { DUPE }\end{array}$} & \multicolumn{6}{|c|}{ DRILING FUNCTIONS } \\
\hline & $\begin{array}{l}\text { TRANSMTT } \\
\text { ENERGY }\end{array}$ & $\begin{array}{l}\text { REDUCE } \\
\text { ROCK }\end{array}$ & $\begin{array}{l}\text { REMOVE } \\
\text { ROCK }\end{array}$ & $\begin{array}{l}\text { CONTROL } \\
\text { WELL }\end{array}$ & $\begin{array}{l}\text { MAINTAIN } \\
\text { HOLE = } \\
\text { STABILIY }\end{array}$ & $\begin{array}{l}\text { PRESERVE } \\
\text { WELLBORE }\end{array}$ \\
\hline BASELINE & $\begin{array}{l}\text { Mechanical } \\
\text { energy to rock } \\
\text { through rotary } \\
\text { table and } \\
\text { drillstring; drill } \\
\text { pipe moved by } \\
\text { drawworks }\end{array}$ & $\begin{array}{l}\text { Crushing or } \\
\text { shearing by } \\
\text { roller-cone } \\
\text { or drag bits }\end{array}$ & $\begin{array}{l}\text { Drilling } \\
\text { mud, } \\
\text { circulated } \\
\text { by pumps, } \\
\text { or gas, } \\
\text { driven by } \\
\text { compressors }\end{array}$ & $\begin{array}{l}\text { Mechanical } \\
\text { closure by } \\
\text { blow-out } \\
\text { preventers; } \\
\text { pressure } \\
\text { control by } \\
\text { mud column }\end{array}$ & $\begin{array}{l}\text { Hydrostatic } \\
\text { pressure of } \\
\text { mud; } \\
\text { chemical } \\
\text { treatment by } \\
\text { mud } \\
\text { additives }\end{array}$ & $\begin{array}{l}\text { Steel casing } \\
\text { cemented in } \\
\text { place; handled } \\
\text { by mast and } \\
\text { drawworks }\end{array}$ \\
\hline MICROWAVE & $\begin{array}{l}\text { Baseline, plus } \\
\text { electric/thermal } \\
\text { (microwave) }\end{array}$ & $\begin{array}{l}\text { Baseline, } \\
\text { enhanced by } \\
\text { heating rock }\end{array}$ & $\begin{array}{l}\text { Pneumatic, } \\
\text { air } \\
\text { compressor }\end{array}$ & $\begin{array}{l}\text { Blowout } \\
\text { preventer }\end{array}$ & None & Baseline \\
\hline
\end{tabular}

When rock is heated, mechanical cutters can reduce it more efficiently. Either surface energy deposition or bulk heating can be used to heat rock in a wellbore, but microwaves have the advantage that, unlike lasers or electron-beam heating, the waves penetrate and heat a volume of rock below the rock face, not just the exposed surface. (This system would not directly reduce rock through either spallation or complete meiting, but it may significantly weaken the rock either through pre-stresses created by differential thermal expansion of various mineral constituents or by partial melting of some minerals.) The U.S. Bureau of Mines has investigated the use of microwave energy in this manner (Lindroth, et al).

A microwave rock-heating system would have the following attributes:

1. (+) Increased rate of penetration comes from rock-strength reduction, so any mechanical cutting system would have improved performance.

2. (-) It is unclear that the system will operate in a liquid environment.

3. (-) System requires a method to get microwave energy downhole.

(1) At the U.S. Bureau of Mines, a microwave generator was used to heat rock which was then drilled by a 2 " diameter drag bit. Raising the bulk temperature of the rock (measured at the surface) to approximately $1100^{\circ} \mathrm{C}$ increased ROP by a factor of two in Dresser basalt and by a factor of three in St. Cloud gray granodiorite, although there was considerable scatter in the data. These bench-scale experiments, intended to simulate tunneling or excavation, used a wave guide to transmit the microwaves to an exposed rock face, after which the rock was drilled.

(2) Since the laboratory experiments were done with a rock face exposed to air, it is unclear, and probably unlikely, that the microwave system will work in a liquid environment. This limits 
its applicability to drilling environments which would ordinarily be air-drilled, giving the problems with hole stability and well control discussed in more detail on page IV-13.

(3) Total electrical power requirement for a microwave system is about $18 \mathrm{~kW} / \mathrm{fph}$, based on heating the volume of rock removed from a $12-1 / 4^{\prime \prime}$ hole to $1100^{\circ} \mathrm{C}$. This power level may be unnecessary, however, since some rocks are either melted or very near melting at this temperature. Total power required is also directly proportional to the temperature increase in the rock and/or to the hole area. The ultimate strength of unconfined charcoal granodiorite, for example, decreases from $360 \mathrm{MPa}$ at $25^{\circ} \mathrm{C}$ to $30 \mathrm{MPa}$ at $1000^{\circ} \mathrm{C}$ (Friedman, et al), and any rock which contains a significant amount of glassy constituents such as obsidian loses almost all strength at $800^{\circ} \mathrm{C}$.

Microwaves can be generated either uphole or downhole. In existing technology, the magnetron in a microwave generator is not especially rugged. If it is at the surface, the microwave energy must be transmitted downhole by either a coaxial cable or a wave-guide. Since it is difficult to transmit high power levels down a coaxial cable, and a wave-guide cross-section for the appropriate frequencies is too large for a drill string, the configuration of a drilling system which would transmit the microwave power and include a mechanical rock cutter of some sort is not apparent, although it might be possible for the drill string to act as a coaxial conductor. If a rugged magnetron were developed as part of the BHA, it would still require high-level power transmission downhole.

In addition to the power transmission problem, high-temperature-basalt data from the Bureau of Mines is quite variable, probably as a result of differences in mineralogy and dielectric constant. This probably means that a microwave system should be tunable for best performance.

The Bureau of Mines also did a few experiments with an electrical system which used microwaves to heat rock enough for the resistivity to fall dramatically. A high current was then passed through the rock to reduce it by spark discharge in the resistivity breakdown channel (Berglund, personal communication). This effort, also aimed at tunneling and excavation, was primarily a demonstration of principle, with further work curtailed by the shutdown of the Twin Cities Research Center and the Bureau of Mines.

In summary, thermally-assisted rock cutting shows significant performance enhancement but has many technical challenges in the power-delivery system. 
MUD HAMMER:

\begin{tabular}{|c|c|c|c|c|c|c|}
\hline \multirow{2}{*}{$\begin{array}{c}\text { SYSTEM } \\
\text { TVPE }\end{array}$} & \multicolumn{6}{|c|}{ DRILIING FUNCTIONS } \\
\hline & $\begin{array}{l}\text { TRANSMIT } \\
\text { ENERGY }\end{array}$ & $\begin{array}{l}\text { REDUCE } \\
\text { ROCK }\end{array}$ & $\begin{array}{l}\text { REMOVE } \\
\text { ROCK }\end{array}$ & $\begin{array}{l}\text { CONIROL } \\
\text { WELL }\end{array}$ & $\begin{array}{l}\text { MAINTAIN } \\
\text { HOLE } \\
\text { STABLITY }\end{array}$ & $\begin{array}{l}\text { PRESERVE } \\
\text { WELLBORE }\end{array}$ \\
\hline BASELINE & $\begin{array}{l}\text { Mechanical } \\
\text { energy to rock } \\
\text { through rotary } \\
\text { table and } \\
\text { drillstring, drill } \\
\text { pipe moved by } \\
\text { drawworks }\end{array}$ & $\begin{array}{l}\text { Crushing or } \\
\text { shearing by } \\
\text { roller-cone } \\
\text { or drag bits }\end{array}$ & $\begin{array}{l}\text { Drilling } \\
\text { mud, } \\
\text { circulated } \\
\text { by pumps, } \\
\text { or gas, } \\
\text { driven by } \\
\text { compressors }\end{array}$ & $\begin{array}{l}\text { Mechanical } \\
\text { closure by } \\
\text { blow-out } \\
\text { preventers, } \\
\text { pressure } \\
\text { control by } \\
\text { mud column }\end{array}$ & $\begin{array}{l}\text { Hydrostatic } \\
\text { pressure of } \\
\text { mud; } \\
\text { chemical } \\
\text { treatment by } \\
\text { mud } \\
\text { additives }\end{array}$ & $\begin{array}{l}\text { Steel casing } \\
\text { cemented in } \\
\text { place; handled } \\
\text { by mast and } \\
\text { drawworks }\end{array}$ \\
\hline $\begin{array}{l}\text { MUD } \\
\text { HAMMER }\end{array}$ & $\begin{array}{l}\text { Baseline, plus } \\
\text { hydraulic power } \\
\text { to hammer }\end{array}$ & $\begin{array}{l}\text { Roller or } \\
\text { flathead bits } \\
\text { crushing } \\
\text { rock by } \\
\text { impact }\end{array}$ & Baseline & Baseline & Baseline & Baseline \\
\hline
\end{tabular}

These hammers, unlike the air-hammers described earlier (page III-9), use mud to drive a reciprocating mass (also called the "hammer") which applies impulse loading to the bit (see Figure 9). These impulses increase the effective WOB, and thus ROP, without adding the equivalent drill-collar weight which would damage the bit's bearings. Some of the positive and negative features of this system include the following:

Pro - Penetration rate increases with more effective rock reduction.

- Lower weight-on-bit gives longer bit life.

- Lower WOB gives less tendency for hole deviation.

- Mud hammer requires little modification to standard drilling practice (possible addition of a shock-absorber above the hammer).

Con - Performance improvement decreases with depth.

- Hammer designs which valve the total mud flow are a hindrance to well control operations.

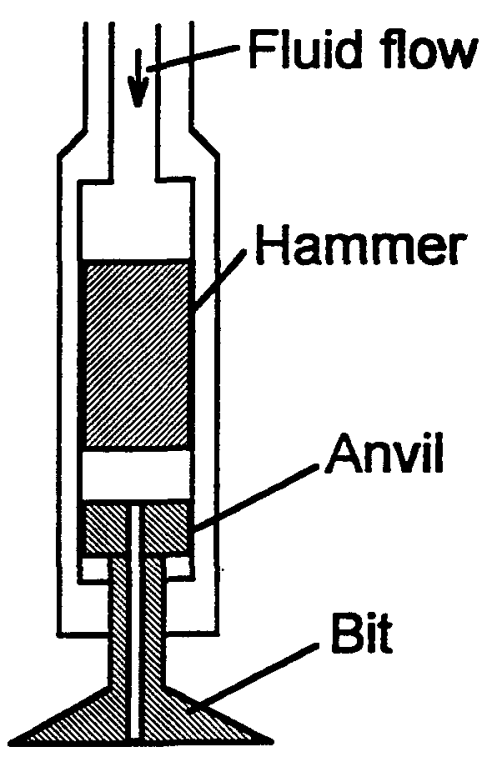

Figure 9 - Hammer drill (valving not shown)

- Hammer interferes with mud-pulse or acoustic MWD.

- Poor design or incorrect operation can cause excessive damage at the hammer-anvil interface.

- Abrasives in mud cause erosion and wear at the control valve.

- Fatigue may cause mechanical failure of the valve and/or spring. 
It should be noted, however, that by-pass valving can solve some of the valve and flow problems and improved material science can mitigate erosion and impact damage. Since hydraulic energy is used to drive the hammer, there will be a loss of hydraulic horsepower during hammer operation. However, it should be straightforward to increase flow or pressure to allow for these losses and still maintain adequate hole-cleaning hydraulics at the bit. Mud hammers are now used with standard roller-cone drill bits, but widespread hammer use would likely lead to development of bits tailored to this application.

Mud hammers have been investigated since the late 1800 s, with efforts peaking in the United States following World War II. Particular efforts have included those by Bassinger, Hughes Tool, Gulf Research, Pan American Petroleum (Amoco), and Ingersoll-Rand (Pixton). The Chinese are currently active in hammer technology and initially supplied mud hammers to the German KTB deep drilling project (Renjie, Deutsch). Currently, the only known U. S. mud hammer development is by Novatek, of Provo, UT.

Air hammers have demonstrated increased penetration rate by factors up to ten in hard formations, but, as with any tool that requires air drilling, there is reduced ability both to maintain borehole stability and to control formation fluids, where these are problems. A mud hammer would provide at least some performance improvement, while using drilling muds for well control and formation stability. Laboratory tests of two air hammers and one mud hammer (at surface pressure) showed about the same performance (Finger), but as depths increased the performance of the mud hammer, relative to the air hammers, would probably not be maintained. Increased penetration rate and longer bit life with mud hammers, relative to conventional rotary drilling with roller-cone bits, have been demonstrated in the field. Using conventional drilling as a base for comparison, the Bassinger hammer demonstrated penetration rate increases ranging from $20 \%$ in sand to three times in granite (Brown). Bits used with the Bassinger tool lasted nearly $50 \%$ longer in sand and over five times as long in granite. Tests with the Bassinger hammer also demonstrated better deviation control in crooked hole sections.

There are many methods, generally using some combination of fluid pressure and springs, for driving percussion tools (Brown, Pixton). An important performance measure is the energy delivered per unit time, which varies with the product of force/blow and blow frequency. In general, changes in design that increase force/blow (increased hammer mass, increased stroke, etc.) will reduce blow frequency, but increasing the fluid pressure increases both force per blow and blow frequency. Bassinger noted increased performance with conventional roller bits delivering high-frequency, light blows (Bassinger), but he also stated that such blows would be ineffective if blow force and cutter sharpness were insufficient to penetrate rock.

Novatek, in Provo, UT, currently has an operational mud hammer which uses fluid pressure to drive the hammer in both directions. This design has a number of features which alleviate 
problems associated with previous hammers. Eliminating springs eliminates problems with spring failure. The differential area on the hammer assures that it will reciprocate when fluid flow begins.

The Novatek design also uses partitioned flow through the hammer, directing most of the mud to the bit for adequate cleaning. This parallel flow reduces or eliminates many stress problems, particularly stresses due to water hammer when shutting off the total mud flow, and also reduces concerns about flow through the hammer during well-kill operations. With the parallel flow path, conventional drilling can continue even if the reciprocating mechanism fails, which will relieve concerns about the reliability of the hammer.

Novatek has three tools, each with a 61-lb. reciprocating mass, or hammer, and they are developing another tool with a somewhat larger hammer, capable of delivering higher energy to the bit. Although there are certainly limits, the hammer weight can be increased significantly. Novatek has recently entered an agreement through the Geothermal Drilling Organization to test their hammer both in oilfield and in geothermal drilling. These tests are directed toward optimization of the hammer and bits. 


\section{THERMAL SPALLATION:}

\begin{tabular}{|l|l|l|l|l|l|l|}
\hline \begin{tabular}{|l|l|} 
SYSTEM \\
TYPE
\end{tabular} & $\begin{array}{l}\text { TRANSMIT } \\
\text { ENERGY }\end{array}$ & $\begin{array}{l}\text { REDUCE } \\
\text { ROCK }\end{array}$ & $\begin{array}{l}\text { REMOVE } \\
\text { ROCK }\end{array}$ & $\begin{array}{l}\text { CONTROL } \\
\text { WEIL }\end{array}$ & $\begin{array}{l}\text { MAINTAIN } \\
\text { HOLE } \\
\text { STABIIYY }\end{array}$ & $\begin{array}{l}\text { PRESERVE } \\
\text { WELLBORE }\end{array}$ \\
\hline BASELINE & $\begin{array}{l}\text { Mechanical } \\
\text { energy to rock } \\
\text { through rotary } \\
\text { table and } \\
\text { drillstring, drill } \\
\text { pipe moved by } \\
\text { drawworks }\end{array}$ & $\begin{array}{l}\text { Crushing or } \\
\text { shearing by } \\
\text { roller-cone } \\
\text { or drag bits }\end{array}$ & $\begin{array}{l}\text { Drilling } \\
\text { mud, } \\
\text { circulated } \\
\text { by pumps, } \\
\text { or gas, } \\
\text { driven by } \\
\text { compressors }\end{array}$ & $\begin{array}{l}\text { Mechanical } \\
\text { closure by } \\
\text { blow-out } \\
\text { preventers; } \\
\text { pressure } \\
\text { control by } \\
\text { mud column }\end{array}$ & $\begin{array}{l}\text { Hydrostatic } \\
\text { pressure of } \\
\text { mud; } \\
\text { chemical } \\
\text { treatment by } \\
\text { mud } \\
\text { additives }\end{array}$ & $\begin{array}{l}\text { Steel casing } \\
\text { cemented in } \\
\text { place; handled } \\
\text { by mast and } \\
\text { drawworks }\end{array}$ \\
\hline $\begin{array}{l}\text { THERMAL } \\
\text { SPALLATION }\end{array}$ & $\begin{array}{l}\text { Primarily } \\
\text { chemical (fuel } \\
\text { and oxidizer) }\end{array}$ & $\begin{array}{l}\text { Spallation } \\
\text { due to high } \\
\text { thermal } \\
\text { gradients } \\
\text { and/or dif- } \\
\text { ferential } \\
\text { expansion }\end{array}$ & $\begin{array}{l}\text { Gas, air } \\
\text { compressor } \\
\text { plus } \\
\text { products of } \\
\text { combustion }\end{array}$ & $\begin{array}{l}\text { Blowout } \\
\text { preventer }\end{array}$ & None & Baseline \\
\hline
\end{tabular}

Thermal spallation drilling uses a large, downhole burner, much like a jet engine, to apply a high heat flux to the rock face. This heating induces stresses and reduces the rock by at least two mechanisms: (1) there are large thermal gradients between the surface and the deeper structure of the rock, (this causes the rock face to fragment into small flakes called spalls, which typically have lateral dimensions several times the thickness) and (2) the different minerals which compose the rock have different coefficients of thermal expansion, so their dimensions do not change the same amount as they change temperature.

A thermal spallation drilling system transfers energy by feeding fuel and an oxidizer to the burner at the lower end of the drill string. Spalls are flushed out of the wellbore with the products of combustion from the burner and sometimes by additional air injected into the annulus above the burner.

Two major companies have developed thermal spallation drilling systems: the Linde Air Division of Union Carbide, and Browning Engineering. In the 1940s, Linde developed a jet piercing tool, burning fuel oil and oxygen, which was used for drilling blast holes in mining taconite ore. This system drilled between thousands (Rauenzahn) and millions (Williams 1985) of feet . Linde built over forty systems in at least three different models and did a significant amount of work to optimize burner efficiency and cutting ability. Linde's spallation activity declined significantly in the early 1970s and ended in 1983 for three major reasons: their principal business was the production and sale of industrial gases, not the development and operation of drilling equipment; the cost of both oxygen and fuel was increasing; and improvements in roller-cone bit 
life made it difficult for thermal spallation systems to compete (Calaman, personal correspondence). The Linde Air Division spun off from Union Carbide in 1992 to form Praxair, Inc. but Praxair is not now active in thermal spallation systems.

In the 1960s Browning Engineering developed a hand-held spallation tool for cutting rock. Several hundred of these were sold worldwide and in the 1970s, Browning leveloped a truck mounted flame jet system capable of drilling holes or creating underground chambers in hard rock. This system burned \#2 fuel oil and air, and has drilled to depths in excess of 1,000 feet. Rinaldi's analysis of this system indicates penetration rates with this system can be more than 200 $\mathrm{ft} / \mathrm{hr}$ in some rock types, depending on hole diameter, air pressure, and air flow rate (Rinaldi July 1984).

A third, but minor, developer in spallation drilling systems was Flame Jet Partners. This company built and tested a system that mixed fuel, hydrazine, and nitrogen tetroxide in a combustion chamber to give very high flame temperatures. The system was designed to rotate downhole resulting in alternating periods of exposure of the rock to the exhaust gases. The exhaust gas temperature for this system was hot enough to meit rock that would not spall. No record of current activity of this company has been found.

Spallation systems have the following major positive and negative attributes. Discussions of each attribute are numbered as in the list below:

Pro 1. High penetration rates in hard rock have been predicted and demonstrated.

2. Burner life should be longer than current bit life due to lack of contact between the burner and the rock face. This reduces the number of trips.

3. Since the drill pipe does not rotate, abrasive wear will be reduced.

Mixed 4. Hole diameter varies with the drilling advance rate (holes can be under-reamed by slowing the advance rate, but it's more difficult to maintain gauge).

Con 5. System must (probably) operate in a gas filled hole, limiting application.

6. A multi-channel umbilical for fuel, oxidizer, and cooling water is required.

7. Some safety concerns, with air-fuel mixture downhole, exist.

8. Performance (ability to spall) varies significantly with rock type.

(1) Penetration rates up to $100 \mathrm{ft} / \mathrm{hr}$ have been predicted for drilling in competent, nonfractured hard rock such as granite (Wilkinson). Browning Engineering Company drilled an eight- to ten-inch diameter hole in granite, over a thousand feet deep, at an average penetration rate of $52 \mathrm{ft} / \mathrm{hr}$ and with penetration rates exceeding $100 \mathrm{ft} / \mathrm{hr}$ toward the end of the operation (Williams 1985). For comparison, Williams points out that a 9-5/8" hole in granite drilled with roller-cone bits at Fenton Hill, NM, had a maximum penetration rate of $12 \mathrm{ft} / \mathrm{hr}$. 
$(2,3)$ Although reduced abrasion and relatively long burner life seem very reasonable, these attributes have not been documented and can only be demonstrated by field trials.

(4) Control of hole size has also been demonstrated (Williams 1988). This provides the ability to under-ream (create intervals of hole larger in diameter than the hole above them).

(5) To date, thermal spallation drilling systems have primarily been developed to operate in a gaseous environment, but there is experience with systems which function under some liquid column. (Williams 1988) When there is indigenous water or water influx from the formation, spallation usually occurs after the water is blown away and the rock dried. Linde operated a mining system under 50 feet of water in taconite mines, and the same company designed a supersonic torch and blow-pipe system which was used for excavation in the St. Lawrence Seaway under 16 to 30 feet of water. Tester discusses the theoretical basis for submerged spallation, using a hot, dense supercritical fluid to transfer heat to the formation. (Tester). Although the question of submerged spallation has been addressed, there is no satisfactory evaluation of possible performance under the conditions in a mud-filled wellbore of moderate depth.

(6) If rigid drill pipe is not required, the individual conduits for fuel, oxidizer, and air can be bundled together and reeled into and out of the hole like coiled tubing. If drill pipe must be used, then the problems of manufacturing pipe for partitioned flow are very similar to those described in the section of jet-assisted drilling (page III-17), except that the pressure levels are much lower.

(7) If there are hydrocarbons in the formation, downhole fires can occur even in conventional rotary air-drilling, and thermal spallation systems would be even more susceptible to this possibility. If there is no downhole fuel source, shutting off fuel and air at the surface will control a downhole fire but will not spare equipment and material already damaged.

(8) The variation of spallability in different formations is a serious hindrance to widespread use of this system, although recent work indicates that spallation may be extended to a larger number of rock types. Williams reports that basalt, which is generally thought to be unspallable, will readily spall under slow heating conditions (Williams 1988). Research aimed at extending the use of spallation to such rocks as limestone and shale is currently being conducted at both Los Alamos National Laboratory and the New Mexico Institute of Mining and Technology (Wilkinson). In general, low thermal diffusivity, resulting in high gradients, coupled with a high thermal expansion coefficient, yielding high stresses, will increase spallability.

One solution to the problem of non-spallable rocks would be a thermal spallation system which augments a conventional rotary drill rig. Rinaldi describes such a system, with minimal modification to normal rig operations, procedures, and equipment, and discusses its use (Rinaldi October 1984); Tester proposed a number of necessary features for such a system (Tester). 
There are proposals to use thermal spallation on a conventional drill rig without changing the drill string. Fuel, air, and cooling water would be mixed at the surface and pumped to a downhole separator. This unit would separate the three components, directing the fuel and part of the air to the burner, the water to cooling ports, and the remainder of the air to the annulus for lift. A British company, Worldrill Corporation, has applied for a European patent for this kind of downhole separation system (Worldrill). This system would use an electrical connection to the surface for downhole ignition, but Rinaldi proposed the inclusion of a downhole electric generator or storage batteries. Elimination of an electrical connection would greatly simplify adaptation of spallation to a conventional drill rig with standard drill pipe.

Another possibility for adaptation of spallation drilling to standard rigs is the use of dual-wall pipe. This has a major advantage: it avoids problems in separating a liquid fuel and water or a gaseous fuel and air downhole. Dual-wall pipe does, however, have significant penalties of weight and cost. The weight of dual-wall drill pipe is comparable to casing, which makes handling difficult and slow and increases the required lift capacity for the rig.

Finally, cutting non-spallable rocks can be done with abrasive grit added to the high-velocity flame jet. Browning demonstrated this principle in laboratory experiments, but it is not known to have been used in the field. Significant drawbacks are increased wear on the burner hardware and the necessity for yet another conduit to carry the abrasive material.

In general, past systems were not used to make deep, large diameter holes, but knowledge of thermal spallation has advanced to the point that development of a specialized rig to employ thermal spallation in deep-hole drilling is now an engineering problem. Recent efforts in spallation drilling have concentrated on a better understanding of the physical principles.

In summary, thermal spallation gives high rates of penetration in the somewhat limited spectrum of rock types and wellbore conditions where it can operate. Extension of spallation drilling to other rock types will probably require development of a hybrid system in which spallation augments conventional rotary drilling. 


\section{SPARK DRILL:}

\begin{tabular}{|c|c|c|c|c|c|c|}
\hline \multirow{2}{*}{$\begin{array}{c}\text { SYSTEM } \\
\text { TYPE }\end{array}$} & \multicolumn{6}{|c|}{ DRILING FUNCTIONS } \\
\hline & $\begin{array}{l}\text { TRANSMTT } \\
\text { ENERGY }\end{array}$ & $\begin{array}{l}\text { REDUCE } \\
\text { ROCK }\end{array}$ & $\begin{array}{l}\text { REMOVE } \\
\text { ROCK }\end{array}$ & $\begin{array}{l}\text { CONTROL } \\
\text { WELL }\end{array}$ & $\begin{array}{l}\text { MAINTAIN } \\
\text { HOLE } \\
\text { STABIITY }\end{array}$ & $\begin{array}{l}\text { PRESERVE } \\
\text { WELLBORE }\end{array}$ \\
\hline BASELINE & $\begin{array}{l}\text { Mechanical } \\
\text { energy to rock } \\
\text { through rotary } \\
\text { table and } \\
\text { drillstring; drill } \\
\text { pipe moved by } \\
\text { drawworks }\end{array}$ & $\begin{array}{l}\text { Crushing or } \\
\text { shearing by } \\
\text { roller-cone } \\
\text { or drag bits }\end{array}$ & $\begin{array}{l}\text { Drilling } \\
\text { mud, } \\
\text { circulated } \\
\text { by pumps, } \\
\text { or gas, } \\
\text { driven by } \\
\text { compressors }\end{array}$ & $\begin{array}{l}\text { Mechanical } \\
\text { closure by } \\
\text { blow-out } \\
\text { preventers; } \\
\text { pressure } \\
\text { control by } \\
\text { mud column } \\
\end{array}$ & $\begin{array}{l}\text { Hydrostatic } \\
\text { pressure of } \\
\text { mud; } \\
\text { chemical } \\
\text { treatment by } \\
\text { mud } \\
\text { additives } \\
\end{array}$ & $\begin{array}{l}\text { Steel casing } \\
\text { cemented in } \\
\text { place; handled } \\
\text { by mast and } \\
\text { drawworks }\end{array}$ \\
\hline $\begin{array}{l}\text { SPARK } \\
\text { DRILL }\end{array}$ & $\begin{array}{l}\text { Electrical } \\
\text { energy delivered } \\
\text { to the drill head }\end{array}$ & $\begin{array}{l}\text { Spark- } \\
\text { driven shock } \\
\text { wave }\end{array}$ & Baseline & Baseline & Baseline & Baseline \\
\hline
\end{tabular}

Spark drilling uses the pressure pulse from a downhole spark discharge to break rock in compression; it can be either an independent drilling method or can augment conventional rotary drilling.

A significant amount of development has been done on spark drills and spark-assisted rotary drills. Sandia National Laboratories had a spark-drill development program in the late 1970s. The U.S. Bureau of Mines, Twin Cities Research Center, has recently done experiments using spark discharge to break rocks (briefly discussed under thermally-assisted drilling, page III-23). Tetra Corporation, Albuquerque, NM, has a functional spark discharge system for quarry operations and has patented a spark drill (Moeny patent). Tetra claims to be ready for development of a field spark-drilling system if substantial financial backing can be found. Maurer describes spark-drilling development efforts in three publications (Maurer 1968, Maurer 1980, Maurer GRI).

Spark drilling has the following positive and negative attributes:

Pro 1. Higher rates of penetration may be possible (and may be aided by the beneficial use of insulation flashover).

2. Unlike many alternative systems, spark drill operates in liquid-filled wellbore.

3. With adequate instrumentation, system can improve directional control.

Con 4. Energy transmission requires electrical conduit downhole.

5. High currents cause insulation breakdown.

6. System has reduced cutting ability at increased depth.

7. Gas is generated downhole by electrical discharge. 
(1) Higher rates of penetration for spark drills have been claimed, based on theoretical considerations and supported by some laboratory experiments, but a field-operable system has never been designed or demonstrated. Although early work addressed the problem of flashover spark discharge that is not between the electrodes -- Moeny's patent claims that

"one embodiment of the present invention does not eliminate this insulation flashover but uses it in a beneficial manner ..." and ". . the problem of flashover, which hindered prior art spark discharge, is used as an advantage."

that is, the insulation breakdown at the spark gap helps to create the destructive pressure pulses which break rock.

(2) A spark drill operates in a liquid environment, expanding its applicability in various types of drilling. This also enhances borehole stability and control of formation fluids, compared to systems which can only function in a gas environment..

(3) In theory, a spark drill might have significant advantages over other advanced concepts in the area of directional drilling and control. The pulses created by the spark will produce pressure waves in the rock which can be detected at the surface. Given a geophone array and the acoustic characteristics of the rock, the position of the drill head could be estimated, but inhomogeneities in the formation may degrade this estimate to a point at which it is of little value. Tetra's patent describes the use of a system in which continuous position information would be input to a computer and drilling direction would be changed by timing the discharge across different spark arrays on the face of the bit.

(4) Since both drilling fluids and electrical energy need to be transmitted, a spark drill will require multiple conduits downhole. It may be possible to operate a spark drill on coiled tubing, but this presents the problems discussed under coiled tubing on page III-11.

(5) Sandia researchers found peak discharge currents of $25 \mathrm{kA}$ to $45 \mathrm{kA}$ and rates of change on the order of $10^{10}$ amps per second (Drilling Research Division). Under these conditions, the electrical characteristics of the transmission line will have a significant effect on output of the system. Moeny maintains that the current Tetra design has solved the problem of energy transmission.

(6) Reduced cutting ability with depth may be due to a basic characteristic of the spark drill. The shock wave from a spark drill induces compressive stress in the rock, but in-situ stress increasing with depth causes the rock to deform plastically, reducing the effect of additional compressive stress. Earlier designs had maximum power outputs on the order of $100 \mathrm{~kW}$, but Moeny's patent claims power outputs up to $1 \mathrm{MW}$, which should significantly increase cutting ability at all depths. Although he does not explain how, Moeny claims that increased depth will aid in breaking rock. 
Experimental drilling facilities are available in which borehole fluid pressure, pore fluid pressure, and in-situ stress at depth can be independently simulated. These facilities can be used to investigate spark-cutting ability at wellbore conditions before expending significant funds on development of a spark drilling system.

(7) One characteristic of a spark drill could introduce uncertainties into=well control and formation stability. Moeny's patent states:

"significant amounts of gas will be evolved during the underwater spark discharging and, in deep wells, this gas will expand and push the drilling mud ahead to form a bubble lift".

The presence of this gas will alter the effective weight of the drilling mud, introducing complications in well control and formation stability, especially if the gas generation cannot be predicted and controlled. 


\section{EXPLOSIVE DRILL:}

\begin{tabular}{|l|l|l|l|l|l|l|}
\hline \multicolumn{1}{|c|}{$\begin{array}{c}\text { SYSTEM } \\
\text { TYRE }\end{array}$} & \multicolumn{1}{|c|}{$\begin{array}{c}\text { DRANSMIT } \\
\text { ENERGY }\end{array}$} & $\begin{array}{l}\text { REDUCE } \\
\text { ROCK }\end{array}$ & $\begin{array}{l}\text { REMOVE } \\
\text { ROCK }\end{array}$ & $\begin{array}{l}\text { CONIROL } \\
\text { WELL }\end{array}$ & $\begin{array}{l}\text { MAINTAIN } \\
\text { HOLE } \\
\text { STABRITY }\end{array}$ & $\begin{array}{l}\text { PRESERVE } \\
\text { WELLBORE }\end{array}$ \\
\hline BASELINE & $\begin{array}{l}\text { Mechanical } \\
\text { energy to rock } \\
\text { through rotary } \\
\text { table and } \\
\text { drillstring, drill } \\
\text { pipe moved by } \\
\text { drawworks }\end{array}$ & $\begin{array}{l}\text { Crushing or } \\
\text { shearing by } \\
\text { roller-cone } \\
\text { or drag bits }\end{array}$ & $\begin{array}{l}\text { Drilling } \\
\text { mud, } \\
\text { circulated } \\
\text { by pumps, } \\
\text { or gas, } \\
\text { driven by } \\
\text { compressors }\end{array}$ & $\begin{array}{l}\text { Mechanical } \\
\text { closure by } \\
\text { blow-out } \\
\text { preventers, } \\
\text { pressure } \\
\text { control by } \\
\text { mud column }\end{array}$ & $\begin{array}{l}\text { Hydrostatic } \\
\text { pressure of } \\
\text { mud; } \\
\text { chemical } \\
\text { treatment by } \\
\text { mud } \\
\text { additives }\end{array}$ & $\begin{array}{l}\text { Steel casing } \\
\text { cemented in } \\
\text { place; handled } \\
\text { by mast and } \\
\text { drawworks }\end{array}$ \\
\hline $\begin{array}{l}\text { EXPLOSIVE } \\
\text { DRILL }\end{array}$ & $\begin{array}{l}\text { Chemical } \\
\text { explosive } \\
\text { delivered to } \\
\text { rock face }\end{array}$ & $\begin{array}{l}\text { Explosively- } \\
\text { driven shock } \\
\text { wave, or } \\
\text { explosive- } \\
\text { enhanced } \\
\text { conventional }\end{array}$ & Baseline & Baseline & Baseline & Baseline \\
\hline
\end{tabular}

Drill and blast techniques are extensively used to remove rock in excavation, mining, and tunneling; and explosive components are used in the drilling industry for well stimulation, casing perforation, and cutting stuck pipe. For actually making hole using explosives, at least four systems have been investigated: explosive capsule drills, liquid explosive drills, shaped and gauge charges, and an explosive-assisted rotary system. While there have been efforts to develop explosive drill systems both in this country and in the former Soviet Union, regular use of explosives for making hole has not occurred. This work has been reviewed elsewhere in significant detail (Maurer 1968, Maurer 1980, Maurer GRI, Olson). With the exception of a projectile system described earlier (page III-21), there has been no effort in the U.S. in the last twenty years to develop a drilling system in which rock reduction was accomplished by explosive energy. An explosive drilling system would have the following attributes, discussed in more detail below:

1. (+) System has demonstrated increased rate of penetration.

2. $(+)$ Performance is maintained or increased with depth.

3. (+/-) Explosive system retains most components of conventional drilling (probably needs reamer above explosive system to maintain hole gauge).

4. (-) Ignition must be reliable, correctly timed, and safe.

5. (-) Explosive must be properly distributed and counted in wellbore.

(1) The Bureau of Mines reported theoretical penetration rates with an explosive-capsule system greater than $100 \mathrm{ft} / \mathrm{min}$ in granite (Olson). This calculation, which appears to have 
omitted problems with sympathetic detonation and with hole cleaning, assumes a detonation frequency of fifty capsules per second. Robinson discussed igniting a shaped and gauge charge combination once every two to four minutes. Based on considerations of sympathetic detonation, Maurer calculated a maximum delivery rate on the order of six to twelve capsules per minute depending on depth. Using the Bureau of Mines number of about 0.4 " penetration per detonation and Maurer's upper limit on delivery yields $24 \mathrm{ft} / \mathrm{hr}$ penetration rate in hard rock, which could justify significant increases in capital and operating costs.

Another limiting factor in penetration rate is the need to remove cuttings between successive explosions. This was a problem with liquid systems (Maurer 1968), where circulating mud at the bottom caused dispersal of the explosive, but circulating mud above the bottom gave inefficient cleaning. Debris on the hole bottom will always reduce the efficiency of the explosive charge.

(2) Robinson describes an explosive system which uses alternating shaped and "gauging" charges pumped down a drill string with a "drilling head" (essentially a drag bit) at the bottom (Robinson). In this method, the shaped charge creates a deep, relatively narrow hole, which the gauging charge enters and enlarges (Figure 10). Weakened rock is reamed by the abrasive drilling head and debris is circulated out of the hole by conventional means. In laboratory experiments the ratio of rock removed to explosive weight was larger when the explosions occurred at higher insitu pressures, although the reasons for this are not clear. Thus, unlike nearly all other rock reduction concepts, an explosive system may not suffer reduced cutting ability with depth.

(3) Although the ability to use an explosive drilling system with existing rigs would enhance its applicability, it also means that little cost saving in surface equipment is available. Depending on the system chosen, bit costs might decrease, but a reamer near the bottom of the drill string would probably still be necessary to maintain hole gauge. It is not likely that explosive drilling would lower capital or operating costs compared to

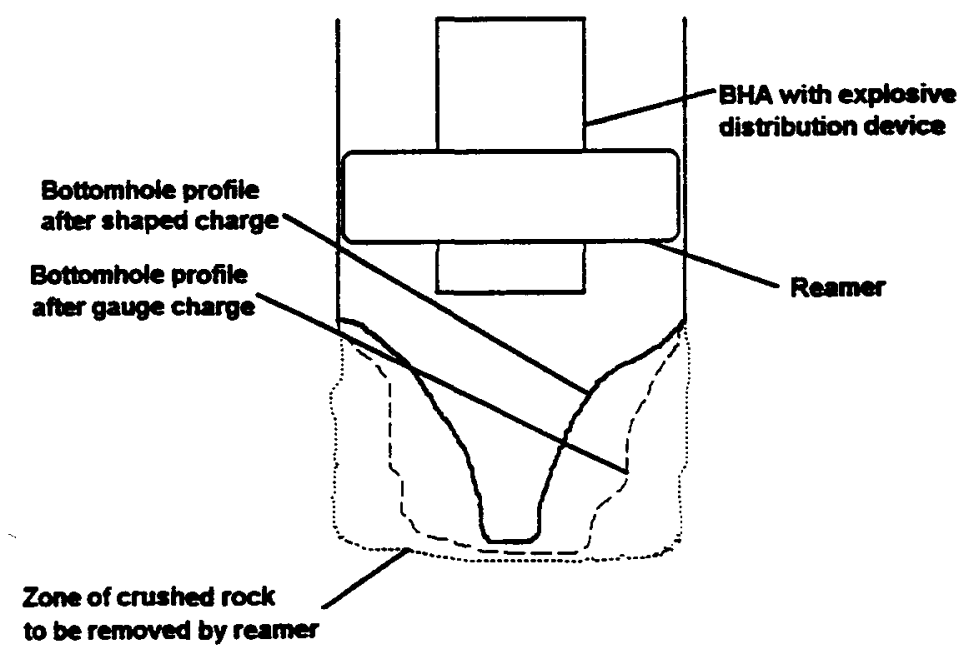

Figure 10 - Shaped and gauge charges conventional technology.

(4) Ignition reliability is a major concern, since unburned explosive in the wellbore presents serious safety problems. In a liquid explosive system, unburned explosive or explosive components could be dispersed in the mud and pumped out of the well if the concentration is low enough. 
In an explosive capsule system, mud circulation will be carrying unfired capsules toward the surface. If ignition fails, the first reaction would be to stop pumping, but if flow stops without pulling off bottom, there is a chance of sticking the drill pipe as cuttings settle. It is also likely that additional capsules would be in the drill string and they would tend to concentrate, probably at the top or bottom of the string, depending on buoyancy. The basic paradox is that the drill string must be cleared before tripping, which requires maintaining mud flow, but the flow circulates an armed device, the misfire; toward the surface.

In the shaped and gauge charge system investigated by Robinson, the unexploded charge would be in the end of the drill pipe reducing mud flow. Because of the reduced flow, the driller may have to pull off bottom to prevent sticking the pipe as the cuttings in the annulus settle; but it is not clear that the entire string should be tripped with an armed charge stuck in the bottom. As with the capsule system, the problems would be greatly amplified if additional charges were in the drill string above the bottom-hole assembly.

Two other systems have considered the question of ignition failure. In a rotary-assist system, the bit would crush the explosive device if ignition failed. In one explosive capsule system, the capsules were designed to dissolve before they reached the surface.

From a safety standpoint, the elimination of all primary explosives from the system would be a positive contribution. The Bureau of Mines commissioned a series of tests to try shock-initiated secondary explosives for drilling. Impact velocities as high as $1,000 \mathrm{ft} / \mathrm{sec}$ were attempted without success, and it was finally concluded that a detonator of some type was necessary.

(5) In either an explosive capsule or shaped and gauge charge system, the charges are carried to the rock face in the drilling fluid stream, while the liquid explosive system requires multiple conduit pipe to separately deliver fuel and oxidizer to the hole bottom. In any of these systems stand-off distance and explosive distribution are critical. Stand-off affects drill string damage and explosive efficiency; development of a system to measure and control stand-off could require significant effort.

A system for injecting explosives into the drill string and accounting for them is also necessary. The accounting system would need to count the number and spacing of explosive charges in the system, and then detect their ignition. The detection system could be based on either acoustics or pressure pulses.

In summary, explosive drilling offers the possibility of high penetration rates, either as a standalone system or as augmentation to conventional rotary, but the challenges of reducing this concept to practice are formidable. 


\section{ROCK MELTERS:}

\begin{tabular}{|c|c|c|c|c|c|c|}
\hline \multirow{2}{*}{$\begin{array}{c}\text { SYSTEM } \\
\text { TYPE } \\
\end{array}$} & \multicolumn{6}{|c|}{ DRILLING FUNCTIONS } \\
\hline & $\begin{array}{l}\text { TRANSMIT } \\
\text { ENERGY }\end{array}$ & $\begin{array}{l}\text { REDUCE } \\
\text { ROCK }\end{array}$ & $\begin{array}{l}\text { REMOVE } \\
\text { ROCK }\end{array}$ & $\begin{array}{l}\text { CONTROL } \\
\text { WELL }\end{array}$ & $\begin{array}{l}\text { MAINTAIN } \\
\text { HOLE } \\
\text { STABILITY }\end{array}$ & $\begin{array}{l}\text { PRESERVE } \\
\text { WELLBORE }\end{array}$ \\
\hline BASELINE & $\begin{array}{l}\text { Mechanical } \\
\text { energy to rock } \\
\text { through rotary } \\
\text { table and } \\
\text { drillstring; drill } \\
\text { pipe moved by } \\
\text { drawworks }\end{array}$ & $\begin{array}{l}\text { Crushing or } \\
\text { shearing by } \\
\text { roller-cone } \\
\text { or drag bits }\end{array}$ & $\begin{array}{l}\text { Drilling } \\
\text { mud, } \\
\text { circulated } \\
\text { by pumps, } \\
\text { or gas, } \\
\text { driven by } \\
\text { compressors }\end{array}$ & $\begin{array}{l}\text { Mechanical } \\
\text { closure by } \\
\text { blow-out } \\
\text { preventers; } \\
\text { pressure } \\
\text { control by } \\
\text { mud column }\end{array}$ & $\begin{array}{l}\text { Hydrostatic } \\
\text { pressure of } \\
\text { mud; } \\
\text { chemical } \\
\text { treatment by } \\
\text { mud } \\
\text { additives }\end{array}$ & $\begin{array}{l}\text { Steel casing } \\
\text { cemented in } \\
\text { place; handled } \\
\text { by mast and } \\
\text { drawworks }\end{array}$ \\
\hline $\begin{array}{l}\text { ROCK } \\
\text { MELTERS }\end{array}$ & $\begin{array}{l}\text { Electrical or } \\
\text { optical }\end{array}$ & $\begin{array}{l}\text { Thermal - } \\
\text { rock melting }\end{array}$ & Pneumatic & $\begin{array}{l}\text { Blowout } \\
\text { preventer }\end{array}$ & $\begin{array}{l}\text { Glass-lined } \\
\text { wellbore (?) }\end{array}$ & $\begin{array}{l}\text { Baseline, or } \\
\text { glass lining (?) }\end{array}$ \\
\hline
\end{tabular}

Four methods of rock reduction by direct melting - plasma-arc torch, electron beam, laser thermal, and electric heater - have been examined in some detail. The electric heater and plasmaarc torch heat the rock surface over the entire hole bottom, while the e-beam and laser are much more tightly focused. Regardless of the energy-deposition mechanism, however, all these methods share some positive and negative attributes:

Pro 1. Melters do not need to rotate, enabling the use of coiled-tubing units or conventional rigs simplified by reduction of surface equipment.

2. Generally, these systems will not need mud pumps or mud-cleaning equipment. Although they do not have liquid drilling fluids for hole stability and well control, the melted rock has the potential to form a glassy lining on the wellbore, which might alleviate those problems.

Con 3. This same glassy lining will be detrimental to a production zone.

4. Not all rocks turn to glass-like materials when melted.

5. An electric heater is in direct contact with the hole bottom, but the other three systems require control of stand-off distance.

6. It may be difficult to lift melted rock from the hole bottom.

7. Systems require power (and sometimes fuel) transmission to hole bottom, which implies multi-channel conduit.

(1) Use of a coiled-tubing unit eliminates much of the surface equipment used in a conventional drill rig. Mud pumps, a mud-cleaning system, and the derrick, drawworks, and rotary table will not be used with melters, although it may be necessary to use casing jacks or similar equipment for running casing. As an alternative to the coiled-tubing unit, a conventional 
rig could be simplified by eliminating the mud system and could possibly be down-sized because the wellbore lining discussed below might reduce the casing string requirements.

(2) Any of these systems has the potential to create at least a hole-volume of melted rock, some of which will be absorbed by the formation's permeability and some of which will be lifted into the wellbore where it may be deposited onto the wellbore wall in the form of a glassy lining. Although it is not clear that this lining will be adequate for control of fluid influx, hole preservation, or even wellbore stability, it should mitigate some of these problems commonly found in air drilling.

(3) If the wellbore penetrates a pay zone - oil, gas, or geothermal fluid - any glassy lining will impede or prevent production of the fluids. Standard drilling techniques, such as fracturing or perforating, would create openings in the lining to allow useful productive capacity.

(4) A great many rocks melt at temperatures on the order of $1300^{\circ} \mathrm{C}$, with a heat of fusion approximately 80 calories/gram, but there are important exceptions. Granite and sandstone will form glass; basalt will probably form glass, though it contains magnetite, a glass inhibitor; and some rocks, such as limestone and dolomite, will not form glass after melting unless significant quantities of silica are supplied. This variability means that acceptance by drillers and regulatory agencies of vitrified wellbore lining as sufficient hole preservation (i.e., no casing required) is distant.

(5) An electric heater can (and must) have direct contact with the hole bottom, but the other systems need some method to measure and control stand-off distance from the rock face. This is especially critical with e-beams and lasers, the more focused systems. Because of their tight beams, it may be that the principal application for e-beams and lasers is to cut a kerf at the wellbore circumference, relieving the compressive stress and enhancing efficiency of mechanical cutters. In this combination, incorporating the beam's power head into a mechanical bit will also provide stand-off control.

(6) An electric-heater bit can either force melted rock into the formation, extrude melted rock up the center of the bit, or leave standing a core which can be wire-line extracted. It is also possible that the electric heater can operate in the presence of a drilling fluid. The other three concepts, however, are more problematic. Lasers and e-beams cannot stand the presence of liquid because of its beam dispersion. None of the three operates in contact with the rock to force the molten material outward. The plasma gas from the plasma-arc torch may blow molten material from the hole bottom, exposing new rock surface, but high-speed gas flow will create diffusion problems for either the e-beam or the laser. It is not clear that any of these concepts could efficiently remove molten rock from the hole bottom or force it into the formation. If the formation is not highly permeable, it is then likely that molten rock would remain on the hole bottom, absorbing energy until it vaporizes, which is extremely inefficient. 
(7) With the possible exception of laser-light transmission by fiber-optic cable, all the systems require transmission of electrical power downhole. Using typical rock properties (Maurer 1968, Maurer GRI), power required to melt rock is approximately $27 \mathrm{~kW} / \mathrm{fph}$ for 12-1/4" hole. Assuming $50 \%$ efficiency in transferring heat to the rock, over $50 \mathrm{~kW}$ of thermal energy must be delivered to the hole bottom for each foot per hour of penetration rate. It must be remembered, however, that the power requirement varies linearly with rate of penetration, but as the square of the hole diameter, so drilling by rock-melting may be much more realistic in smaller holes for such applications as environmental monitoring. These operations are generally close to the surface in uncompacted materials where the molten material is more likely to be forced into the formation and form a temporary, if not permanent, borehole seal.

Each of these systems has been examined to at least the level of bench-scale experiments. Unique characteristics, history and present status of each type are described in more detail below.

\section{Plasma-arc torch}

A plasma arc torch passes gas such as air or nitrogen through a spark discharge to create a plasma "torch" at extremely high temperature $\left(10,000-12,000{ }^{\circ} \mathrm{C}\right)$. Because the temperature of the plasma is much higher than can be survived by the mechanical parts of the torch, a flow of cooling fluid through the assembly is required. A drilling system based on this concept will require conduit with one channel for cooling fluid, another for plasma gas, and possibly a third to carry additional air for hole cleaning. At least two electric lines are required for the spark discharge and additional lines for command and control may be needed. The torch will also need a mechanical support which can aim the torch, preserve stand-off distance from the hole bottom, and survive exceptionally high temperatures. For near-vertical holes, the support may be a simple rolling or bow-spring support, but for directional or high-angle drilling a more elaborate thrusterretractor would be required. It may be possible to reduce the temperature extremes on this equipment by designing the support to operate far behind the torch.

In addition to melting rock, it may also be possible to use the torch for spallation drilling by operating at a greater stand-off. The only way to avoid vaporizing rock is for the flow of the plasma gas to lift the melted rock off the bottom. If this occurs, the molten rock may then solidify and be lifted from the hole by the plasma gas in combination with the ejected cooling fluid. Electric losses of $20 \%$ and thermal losses of $45 \%$ to the cooling water may raise the power estimate given previously to $110 \mathrm{~kW}$ input to the torch for each foot-per-hour of penetration rate.

There are no current efforts in this area. Both the Bureau of Mines (Olson and Olson) and Maurer (Maurer 1968; Maurer 1980) discuss the use of plasma torches in drilling. There is no doubt that a plasma torch would be capable of developing temperatures and heat flux adequate to 
reduce rock, but the use of plasma torches as drilling tools has not progressed past the point of bench tests.

\section{Electron beam and Laser thermal}

Lasers and E-beams are similar in the sense that both produce a highly concentrated energy source. Maurer (Maurer 1968, Maurer 1980, Maurer GRI) and the Twin Cities Research Center of the U. S. Bureau of Mines (Olson, Fogelson) have investigated lasers and electron-beams for drilling in some detail.

The Bureau of Mines found e-beams attractive due to their high conversion efficiency and energy transmission characteristics, but these devices have several drawbacks. Downhole high voltage and vacuum lines present major engineering problems. Filament life, beam scattering, equipment size, the need for rugged equipment, and X-ray production all limit life or applicability. The short range of the electron-beam was identified as the most serious limitation. Bureau of Mines concluded that the close standoff requirements, the need for vacuum, and the production of $\mathrm{X}$-rays precluded use of e-beam guns for either kerfing or heat-weakening rock in tunnel boring; the same problems plague the use of e-beam guns in drilling.

Three modes of operation have been discussed for lasers in drilling: as fusion devices, as spallation devices, and as kerfing devices to aid mechanical breakage, but in general lasers are limited by their relatively low power levels and poor efficiency. Significantly more energy is needed to melt rock than to spall it, so it may be possible to use a laser in thermal spallation rather than in fusion. When compared to some other spallation devices, lasers would have an advantage of being able to melt rock that will not spall. The most realistic approach to the use of lasers in large hole drilling may be as a kerfing mechanism to augment mechanical rock-cutting, but this poses significant problems in energy transmission, particularly rotation of the transmission line.

The only current program found in either laser or e-beam drilling is at Westinghouse-Hanford, where there is a proposed development project on a laser-driven system for environmental drilling (Miller, personal communication). This system is designed for near-surface applications in the vadose zone, with system reach limited to between 500 feet and 1000 feet by the available length of transmission lines. Recent bench tests have been promising. Neither system has progressed past the point of bench tests.

\section{Electric heater}

Los Alamos National Laboratory has done a significant amount of research on the use of electric heaters for drilling, developing a system called the "Subterrene" to the point of lab tests in the 1970s. Altseimer (Altseimer 1974, Altseimer 1976) gives a system description, compares costs of drilling with rock melting devices to the costs of wells drilled with conventional 
technology, and discusses the problem of bit extraction without damaging the bit. The Earth and Environmental Sciences Division at Los Alamos is currently investigating the use of rock melters for small-hole environmental drilling (Goff).

Rock-melting core bits are more efficient than full-hole bits because they require less rock to be melted, but there is a problem with core retrieval. The rock-melting systems have been predicated on the use of coiled-tubing drilling units, but conventional wireline core retrieval cannot be done through coiled tubing. On the other hand, rigid drill pipe would make core retrieval easy, but would greatly complicate the problem of power transmission to the heater. The contradiction of these design requirements has led to the assumption of an extrusion bit for electric-heater rock melting. 


\section{PULSED-LASER WATER JET:}

\begin{tabular}{|l|l|l|l|l|l|l|}
\hline \multicolumn{1}{|c|}{$\begin{array}{c}\text { SYSTEM } \\
\text { IVRE }\end{array}$} & \multicolumn{6}{|c|}{ DRILLING FUNCTIONS } \\
\hline ENERGY & $\begin{array}{l}\text { REDUCE } \\
\text { ROCK }\end{array}$ & $\begin{array}{l}\text { REMOVE } \\
\text { ROCK }\end{array}$ & $\begin{array}{l}\text { CONTROL } \\
\text { WELL }\end{array}$ & $\begin{array}{l}\text { MAINTAIN } \\
\text { HOLE } \\
\text { STABIITY }\end{array}$ & $\begin{array}{l}\text { PRESERVE } \\
\text { WELLBORE }\end{array}$ \\
\hline BASELINE & $\begin{array}{l}\text { Mechanical } \\
\text { energy to rock } \\
\text { through rotary } \\
\text { table and } \\
\text { drillstring, drill } \\
\text { pipe moved by } \\
\text { drawworks }\end{array}$ & $\begin{array}{l}\text { Crushing or } \\
\text { shearing by } \\
\text { roller-cone } \\
\text { or drag bits }\end{array}$ & $\begin{array}{l}\text { Drilling } \\
\text { mud, } \\
\text { circulated } \\
\text { by pumps, } \\
\text { or gas, } \\
\text { driven by } \\
\text { compressors }\end{array}$ & $\begin{array}{l}\text { Mechanical } \\
\text { closure by } \\
\text { blow-out } \\
\text { preventers, } \\
\text { pressure } \\
\text { control by } \\
\text { mud column }\end{array}$ & $\begin{array}{l}\text { Hydrostatic } \\
\text { pressure of } \\
\text { mud; } \\
\text { chemical } \\
\text { treatment by } \\
\text { mud } \\
\text { additives }\end{array}$ & $\begin{array}{l}\text { Steel casing } \\
\text { cemented in } \\
\text { place; handled } \\
\text { by mast and } \\
\text { drawworks }\end{array}$ \\
\hline $\begin{array}{l}\text { PULSED- } \\
\text { LASER } \\
\text { WATER JET }\end{array}$ & $\begin{array}{l}\text { Optical (fiber } \\
\text { optic) }\end{array}$ & $\begin{array}{l}\text { Mechanical } \\
\text { resonance }\end{array}$ & $\begin{array}{l}\text { Undeter- } \\
\text { mined }\end{array}$ & $\begin{array}{l}\text { Undeter- } \\
\text { mined }\end{array}$ & $\begin{array}{l}\text { Undeter- } \\
\text { mined }\end{array}$ & Baseline \\
\hline
\end{tabular}

The pulsed-laser water jet is the only fundamentally new concept in rock reduction introduced in the last twenty years. In contrast to the laser-thermal rock melter described previously, this system would use a laser to mechanically pulse the rock at its resonant frequency. Although Sellar proposes (Sellar, March 1993) five different and simultaneous excavation mechanisms, rock failure would primarily result from tensile stresses created by the resonant vibration. To date, rock breakage by single pulses has been demonstrated in the laboratory, with significant improvement expected from resonance.

The use of lasers to excite vibration was studied as part of an effort to use force magnification through resonance. Experiments showed that the natural frequency of a rock surface is in the range of $5-10 \mathrm{kHz}$, and large mechanical devices which can operate at that speed are not easily portable. Original development of this concept was sponsored by EPRI through the Center for Materials Production (Sellar EPRI) and current investigation is by PowerPulse Systems of Lakeland, CO.

Two lasers, with a relatively low total power of $5-10 \mathrm{~kW}$, are required: a pulsed laser to mechanically load the rock face, and a continuous-wave laser to read the rock's natural frequency and tune the destructive pulse laser to it. The laser beams travel to the rock face through a laminar-flow stream of clear water emitted from the drilling head. Once fragments are detached from the rock face, they must be cleared away from the laser/water stream to present a fresh surface for pulse loading. Bench-scale experiments have demonstrated rock breakage and have shown that rock damage is enhanced by the presence of water on the rock surface, but an actual drilling system is only a concept.

A pulsed-laser water jet would have the following attributes: 
Pro - It is a new concept with potential for significant advancement.

- The combination of tensile rock failure and resonant vibration means efficient energy transfer.

Con - System requires multi-channel conduit.

- System requires stand-off control and gauge maintenance.

- System requires laminar flow of clear water downhole.

One of the principal problems to be solved in designing a pulsed-laser drilling system is the method for cleaning the hole bottom. The requirement for laminar fluid flow between the laser and the rock surface is not consistent with flow rates required for conventional hole cleaning, where fluid is well into the turbulent regime. This means that it may be necessary to have dual conduits in the drill string, one for laminar-flow clear water which transmits the laser pulse and moves rock fragments off the hole bottom and one for the larger, turbulent mud flow which lifts the debris out of the hole. It may also be possible to use air instead of liquid for hole cleaning, but a large flow of either mud or air will probably disturb the laminar flow and reduce the laser's effect on the rock. Use of air will present the usual limitations of air-drilling. As a positive feature, a pulsed-laser system does not rotate, so it can run on coiled tubing, which greatly simplifies both the dual-conduit drill string and the fiber-optic cable for laser transmission downhole. 


\section{IMPACT OF ADVANCED SYSTEMS}

The preceding descriptions of the various advanced systems will have made it clear that their individual impacts on conventional practice will be widely different. At one extreme, mudhammers or downhole intensifiers could be inserted into a normal drill-string with almost no modification to the drill rig, but for microwave or pulsed-laser water jet systems, there is not even a conceptual design for a rig to employ those technologies. One measure of an advanced system's impact is the number of sub-systems on a conventional rig which would be changed by the advanced system's introduction. This measure is shown graphically in Table 4, where the " $x$ " symbols indicate the conventional sub-systems which would change with the use of a given advanced system and the "?" indicates that design of the advanced system is not well enough defined to determine the change. This impact is discussed in more detail with the individual system descriptions.
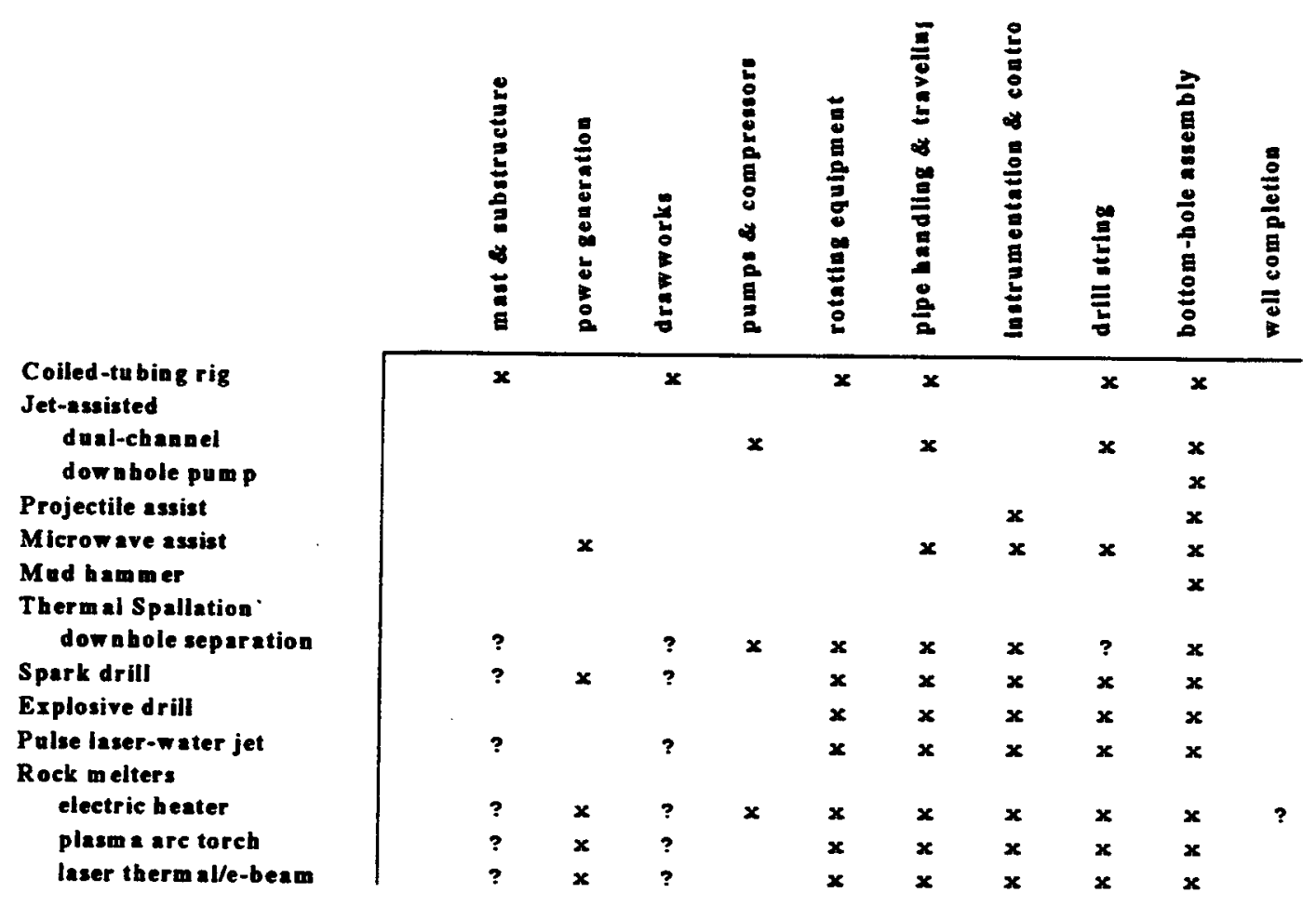

Table 4 - Impact of advanced drilling systems on a conventional drill rig 
Another feature of the system descriptions is their significant difference in scope. The principal reason for this is the great variation in technical maturity among the systems. Despite that, we have tried to use a standard description format to the extent possible. A graphical representation of this maturity variation is given in Table 5, where the horizontal axis labels have the following definitions:

- Proposed - The system has been identified and proposed as a candidate for drilling.

- Conceptual - Some conceptual design and analyses have been completed.

- Bench tests - The concept, in parts or as a whole, has been demonstrated in a laboratory.

- Drilling lab - The concept, in parts or as a whole, has been tested in a drilling simulator.

- Field tests - The system has been in a well and tested under some drilling conditions.

- Commercial - The system or parts of it are commercially available.

This subject is addressed in more detail in Section VI.

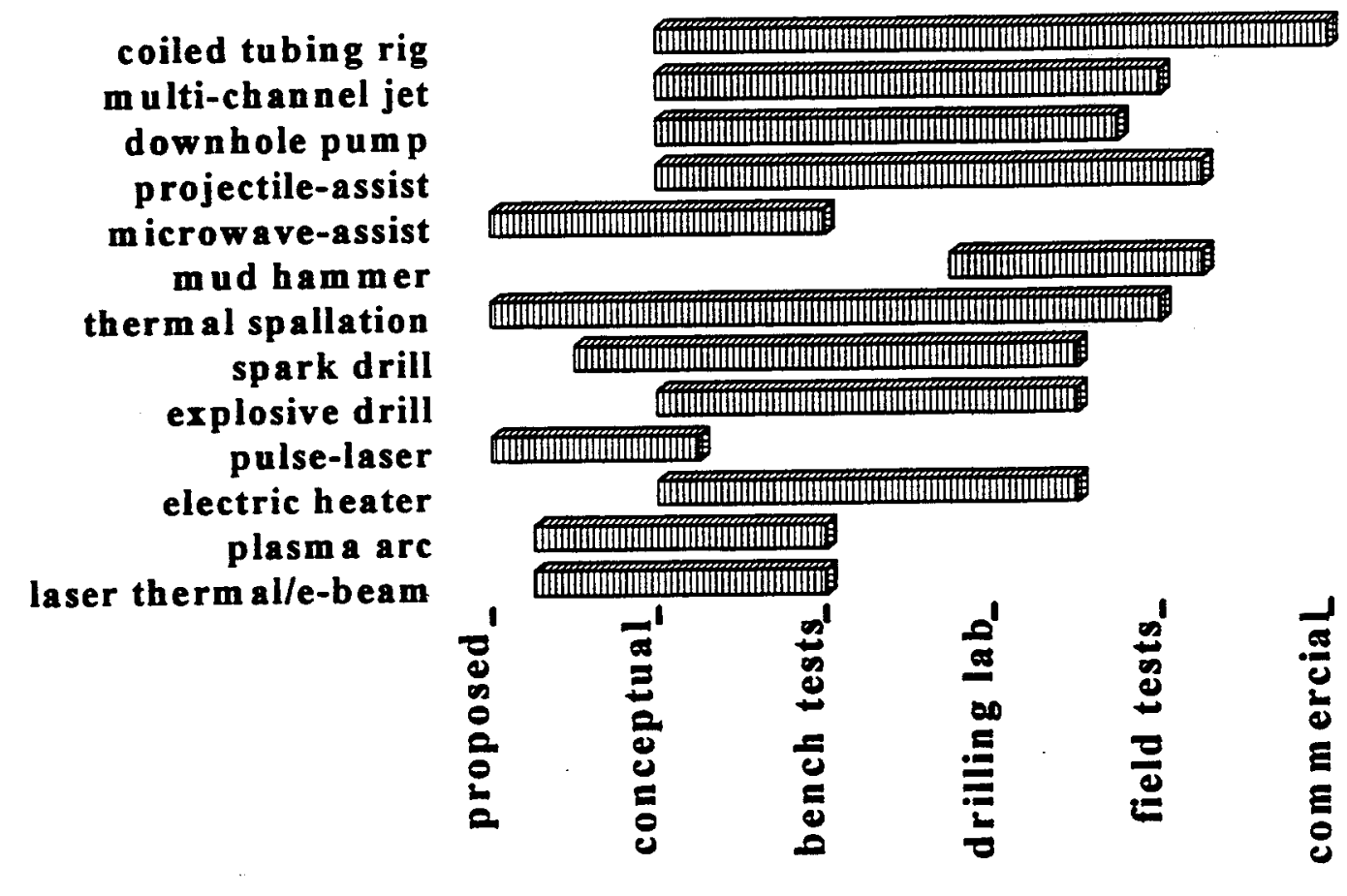

Table 5 - Technical maturity of advanced systems 


\section{SYSTEM LIMITATIONS, NEEDS, AND COMMON PROBLEMS}

This section of the report defines and discusses limitations of the drilling systems previously described, and identifies the technology developments needed to transform these concepts into commercially viable systems. In doing so, however, it is important to understand these limitations and needs in the context of today's drilling industry.

First, a bit of history. At the height of the last oil boom, in 1980, more than 4,500 rigs were running in the United States alone. A year later that number had dropped to less than 2,000 and for the last ten years the U. S. rig count has hovered around a thousand. Many drilling contractors and service companies went out of business, and the survivors are typically cautious and very price-competitive. It is generally believed that rig day-rates (see below) are now artificially low, since in many cases a rig can be contracted today for a lower price (in 1996 dollars) than it cost in 1980 dollars at that time.

When an operator (the person or company who owns the mineral rights to a given location) hires a drilling contractor (who owns the rig and provides the crew) to drill a well, there are three possible kinds of contract:

- Day work - The operator pays the contractor a given sum for each day the rig is working.

- Footage - The operator pays a given sum for each foot drilled (generally a higher cost per foot at greater depths.)

- Turnkey - The contractor agrees to drill to a specified depth for a fixed price.

Most conventional rotary drilling contracts are day-work, since the contractor wants the assurance that he will be paid even if there are drilling problems. In many cases the operator would like a footage or a turnkey contract, believing that it would save him money, but few contractors offer them. In this light, it might seem that the contractor has no incentive to adopt new technology which would shorten the job and reduce his payments, but in fact the contractor's principal problem is that fierce competition means his rigs are frequently idle. If new technology enables the contractor to drill more cheaply, he can offer a lower price or a footage/turnkey contract that will attract more business and still provide a provide a profit. New (unproved) technology also adds to the contractor's risk, however, because the contractor is not paid during any work delays caused by failure of his equipment, even on a day-work contract. It is also worth noting that new drilling technology is most often introduced into operation by service companies, which specialize in a particular tool or service, renting it to the operator to be used on a rig as needed. Drilling contractors support, but generally do not initiate, this kind of development.

In addition to the operational aspects of new technology, it would be quite expensive to put a 
complete new drilling system in place. The cost to build a new rig which can drill to $18,000^{\prime}$ is greater than $\$ 9,000,000$, so it is almost certain that any advanced system would first be tried on an existing rig. Even so, the costs of modifying the rig and training crews, coupled with the increased operational risk, could seem prohibitive.

None of these factors preclude the development and use of new tools and techniques: coiled tubing, downhole motors, horizontal drilling, and PDC bits all testify otherwise. At the same time we should remember that each of these technologies overcame early resistance by the industry, has undergone decades of development, and is still lacking in some respects.

\section{SYSTEM LIMITATIONS AND TECHNOLOGY NEEDS:}

In this section of the report, we identify operational limitations for the various advanced systems and suggest technology needs which are required to overcome those limitations. We must be careful, however, when defining "limitations" because all drilling systems are not intended for all drilling situations. Coiled tubing units, for example, are commercially available and are used in many workover operations where easy portability and speed of tripping offset the cost, but they are not widely used in drilling because the requisite downhole motors are expensive and because available tubing sizes limit torque and bit hydraulics for larger holes. We can't assume, however, that solving the "small hole size" limitation by providing the "larger tubing" technology needed will propel coiled tubing into the large-hole-drilling market, since the cost of downhole motors may keep CT too expensive to compete with conventional drilling. On the other hand, less expensive motors would expand the existing $\mathrm{CT}$ drilling market for hole sizes less than about eight inches.

Similarly, several of the advanced systems cannot function under a liquid column, but they could at least compete with current air-drilling methods if their performance were adequate. For some systems, there is even a possibility of further development to enable operation in liquid, but the remainder have fundamental physical constraints which appear to prevent this. Both types of system are limited by their inability to drill with mud, but their technology needs are different. In general, limitations and needs are defined in this section in terms of what is required to transform a specific technology into a technically viable drilling system, even though all these systems may not have the same applications. A summary table is given below, followed by a brief discussion of each system. Items in the "Technology Needs" column of the summary table correspond with the "Limitation" on the same line; the designation "Undefined" means that it is not clear whether that particular limitation can be overcome by technology development. It should also be remembered that just because a technology need is identified, that does not necessarily imply an existing concept for how that need could be met. 


\begin{tabular}{|c|c|c|}
\hline SYSTEM & LIMITATIONS & TECHNOLOGY NEEDS \\
\hline $\begin{array}{l}\text { COILED } \\
\text { TUBING }\end{array}$ & $\begin{array}{l}\text { - CT units are expensive } \\
\text { - Increased differential sticking } \\
\text { - Hole size, hydraulics limited by tubing size } \\
\text { - Weight-on-bit and torque limited } \\
\text { - Tubing fatigue }\end{array}$ & $\begin{array}{l}\text { - Less expensive downhole motors } \\
\text { - Undefined } \\
\text { - Larger tubing and reels } \\
\text { - Downhole thruster-retractor } \\
\text { - Improved materials, larger reels } \\
\end{array}$ \\
\hline $\begin{array}{l}\text { JET ASSISTED } \\
\text { (full surface } \\
\text { press.) }\end{array}$ & $\begin{array}{l}\text { - Requires the full fluid-supply system to } \\
\text { withstand high pressure } \\
\text { - Difficult to seal drill-pipe connections } \\
\text { - Working fluid pH is critical to pipe life } \\
\text { - High operating cost } \\
\text { - Pressure-safety concerns }\end{array}$ & $\begin{array}{l}\text { - High-pressure pumps, hoses, swivel, drill- } \\
\text { pipe } \\
\text { - Improved joint-seal design } \\
\text { - Drilling fluid development, pipe materials } \\
\text { - Undefined } \\
\text { - Undefined } \\
\end{array}$ \\
\hline $\begin{array}{l}\text { JET ASSISTED } \\
\text { (multiple } \\
\text { conduit) }\end{array}$ & $\begin{array}{l}\text { - High pressure losses } \\
\text { - Time-consuming joint makeup } \\
\text { - Dual pumps and flow channels required } \\
\text { - Pressure-safety concerns }\end{array}$ & $\begin{array}{l}\text { - Larger conduit } \\
\text { - Improved joint design } \\
\text { - Multi-conduit swivel, drill-pipe, and bit } \\
\text { - Undefined }\end{array}$ \\
\hline $\begin{array}{c}\text { JET ASSISTED } \\
\text { (downhole } \\
\text { intensifier) }\end{array}$ & $\begin{array}{l}\text { - Not developed to the point of field service } \\
\text { - Limited high-pressure flow rate } \\
\text { - Dual channels from intensifier to bit }\end{array}$ & $\begin{array}{l}\text { - Complete and test intensifier design } \\
\text { - Re-design intensifier for higher flow rate (?) } \\
\text { - Multi-conduit drill-pipe and bit }\end{array}$ \\
\hline $\begin{array}{l}\text { PROJECTILE } \\
\text { ASSISTED }\end{array}$ & $\begin{array}{l}\text { - Complex firing mechanism and magazine } \\
\text { may limit life } \\
\text { - System does not function in liquid }\end{array}$ & $\begin{array}{l}\text { - Field-test prototype for extended time; } \\
\text { refine design } \\
\text { - Develop proposed valve system }\end{array}$ \\
\hline $\begin{array}{c}\text { MUD } \\
\text { HAMMER }\end{array}$ & $\begin{array}{l}\text { - Designs with total-mud-flow valving hinder } \\
\text { well control } \\
\text { - Interferes with acoustic or mud-pulse MWD } \\
\text { - Damage at hammer-anvil interface } \\
\text { - Valve erosion from mud abrasives } \\
\text { - Fatigue failure of vaive and/or spring }\end{array}$ & $\begin{array}{l}\text { - Use partial flow to drive reciprocating } \\
\text { mechanism } \\
\text { - Develop non-acoustic MWD } \\
\text { - Re-design hammer/anvil interface } \\
\text { - Re-design valve (or materials development) } \\
\text { - Re-design valve system } \\
\end{array}$ \\
\hline $\begin{array}{l}\text { THERMAL } \\
\text { SPALLATION }\end{array}$ & $\begin{array}{l}\text { - Difficult to maintain hole gauge } \\
\text { - Must (probably) operate in air } \\
\text { - Needs umbilical for fuel, air, cooling water } \\
\text { - Performance varies with rock type } \\
\text { - Safety concerns } \\
\end{array}$ & $\begin{array}{l}\text { - Downhole thruster/control head } \\
\text { - Pursue development of underwater system } \\
\text { - Multi-chamel pipe or downhole separator } \\
\text { - Spallation augments mechanical drilling } \\
\text { - Undefined } \\
\end{array}$ \\
\hline SPARKDRILL & $\begin{array}{l}\text { - Not demonstrated as a drilling system } \\
\text { - Requires electrical conduit downhole } \\
\text { - Insulation breakdown from high currents } \\
\text { - Gas generation downhole }\end{array}$ & $\begin{array}{l}\text { - Build and demonstrate prototype } \\
\text { - Electrical conduit in drill-pipe } \\
\text { - Undefined } \\
\text { - Undefined }\end{array}$ \\
\hline $\begin{array}{l}\text { EXPLOSIVE } \\
\text { DRILL }\end{array}$ & $\begin{array}{l}\text { - Efficiency at depth is not known } \\
\text { - Mud flow for cleaning disperses explosive } \\
\text { - Explosive must be reliably initiated } \\
\text { - Explosive must be counted and tracked } \\
\text { - Safety concerns with mis-fire }\end{array}$ & $\begin{array}{l}\text { - Test prototype or build test facility } \\
\text { - Undefined } \\
\text { - Develop initiation system } \\
\text { - Develop counting and tracking system } \\
\text { - Re-configure explosive delivery system }\end{array}$ \\
\hline MICROWAVE & $\begin{array}{l}\text { - Not known if system will operate in liquid } \\
\text { - Must transmit microwave energy downhole }\end{array}$ & $\begin{array}{l}\text { - Analysis and testing to resolve this issue } \\
\text { - Coaxial cable, wave guide, or downhole } \\
\text { magnetron }\end{array}$ \\
\hline $\begin{array}{c}\text { ROCK } \\
\text { MELTERS } \\
\text { (general) }\end{array}$ & $\begin{array}{l}\text { - Only operate in air } \\
\text { - Need electrical conduit downhole } \\
\text { - Difficult to lift melted rock from hole } \\
\text { - Variation in rock behavior when meited }\end{array}$ & $\begin{array}{l}\text { - Undefined } \\
\text { - Electrical conduit in drill-pipe } \\
\text { - Undefined } \\
\text { - Undefined } \\
\end{array}$ \\
\hline $\begin{array}{c}\text { ROCK } \\
\text { MELTERS } \\
\text { (laser, e-beam, } \\
\text { plasma torch) }\end{array}$ & $\begin{array}{l}\text { - Require stand-off control } \\
\text { - Plasma torch requires separate gas for plasma } \\
\text { - E-beam produces X-rays } \\
\text { - Laser has low power and efficiency }\end{array}$ & $\begin{array}{l}\text { - Thruster-retractor control head } \\
\text { - Multi-conduit drill-pipe } \\
\text { - Undefined } \\
\text { - Use to kerf and augment mechanical }\end{array}$ \\
\hline $\begin{array}{l}\text { PULSED- } \\
\text { LASER WATER } \\
\text { JET }\end{array}$ & $\begin{array}{l}\text { - Only limited laboratory data on concept } \\
\text { - Requires laminar-flow clear water downhole } \\
\text { - Requires additional fluid for hole cleaning } \\
\text { - Requires stand-off control }\end{array}$ & $\begin{array}{l}\text { - Develop into prototype drilling systern } \\
\text { - Undefined } \\
\text { - Multi-conduit drill-pipe } \\
\text { - Thruster-retractor control head }\end{array}$ \\
\hline
\end{tabular}




\begin{tabular}{|l|l|l|}
\hline COIKED & $\bullet$ CT units are expensive & $\begin{array}{l}\text { - Less expensive downhole motors and } \\
\text { surface equipment }\end{array}$ \\
& $\begin{array}{l}\text { - Increased differential sticking } \\
\text { - Hole size, hydraulics limited by tubing size } \\
\text { - Weight-on-bit and torque limited } \\
\text { - Tubing fatigue }\end{array}$ & $\begin{array}{l}\text { - Larger tubing and reels } \\
\text { - Downhole thruster-retractor } \\
\text { - Improved materials, larger reels }\end{array}$ \\
\hline
\end{tabular}

As mentioned above, a discussion of coiled tubing's limitations must be considered in the context that $\mathrm{CT}$ is already a substantial industry. Its applications are somewhat specialized because now it is usually an add-on cost to a conventional drill rig and the day-rates for CT units are comparable to those for medium-size drill rigs. For $\mathrm{CT}$ to become competitive in drilling an "average" well, we should assume that a CT rig (which would be smaller, lighter, and cheaper than a conventional rig) is specifically built for drilling rather than for workover operations. Given this situation, the CT penetration rate must be better than conventional rotary by the ratios shown on page V-8, and it would still be limited to small hole sizes. A high priority in development of a CT rig would be larger-diameter tubing, possibly with integral conductors for downhole electric motors. CTs advantages are very attractive, however, with the abilities to trip quickly, circulate while tripping, and use insulated or electrically-wired tubing with relative ease. Before selecting a research and development project aimed at improving coiled tubing, it is very important to define the projected market for the improved system.

\begin{tabular}{|c|c|c|}
\hline $\begin{array}{l}\text { JET ASSISTED } \\
\text { (full surface } \\
\text { pressurization) }\end{array}$ & $\begin{array}{l}\text { - Requires the full fluid-supply system to } \\
\text { withstand high pressure } \\
\text { - Difficult to seal drill-pipe connections } \\
\text { - Working fluid pH is critical to pipe life } \\
\text { - High operating cost } \\
\text { - Pressure-safety concerns }\end{array}$ & $\begin{array}{l}\text { - High-pressure pumps, hoses, swivel, drill- } \\
\text { pipe } \\
\text { - Improved joint-seal design } \\
\text { - Drilling fluid development, pipe materials } \\
\text { - Undefined } \\
\text { - Undefined }\end{array}$ \\
\hline
\end{tabular}

Full surface pressurization of the drilling fluid is fundamentally simple in concept, but has a number of development problems. Considerable industry effort was devoted to this system, but further work was curtailed by the numerous technology needs summarized above and by the apparent diminution of performance enhancement described on page III-16. There is no current industry activity in full-pressure drilling for conventional holes. In considering the technology needs, it should also be remembered that in many of the advanced systems, satisfying one of the needs does not make an incremental improvement in the system's acceptability; because all of the needs must be met for the system to be considered viable. For the full-pressure jet assist, all of the high-pressure components must be developed, while the high operating costs and pressuresafety concerns might be acceptable in some situations. In general, this system has fielddemonstrated performance improvement at certain depths, and the principles of its operation are 
fairly well understood. Because power requirements are roughly proportional to the product of fluid pressure and flow rate, high operating costs are inherent in this system (e. g., pumping 300 gpm at 20,000 psi will cost $\$ 230 / \mathrm{hr}$ in fuel alone.) If the performance improvement at substantial depth can be quantified, then engineering development of this system could be easily defined.

\begin{tabular}{|c|c|c|}
\hline $\begin{array}{l}\text { JET ASSISTED } \\
\text { (multiple } \\
\text { conduit) }\end{array}$ & $\begin{array}{l}\text { - High pressure losses } \\
\text { - Time-consuming joint makeup } \\
\text { - Dual pumps and flow channels required } \\
\text { - Pressure-safety concerms }\end{array}$ & $\begin{array}{l}\text { - Larger conduit } \\
\text { - Improved joint design } \\
\text { - Multi-conduit swivel, drill-pipe, and bit } \\
\text { - Undefined }\end{array}$ \\
\hline
\end{tabular}

Relative to the full-pressure system described above, this method of jet-assist trades off reductions in operating cost and pressure-safety concerns for diminished high-pressure flow rate and increased mechanical complexity. FlowDril had an extensive development program for this technology, and TeleJet is pursuing it now. As in the full-pressure system, technology needs are fairly well defined, but there are conflicting data on the performance of high-pressure jets at depth, and the actual performance enhancement mechanism is undefined. For this system, the multi-conduit drill string components are necessary for operation, while the larger conduit and slow joint make-up are situation-specific and might be acceptable under some circumstances.

\begin{tabular}{|c|l|l|}
\hline $\begin{array}{c}\text { JET ASSISTED } \\
\text { (downhole } \\
\text { intensifier) }\end{array}$ & $\begin{array}{l}\text { - Not developed to the point of field service } \\
\text { - Limited high-pressure flow rate }\end{array}$ & $\begin{array}{l}\text { - Complete and test intensifier design } \\
\text { - Re-design intensifier for higher flow rate (?) } \\
\text { - Mul channels from intensifier to bit }\end{array}$
\end{tabular}

Downhole intensifiers have been built by FlowDril and designed by Maurer Engineering. This technology eliminates the pressure-safety concerns of the other jet-assist methods, but has limited high-pressure flow rate and requires high wear-resistance in the intensifier itself. Again, the mechanical design problems for these systems are reasonably well-defined, but the uncertain benefit of limited-flow jets at depth has probably slowed pursuit of this concept.

\begin{tabular}{|c|l|l|}
\hline $\begin{array}{c}\text { PROJECTILE } \\
\text { ASSISTRD }\end{array}$ & $\begin{array}{l}\text { Complex firing mechanism and magazine } \\
\text { may limit life } \\
\text { - System does not function in liguid }\end{array}$ & $\begin{array}{l}\text { - Field-test prototype for extended time; } \\
\text { refine design } \\
\text { Develop proposed valve system }\end{array}$ \\
\hline
\end{tabular}

This system has demonstrated significant performance improvements in a variety of rock types, but it is hindered by its complex mechanism and inability to function in mud. Neither of these problems is fundamentally intractable; other complex mechanisms have been made to work downhole, and there is at least a conceptual design for valving which would allow firing in a liquid column. A private company, Tround International, is pursuing development of this concept, although their level of effort is unclear. 


\begin{tabular}{|c|c|c|}
\hline $\begin{array}{c}\text { MUD } \\
\text { RAMMER }\end{array}$ & $\begin{array}{l}\text { - Designs with total-mud-flow valving hinder } \\
\text { well control } \\
\text { - Interferes with acoustic or mud-pulse MWD } \\
\text { - Damage at hammer-anvil interface } \\
\text { - Valve erosion from mud abrasives } \\
\text { - Fatigue failure of valve and/or spring }\end{array}$ & $\begin{array}{l}\text { - Use partial flow to drive reciprocating } \\
\text { mechanism } \\
\text { - Develop non-acoustic MWD } \\
\text { - Re-design hammer/anvil interface } \\
\text { - Re-design valve (or materials deveiopment) } \\
\text { - Re-design valve system }\end{array}$ \\
\hline
\end{tabular}

The mud-hammer concept has a relatively long history in drilling, with experimental models having been tested by several entities. Most of these prototypes foundered on problems in the valving system, which is the principal difference between mud- and air-hammers. Air-hammers, which have been used successfully for years, have no valves per se, since the compressibility of the fluid allows them to function by having the hammer open and close ports in the tool body as it reciprocates. A Utah company, Novatek, has designed and built a mud-hammer which mitigates many of the earlier problems by using only a portion of the total mud flow to operate the valves. Their prototype is currently being field-tested for performance and durability; these results should be evaluated for possible further development.

\begin{tabular}{|c|l|l|}
\hline THERMAL & - Difficult to keep hole in-gauge and straight & - Downhole thruster/control head \\
SPALLATION & - Must (probably) operate in air & - Pursue development of under-liquid system \\
& - Needs umbilical for fuel, air, cooling water & - Multi-channel pipe or downhole separator \\
& - Performance varies with rock type & - Spallation augments mechanical drilling \\
& - Safety concerns & Undefined; limited application for oilgas \\
\hline
\end{tabular}

Thermal spallation drilling was commercially available from Linde Air Division of Union Carbide and from Browning Engineering, principally used for blast-holes in mining. Several factors, including competition from improved drill bits and the increasing cost of fuel, led these companies to discontinue their spallation product lines in the mid-1970s, and there is no current activity in this field. Although previous systems operated under the constraints listed above, they could drill extremely fast (over $100 \mathrm{ft} / \mathrm{hr}$ in granite demonstrated in the field) in spallable rock. Principal opportunities for further development of spallation drilling are probably the following:

- Spallation system which could be used to augment conventional drilling. This would be greatly aided by multi-conduit drill pipe or by development of a downhole separator which allows fuel, air, and cooling water to be pumped downhole as a mixture in a single conduit.

- Development of a small, coiled-tubing type rig which could mobilize quickly and could reel single- or multi-conduit tubing into the hole.

A British company, Worldrill Corporation, has applied for a European patent on a downhole separator, but we know of no other current effort in development of spallation drilling. 


\begin{tabular}{|l|l|l|}
\hline SPARK DRILL & $\begin{array}{l}\text { - Not demonstrated as a drilling system } \\
\text { - Requires electrical conduit downhole } \\
\text { - Insulation breakdown from high currents } \\
\text { - Gas generation downhole }\end{array}$ & $\begin{array}{l}\text { - Build and demonstrate prototype } \\
\text { Electrical conduit in dritl-pipe } \\
\text { - Undefined } \\
\text { - Undefined }\end{array}$ \\
\hline
\end{tabular}

Spark drilling was investigated by Sandia National Laboratories in the late 1970 s and is currently under development by Tetra Corporation, which holds the major patent in this area. The system's major attraction is the possibility of drilling at high penetration rates, but the principal technical difficulties have centered around the transmission of high electrical currents to the drilling head. Certain proof-of-concept tests have been successful in breaking rock, but performance variation with depth and rock type is unknown and electric transmission problems are formidable. Much work will be required to translate this technology into a drilling system.

\begin{tabular}{|l|l|l|}
\hline $\begin{array}{l}\text { EXPLOSIVE } \\
\text { DRILI }\end{array}$ & $\begin{array}{l}\text { - Efficiency at depth is not known } \\
\text { - Mud flow for cleaning disperses explosive }\end{array}$ & $\begin{array}{l}\text { - Test prototype or build test facility } \\
\text { - Undefined } \\
\text { - Explosive must be reliably initiated }\end{array}$ \\
& - Explosive must be counted and tracked & - Develop initiation system \\
& - Safety concerns with mis-fire & - Re-configure explosive delivery system \\
\hline
\end{tabular}

Explosive delivery devices of several configurations have been demonstrated in the laboratory, and have shown the potential for high penetration rates. Once the explosives have been delivered to the rock face, however, there are significant difficulties with ignition timing, hole cleaning, and charge disposal in case of a mis-fire. Performance variation with depth for this system is also unknown. There is no known current activity in explosive drilling.

\begin{tabular}{|l|l|l|}
\hline MICROWAVE & $\begin{array}{l}\bullet \text { Not known if system will operate in liquid } \\
\text { - Must transmit microwave energy downhole }\end{array}$ & $\begin{array}{l}\bullet \text { Analysis and testing to resolve this issue } \\
\text { Coaxial cable, wave guide, or downhole } \\
\text { magnetron }\end{array}$ \\
\hline
\end{tabular}

Fundamental experiments in drilling heated rock gave significant performance improvement compared to ambient temperature. Microwave heating has the powerful advantage that it is a bulk effect and does not depend of conduction of heat from the rock face, but a possible mechanism for delivering microwave energy downhole is not at all clear. The system may also suffer the handicap of being unable to operate in a liquid column, but this is not completely known. There is no known current effort in microwave rock heating.

\begin{tabular}{|c|c|c|}
\hline $\begin{array}{l}\text { ROCK } \\
\text { MELTERS } \\
\text { (general) }\end{array}$ & $\begin{array}{l}\text { - Only operate in air } \\
\text { - Need electrical conduit downhole } \\
\text { - Difficult to lift melted rock from hole } \\
\text { - Variation in rock behavior when melted }\end{array}$ & $\begin{array}{l}\text { - Undefined } \\
\text { - Electrical conduit in drill-pipe } \\
\text { - Undefined } \\
\text { - Undefined }\end{array}$ \\
\hline
\end{tabular}

The concept of direct rock reduction by melting is attractive because the combination of a 
non-rotating drill string and a possible glass-lined borehole (reducing or eliminating casing requirements) might enable a small, coiled-tubing-like rig which would be relatively cheap in capital cost. Los Alamos National Laboratory has done considerable work in rock melting by direct contact with an electric heater, and has field-demonstrated small-hole drilling with this technique. Electric-resistance melters operate with the constraints listed above, but the scale effect -- power requirements are proportional to the square of hole diameter -- suggests that optimum application for this technique is in small scientific, environmental, or thermal gradient holes.

\begin{tabular}{|c|c|c|}
\hline $\begin{array}{c}\text { ROCK } \\
\text { MELTERS } \\
\text { (aser, e-beam, } \\
\text { plasma torch) }\end{array}$ & $\begin{array}{l}\text { - Require stand-off control } \\
\text { - Plasma torch requires separate gas for plasma } \\
\text { - E-beam produces X-rays } \\
\text { - Laser has low power and efficiency }\end{array}$ & $\begin{array}{l}\text { - Thruster-retractor control head } \\
\text { - Multi-conduit drill-pipe } \\
\text { - Undefined } \\
\text { - Use to kerf and augment mechanical }\end{array}$ \\
\hline
\end{tabular}

A plasma torch offers the possibility of bulk rock reduction by a combination of melting and spallation under the very high temperatures of the plasma. These temperatures also present a problem for the survivability of the drilling tools themselves, and delivery of plasma gas, cooling water, additional air for hole cleaning, and at least two electrical conductors downhole requires multi-conduit drill string. Performance of the torch is also dependent on stand-off distance from the rock face, so measurement and control of this parameter is required.

Lasers and electron beams have much more focused energy deposition, and so would require rotation if they were the only method of rock reduction. There are other handicaps, such as production of X-rays by e-beams and low efficiency of lasers, but these do not fundamentally prevent their consideration. It is possible that best use for either a laser or an e-beam is to cut a kerf as augmentation of conventional drilling; this would provide rotation and stand-off control but would still require electrical or fiber-optic connections downhole.

\begin{tabular}{|c|c|c|}
\hline $\begin{array}{l}\text { PULSED- } \\
\text { LASER WATER } \\
\text { JET }\end{array}$ & $\begin{array}{l}\text { - Only limited laboratory data on concept } \\
\text { - Requires laminar-flow clear water downhole } \\
\text { - Requires additional fluid for hole cleaning } \\
\text { - Requires stand-off control }\end{array}$ & $\begin{array}{l}\text { - Develop into prototype drilling system } \\
\text { - Undefined } \\
\text { - Multi-conduit drill-pipe } \\
\text { - Thruster-retractor control head }\end{array}$ \\
\hline
\end{tabular}

The pulsed-laser water jet is the only fundamentally new rock reduction technique developed in the last twenty years, but as a consequence it has more hurdles to becoming a viable drilling system than the other methods. PowerPulse Systems is currently engaged in development, at a relatively low level, of this technology. 


\section{COMMON PROBLEMS:}

Another way of looking at technology needs is to consider those which apply to more than one of the advanced systems. This study has identified a number of problems that aftlict multiple systems, and a graphical representation of this is shown below. The concept of common problems is significant in that a solution for any one of these would advance the viability of all the systems
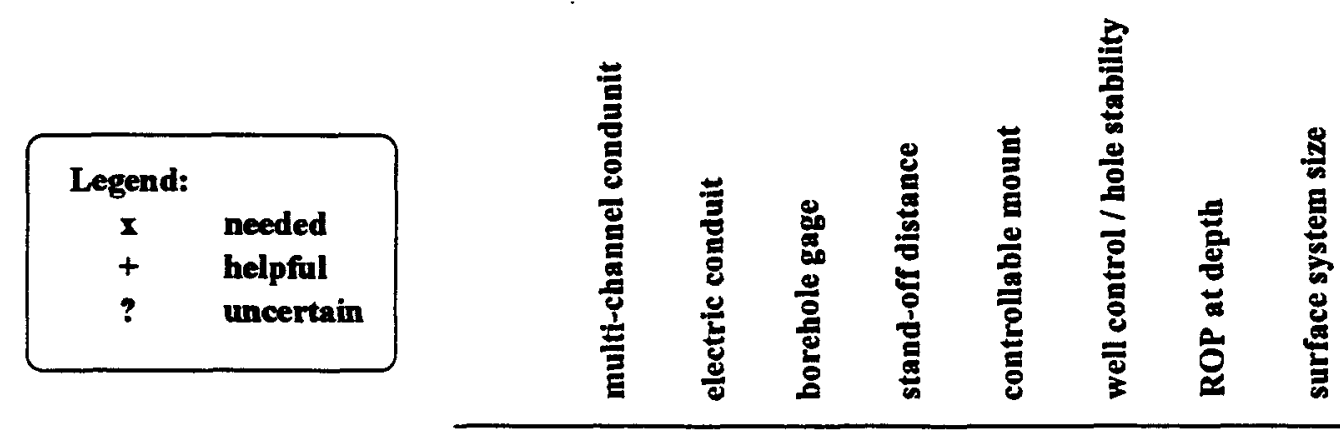

Conventional drilling
Coiled-tubing rig
Jet-assisted
Projectile assist
Microwave assist
Mud hammer
Thermal Spallation'
High-pressure jet
Spark drill
Explosive drill
Pulse laser-water jet
Electric heater
Plasma are torch
Laser thermaVe-beam

\begin{tabular}{|llllllll}
\hline+ & & & + & + & $x$ & $x$ \\
$x$ & & & & + & + & $x$ & $x$ \\
$x$ & $x$ & & & & $x$ & $x$ \\
& & & & & & \\
$x$ & $x$ & $x$ & $x$ & + & $x$ & & $x$ \\
$x$ & & $x$ & $x$ & + & & $x$ & $x$ \\
$x$ & $x$ & $x$ & $x$ & & & $x$ & $x$ \\
$x$ & & $x$ & $x$ & + & & & $x$ \\
$x$ & $x$ & $x$ & $x$ & + & $x$ & $?$ & $x$ \\
$x$ & $x$ & & & + & $x$ & & $x$ \\
$x$ & $x$ & $x$ & $x$ & + & $x$ & & $x$ \\
$x$ & $x$ & $x$ & $x$ & + & $x$ & & $x$
\end{tabular}

cross-cut by that specific problem. As discussed above, however, we must remember that most of the advanced systems will require solution of multiple problems to gain acceptability. The common problems are discussed in the following sections:

- Multi-channel conduit (gas/liquid/electrical)

- Electric conductor downhole

- Maintenance of the borehole diameter and trajectory

- Maintenance of stand-off distance

There are other problems which affect multiple systems, but which may not have a technology 
solution cross-cutting several systems. These are:

- Reduced effectiveness (rate-of-penetration) with depth

- Well control and wellbore stability in the absence of liquids

- The size of the surface system.

Multi-channel conduit: Many of the systems under consideration require multiple conduits to transmit different fluids and/or electrical energy. These include the following applications:

- Jet-assisted drilling: Surface pressure generation of less than the full mud flow requires dual channel pipe and a complete parallel flow path from the pumps to the bit.

- Spark drill: Requires one conduit for drilling fluids and another for electrical power.

- Microwave-assisted drilling: Heating rock with microwaves requires a conduit - either coaxial line or wave guide - to transmit the microwave energy and a flow channel for either air or water to remove cuttings. Even if the microwave generator can be downhole, a second conductor for electrical power would still be needed.

- Thermal spallation: Previous thermal spallation systems need four conduits: air to remove cuttings, fuel, oxygen for the burner, and if tripping in with a lit burner is to be avoided, a fourth conduit for starter power. Development of a downhole separator could eliminate at least one of these conduits.

- Explosive drill: The Russian liquid explosive drill described by Maurer (Maurer, 1968) required three conduits - fuel, oxidizer, and an initiating compound. Fluid used to clear the hole would likely require another conduit.

- Pulse-laser water jet: As currently proposed, the pulse-laser water jet requires two fiber optic cables for laser transmission and a channel for clean water. It is almost certain that a second channel would be needed for fluid to lift the cuttings.

- Rock melters: Laser thermal and e-beam drills need an electrical conduit plus another channel for the fluid used to remove cuttings. The electric heater needs an electrical conduit for power and a second conduit for nitrogen to lift the cuttings. A plasma arc torch would require multiple conduits: power, cooling fluid, plasma gas and, unless the cooling flow was adequate, fluid to lift cuttings.

Multi-conduit pipe has been manufactured. FlowDril used dual wall pipe for their system and TeleJet Technologies has designed multi-conduit pipe for the MultiCon ${ }^{T M}$ system. Concentric, low-pressure drill pipe has been commercially available in the United States for 25 years. When compared to standard drill pipe, multiple conduit pipe is generally heavy, expensive, and difficult to handle.

Electric Conductor Downhole: This is a subset of multiple-conduit drill pipe discussed above. Many systems would benefit from cheap and reliable methods of making an electrical connection between the surface and the bottom of the hole. These include the following: 
- Microwave-assisted drilling: The system needs either microwave transmission downhole or electrical transmission downhole for microwave generation.

- Thermal spallation: An electrical connection would allow downhole ignition of the torch.

- Spark drill: The spark drill needs to transmit power from the surface to the drill head.

- Pulse-laser water jet: This system needs fiber-optic connections to the pulsing laser and to the monitoring laser.

- Rock melters: A laser-thermal system needs fiber-optic cable for laser transmission. An e-beam drill must either transmit beams downhole or provide electrical connection for downhole generation. Both the electric heater and the plasma-arc torch require an electrical connection.

A downhole electrical connection would benefit even rotary technology with the use of electric drilling motors and other tools, and, especially important, it would provide high data-rate transmission for measurement-while-drilling systems. The development of fast, reliable telemetry would not only allow the use of current downhole sensors such as pressure, temperature, and formation evaluation tools; but would add the development and use of systems to evaluate the condition of the bit, to detect kicks almost instantaneously, and to provide data for real-time analyses of downhole conditions.

A number of systems for deploying an electric line while drilling have been developed. The Russians developed and used in the field a system, with a phone-jack-like connector at each tool joint, to drive electric motors downhole. The Electrodril system developed by General Electric used a four-wire cable to drive a downhole electric motor and transmit data while drilling (Traynor). The cable was retracted into the kelly with the addition of each joint of drill pipe. Both Shell and Exxon worked to develop a method of making electrical connections while drilling (McDonald). Shell's system had electrical conduit and cable built into the drill pipe with connectors in the tool joints, while the Exxon system deployed excess cable in the drill string and pulled out sufficient cable with each addition of drill pipe until the excess was depleted. None of these systems was commercially successful in the drilling industry.

While no practical method has been developed to make electrical connections every thirty feet when using drill pipe, electric cables can be run in coiled or flexible tubing. The Flexodrill flexible drill string, manufactured by Coflexip for Institut Francais du Petrole, was a four-inch (ID), steelreinforced hose containing four electrical conductors (Thiery). Coiled tubing sizes to 4-1/2" OD are currently available, but fatigue strength currently restricts coiled tubing for drill pipe to about 2-3/8" OD. This size limits fluid flow and, hence, maximum hole size; space for an electrical wire would limit flow even further.

Maintenance of Borehole Size and Trajectory: Because the borehole must be relatively 
straight and at a minimum diameter to run casing, maintenance of borehole gauge and trajectory is a concern for nearly all of the system concepts that are not rotary hybrids. Conversely, if hole diameter goes too far above the minimum, this variation will cause problems when cementing the casing, and it is essential to be able to deliberately deviate the hole for directional drilling. For the systems which do not reduce rock through load-bearing contact with the rock face, a mechanism to grip the wellbore wall and aim the drilling head will probably be required. This problem will be aggravated by drilling methods which do not leave a relatively smooth, round hole, so it is important to identify the system requirements for the technology in question.

- High-pressure jet drilling: When drilling with high-pressure jets, hole diameter will probably be controlled by the speed of advance. In different formations the advance rate will have to be adjusted to maintain the desired diameter. For vertical holes, the nozzle can simply hang in the well, but the use of a mount to aim the nozzle would give better control and would be required if jets are to be used for high angle or horizontal drilling.

- Spark drill: With the spark drill, hole diameter will be controlled by the speed of advance so this will have to be adjusted in different formations. Direction can be controlled by aiming the drilling head from a mount (this would have benefited the Sandia system). The system proposed by Tetra would control direction by varying the firing order of a spark array on the face of the bit.

- Thermal spallation: Hole diameter is controlled by the speed of advance (Rauenzahn and Tester) so advance rate must be varied in different formations. One of the listed benefits for thermal spallation is the ability to underream an underground chamber by holding the torch at a given depth (Williams 1985, Williams et. al. 1988). For vertical holes, the torch has usually been hung in the well without special mounts, but a mount would allow better control of drilling direction and may be required if thermal spallation is to be used for high angle or horizontal drilling.

- Explosive drill: The hole diameter with an explosive capsule system is at least partly dependent on charge size and frequency (Maurer 1968). Maurer also notes that rocks will tend to fracture along joints and faults causing explosive drills to create irregular shaped holes. Since these devices generally expel explosive from the end of the drill pipe, advance direction can be controlled by aiming the drill pipe.

- Pulsed-laser water jet: Since no drilling tests have been performed, no definition of hole geometry is available, but the theory of operation suggests that the rock surface would be excited at resonance and would break in tension. This type of breakage probably occurs along joints and faults leading to irregular shaped holes. It is likely that the direction of advance for the pulsed-laser water jet will be controlled by the aim of the pulsing laser.

- Non-contact rock melters: As in other systems, hole diameter with non-contact rock melters (plasma arc, laser thermal, e-beam) will vary with advance rate and will require adjustment in different formations. The direction of advance of the non-contact rock melters - plasma arc, laser thermal, e-beam - would be controlled by aiming the drilling head. 
Control of Stand-Off Distance: The efficiency of most systems that do not maintain direct contact with the rock is dependent on stand-off, but control of this distance will vary from system to system. A simple solution is a mechanical probe, but other systems may require more elaborate methods. It is not clear, therefore, that a universal stand-off control mechanism, cross-cutting several drilling systems, can be developed. Systems which require stand-off control include the following:

- High-pressure jet drilling: Past systems have maintained this distance by periodically stopping to touch bottom for calibration. An alternate method is use of a probe.

- Spark drill: It may be possible to maintain stand-off distance with a probe.

- Thermal spallation: Efficient thermal spallation depends on the rate of heat transfer to the rock, which is in turn dependent on stand-off distance. A mechanical probe may be the simplest method, but probe material would be critical in the hot environment.

- Explosive drill: Stand-off is especially important for explosive capsules and shaped-andgauge charges. It is not certain that a mechanical probe would survive, so periodic contact with the hole bottom may be the best way of maintaining proper stand-off.

- Pulsed-laser water jet: Cutting efficiency is not the issue in stand-off for the pulsed-laser water jet. Laminar-flow water is required to transport the laser beam and the distance between the water nozzle and hole bottom must be minimized to preserve this flow. At the same time, rock reduction with this system is relatively violent, so the nozzle could be damaged if it is too close to the bottom of the hole. The optimum stand-off to satisfy these conflicting requirements is not yet clear.

- Non-contact rock melters: In general, these systems should operate as close to the bottom as possible while minimizing the chances of high-temperature damage to the system itself. It may be difficult to find a material that will allow a mechanical probe with these systems.

Well Control and Borehole Stability: A number of the concepts investigated (projectile-assist, microwave, thermal spallation, and pulsed-laser water jet) cannot operate under a full column of liquid, which diminishes the systems' ability to control pressure surges in the wellbore and which does not contribute to wellbore stability by either the static pressure or the chemical additives in drilling mud. Since air-drilling is well established, this limitation does not mean that these systems are unusable, but it does seriously limit their applicability. Some of these systems can be modified to allow them, at least in concept, to operate under a liquid column, but none has been demonstrated. Because of the radical differences in operation, it is unlikely that a solution for any one of the systems would be applicable to any other.

In connection with the principle that most formations drill faster with less wellbore pressure, it is possible that the quickest way to increase penetration rate with conventional rotary technology is to lighten the drilling mud even to the point of underbalanced drilling. The development of methods to control formation fluids and maintain borehole stability while drilling underbalanced 
could significantly increase penetration rate and reduce drilling time.

Reduced Effectiveness with Depth: As with conventional drilling, several of the advanced systems have demonstrated reduced cutting effectiveness at depth. Although this experience is not universal, it is common enough to suggest that there is still a need for better understanding of depth and fluid pressure effects on rock properties as they apply to drilling. More importantly, these experiences imply that the first step in the development of any new rock cutting system should be to test the performance of the concept at depth. Existing facilities can independently simulate pore pressure, rock stress, and borehole fluid pressure at depth. Before spending significant resources on system development, unconventional rock-cutting concepts should be tested at one of these facilities.

Size of Surface System: The size, cost, and complexity of the drill rig's surface system is little affected by the way we cut rock. Sizes and specifications for the mast, substructure, and drawworks are determined by the need to handle casing, and requirements for the mud pumps, pits, and mud-cleaning equipment are determined by the need to remove the cuttings, not by how the cuttings are produced. About the only equipment that depends on how we cut rock is the bottom hole assembly; but it is doubtful that any novel rock cutting mechanism will cost less than drill collars, stabilizers, and bits. Overall, it is unlikely that significant savings in materials and equipment can be achieved by simply changing the way we cut rock.

Daily operational costs are similar, since crew requirements are determined by the surface equipment. Rig insurance is determined by capital investment and liability insurance and workman's compensation costs are proportional to payroll.

Significant reduction of drilling costs can only occur by changing the nature of the surface system or by increasing the rate of penetration. Most of the advanced systems have concentrated on the rock-cutting mechanism, but certain candidates such as coiled-tubing have the potential for serious change in rig configuration. Even though almost all components of the conventional surface system are technologically very mature, there may be opportunities for revolutionary innovation here. 


\section{COST AND PERFORMANCE}

\section{OPERATING COSTS}

There are many ways to assess the viability of advanced drilling concepts. Instead of concentrating only on technical feasibility we have also estimated the capital and operating costs of advanced systems. Using these estimates, we calculate the performance required from these systems to make them commercially competitive with conventional rotary drilling. Due to excess equipment and low demand, rig rates today are artificially low. Thus, it is necessary to estimate the costs of a conventional rotary drilling system built from all new equipment and materials as a basis for equitable comparisons to the expected costs of other systems. We estimate performance requirements for advanced systems competing both with existing rigs and with newly-built rigs which are more expensive but represent the future market.

We estimate that it would cost about nine-million dollars to build and field an 18,000-foot conventional rig from all new equipment and materials. The rental rate for this rig alone would be about $\$ 12,900$ per day. There would be an additional $\$ 6,200$ per day in operator-incurred drill-site charges for a total daily rate of $\$ 19,100$. These costs and charges are discussed in greater detail in Appendix C. Current daily costs for an 18,000-foot rig are about $\$ 13,200$ ( $\$ 7,000$ rig rate plus $\$ 6,200$ additional drilling costs to the operator). These estimates of operating costs are summarized in the following table.

\begin{tabular}{lccc}
\hline \hline \multicolumn{4}{c}{ Estimated Daily Operating Costs for an 18,000-Foot Land Rig } \\
\hline & Rig Rate & Operator Charges & Daily Costs \\
\hline Current land rig & $\$ 7,000$ & $\$ 6,200$ & $\$ 13,200$ \\
New conventional rig & $\$ 12,900$ & $\$ 6,200$ & $\$ 19,100$ \\
\hline \hline
\end{tabular}

The figures given above are used to estimate performance requirements for the novel drilling concepts. In most cases, we present comparisons for both a $\$ 13,200$ daily cost and a $\$ 19,100$ daily cost. A tool or system going on the market today, or in the near future, will have to compete with conventional drilling technology at the lower daily rate. However, as the currently available rigs are retired and new rigs are built, rig rates will approach the larger figure in the table. Thus, concepts with a long development time will likely compete with conventional drilling technology at a higher daily cost 


\section{Cost \& Performance}

Presentation of results at the two daily costs given in the above table has another benefit: comparison of the performance requirements at different costs indicates the sensitivity of these requirements to variations in daily operating costs.

\section{Basis for Performance Requirements}

System performance requirements are based on all costs incurred in drilling a $121 / 4$-inch hole from 4,000 feet to 8,000 feet and completing it with $95 / 8$-inch casing to the surface. System requirements were developed for three general drilling conditions defined as soft, medium-hard, and hard rock. Definitions and baseline performance estimates are given in the following table and discussed in greater detail in Appendix B.

\begin{tabular}{lccl}
\hline \hline \multicolumn{4}{c}{ Rock Definitions and Current Performance } \\
\hline & IADC Series & Baseline ROP & Bit Life \\
\hline Soft rock & $51 \mathrm{x}-52 \mathrm{x}$ & 40 feet per hour & 90 hours \\
Medium-hard rock & $53 \mathrm{x}-61 \mathrm{x}$ & 15 feet per hour & 90 hours \\
Hard rock & $62 \mathrm{x}-74 \mathrm{x}$ & 7 feet per hour & 90 hours \\
\hline \hline
\end{tabular}

The above table assumes that rate-of-penetration is a direct function of rock hardness; and we have treated ROP in this manner throughout this report. This is not entirely correct, since there are abrasive shales which are relatively soft and yet slow to drill. In such soft yet slow-to-drill rock, the benefits of a system whose cutting ability is related directly to the compressive strength of the rock (such as high-pressure jets) will be under-estimated. The best way to interpret the results discussed in this report is to remember the assumed penetration-rate to rock-hardness relationships indicated in the above table.

The performance requirements for the various drilling concepts are determined under the condition that the cost to drill and complete the 4,000-foot interval are equal to or lower than the corresponding costs with conventional rotary technology.

\section{Rental Tools and Capital Expenses}

Most of the concepts we examined could be introduced to drilling operations either as rental tools or as capital items. Rental tools are charged at a fixed rate so they affect performance requirements by increasing operating costs without regard to tool life (tool life is taken into account in estimating rental rate). Capital items, on the other hand, not only have periodic costs for repairs and upkeep, but also have an initial fixed cost that must be distributed over the life of 
the tool. Thus, for capital items, increased tool life will result in decreased performance requirements.

We analyzed the systems and concepts both as rental tools and as capital equipment. The results of analyses as rental tools are presented in tables. The results of analyses as capital equipment are presented graphically with the performance requirement as a function of useful life. Some systems do not lend themselves easily to analysis in one form or the other. For example, a fully-integrated coil-tubing drill rig would be a capital purchase, not a rental tool. However, in our analysis, we estimate a daily operating charge for this system. The daily operating charge looks like a rental rate and, thus, the results appear in a table as if the coiledtubing rig were a rental tool.

\section{CONVENTIONAL ROTARY PERFORMANCE}

In the following sections, we present the performance requirements for various systems and concepts developed under the constraint that drilling with these systems cost no more than drilling with conventional rotary technology. It is also informative to examine the performance of conventional drilling technology.

We based the performance requirements on drilling a 12 1/4-inch hole from 4,000 feet to 8,000 feet and completing it with $95 / 8$-inch casing to the surface. Costs associated with drilling and completing the interval with conventional technology are detailed in Appendix B. The breakout of these costs is illustrated in the figure at right. As shown, the end-of-interval costs (i.e. casing, cement, logging, testing, etc.) do not vary with penetration rate. However, the costs of drilling (bits, tripping, and turning on bottom)

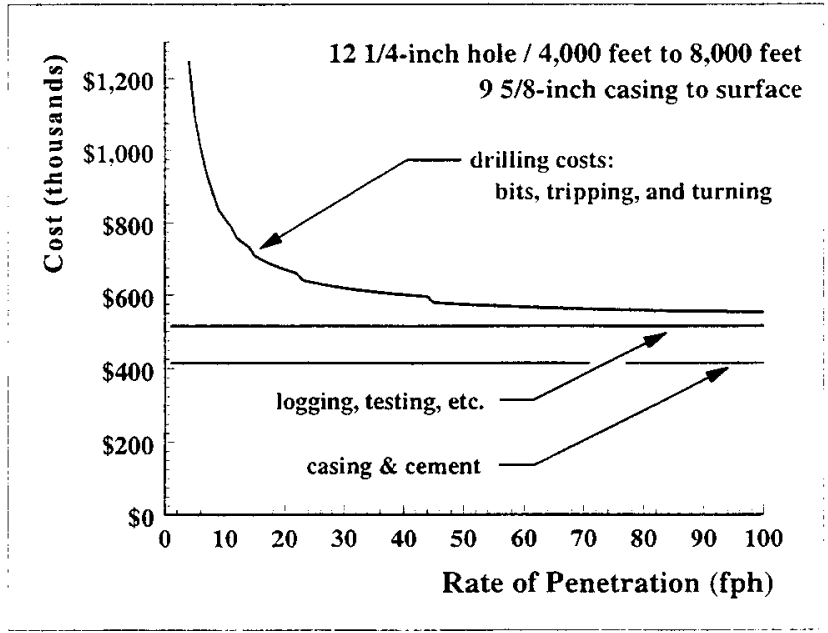

\section{Interval Costs with Conventional Rotary Technology} vary significantly with penetration rate. Most of the systems and concepts we investigated would affect the costs of drilling.

For casing-point to casing-point in a well, the estimated percentages of time and cost attributed to drilling and tripping with a conventional rotary rig are given in the following table. 


\begin{tabular}{lccc}
\hline \multicolumn{4}{c}{ Drilling and Tripping as a Percentage of All Interval Activity } \\
\hline & Time & Cost at \$13.2k/day & Cost at \$19.1k/day \\
\hline Soft rock & $57 \%$ & $13 \%$ & $16 \%$ \\
Medium-hard rock & $77 \%$ & $27 \%$ & $33 \%$ \\
Hard rock & $88 \%$ & $44 \%$ & $51 \%$ \\
\hline \hline
\end{tabular}

Drilling and tripping dominate the interval activities in terms of time, however, drilling and tripping are not nearly so dominant in terms of cost. The above table indicates that if you can make the rock cutting instantaneous and free, you can save $57 \%$ of the time but only $13 \%$ of the cost (at a daily operating rate of $\$ 13,200$ ) in soft rock.

\section{Cost Variations with Hole and Casing Size}

The previous table is based on the times and costs associated with a single $121 / 4$-inch hole from 4,000 feet to 8,000 feet completed with $9 \% / 8$-inch casing. We investigated the effect on costs if the interval were an $83 / 4$-inch hole completed with 7 -inch casing.

The figure at right gives the cost of activities and materials associated with cutting rock with a conventional rig as a percentage of total interval costs for penetration rates up to 100 feet per hour (fph). Costs accounted for in this figure include bits, tripping, and turning on the bottom. This figure is based on $\$ 13,200$ per day operating cost.

As shown, rock cutting accounts for a larger percentage of total interval costs in the smaller hole. Drilling costs (bits, tripping, and turning) decrease significantly with increasing penetration rate. At a penetration rate of 60

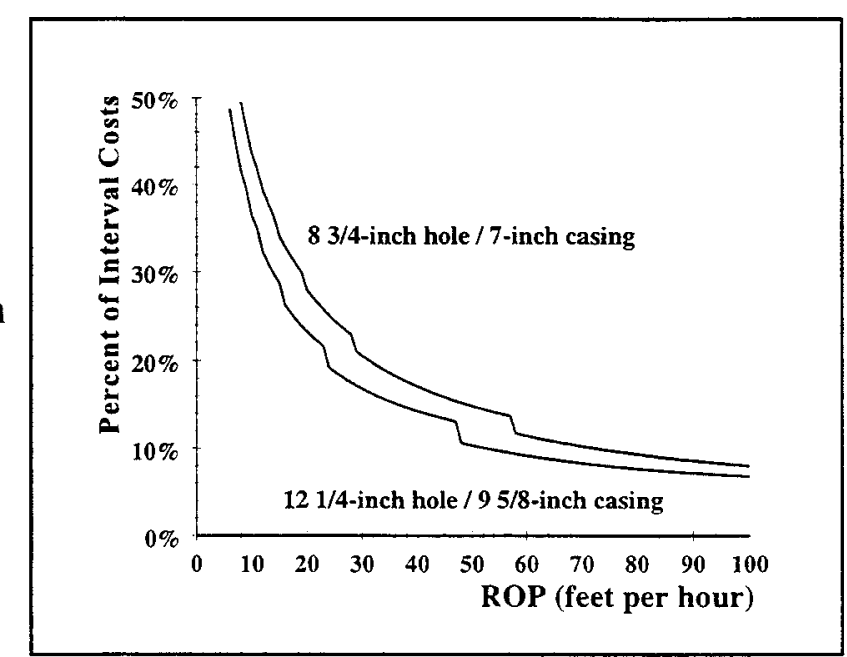

\section{Drilling Costs as a Percentage of Total Interval Costs} fph, the contribution of rock cutting activities to total interval costs is on the order of $10 \%$. Only at penetration rates below 10 fph does the cost of cutting rock approach $50 \%$ of the total interval costs.

Smaller hole size and casing increases drilling costs as a percentage of total interval cost; but using the smaller hole size and casing would affect performance requirements only due to differences in the performance capabilities of rotary bits. Generally, smaller bits exhibit shorter 
lives due to increased bearing load. This reduced performance for conventional technology would result in decreased performance requirements for the advanced systems. The smaller casing size and cost would have no effect on performance requirements.

\section{Activity Costs}

The following pie charts illustrate all activities in the interval by percentage of total cost. As shown, in soft and medium-hard rock, casing and cement account for over half of the costs incurred in the interval. These activities present the greatest opportunity for cost reduction in soft and medium-hard rock. In hard rock (at 7 -fph penetration rate), the costs of cutting rock approach those of completion.
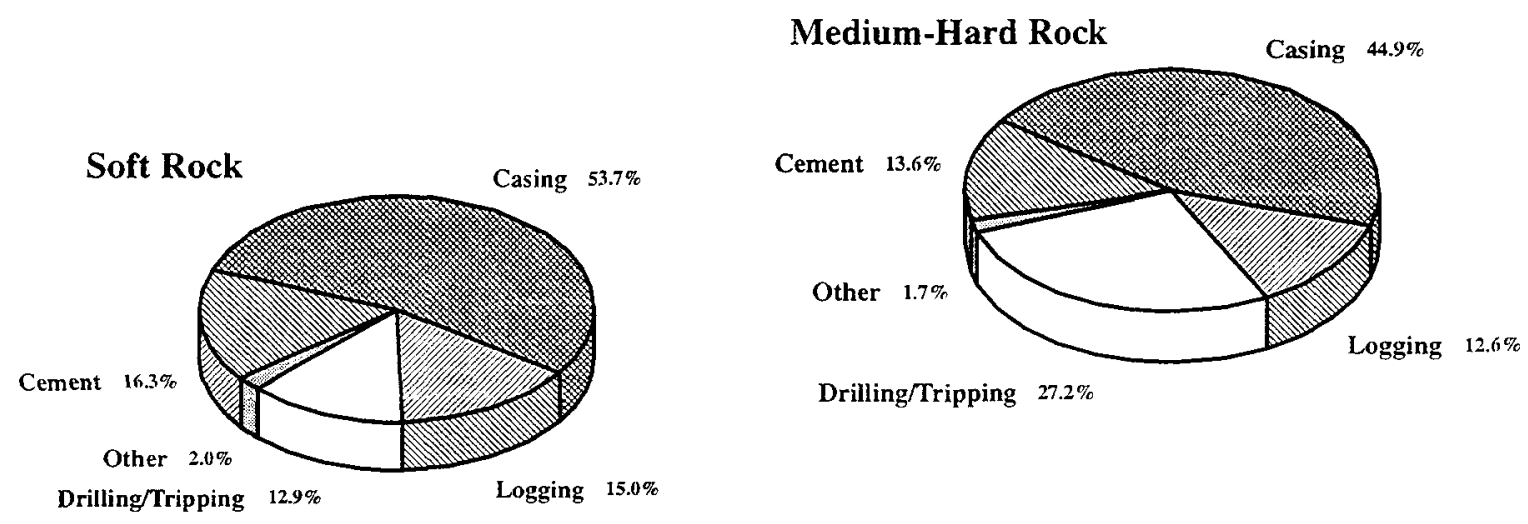

\section{Interval Costs by Source}

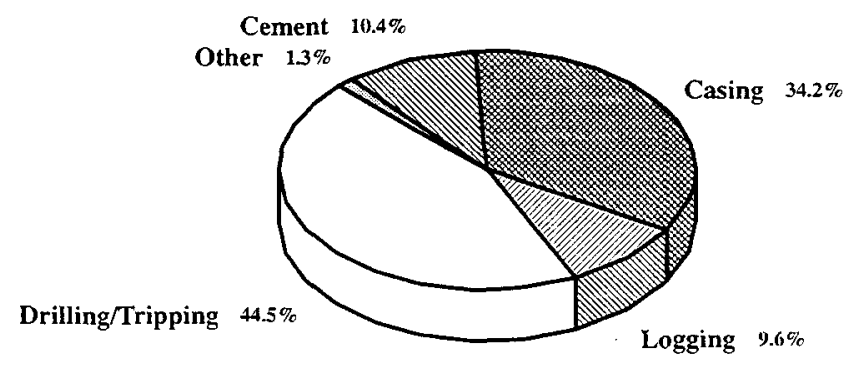

Hard Rock 
Based on the previous figures, the greatest opportunity for reducing costs through improved rock cutting techniques is in hard-rock drilling. That has been the experience of people who have attempted to market new techniques for cutting rock.

\section{Costs and Possible Savings}

The performance requirements were developed under the constraint that the advanced technology cost no more than current technology in completing the defined interval. Another approach would be to estimate savings given a particular improvement in penetration rate.

In most cases, merely matching current performance would be insufficient for a system to achieve commercial success. A system would need to surpass current performance in order to earn acceptance in the drilling industry. With this in mind, the authors investigated the possible savings associated with increasing the penetration rate while holding all other factors constant. The results, under the assumption of doubling and quintupling the penetration rate, are shown in the following figure.

Based on the same 4,000-foot drilling interval used previously, the figure at right shows savings in dollars that could be realized if the penetration rate is increased while all other factors are held constant. As an example of how to interpret this figure, consider the possible savings at an ROP of 20 $\mathrm{fph}$. This figure indicates that doubling the ROP (to $40 \mathrm{fph}$ ) would result in savings of about $\$ 70,000$, while quintupling the ROP (to $100 \mathrm{fph}$ ) would yield savings on the order of $\$ 120,000$.

As shown, the possible savings increases significantly as penetration rates decrease

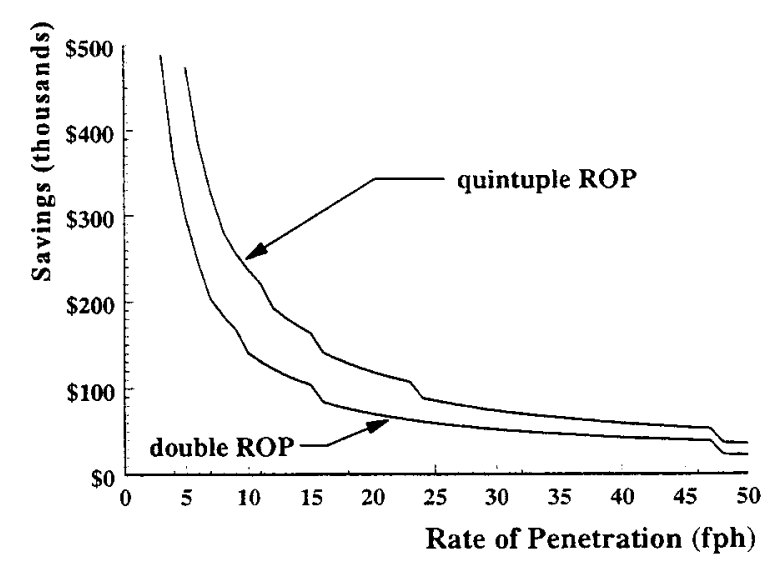

Possible Savings Through Improved Performance below fifteen to twenty feet-per-hour. This region is a particularly attractive target for systems whose primary advantage is to increase the rate of penetration.

\section{PERFORMANCE REQUIREMENTS}

The following sections discuss the performance requirements for the various systems and concepts. Every performance requirement is presented as the necessary ratio of rate-of- 
penetration to current capability. Thus, a requirement of two indicates that the advanced technology needs to double the current penetration rate. Ranges, generated by varying the cost estimates of the advanced technology by $\pm 25 \%$, are given for each system and rock hardness. The definitions of soft, medium-hard, and hard rock are given in Appendix B.

A number of rotary-assisted concepts (jet-assisted, thermal-assisted, projectile-assisted, etc.)

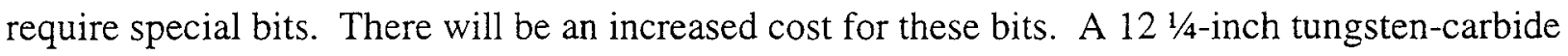
insert (TCI) rock bit currently costs about $\$ 13,000$. For the special bits, the necessary machining, materials, and rework can be completed for under $\$ 4,000$ in most cases. If a technology grows sufficiently to support the regular use and sale of the special-built bits, they will likely be priced about $25 \%$ to $50 \%$ above costs. However, until such bits become regular tools, the bit companies will treat their manufacture as special builds and past experience indicates a 50\% to $100 \%$ markup on the cost of the bit. For this analysis, we have used a cost of $\$ 26,000$ for all special-built bits.

In considering performance requirements of tools as capital items, we assumed that two units had to be available at the drill rig. The cost of each unit is based on a 100\% markup above the cost estimates to build the device: a tool costing $\$ 50,000$ to build is assumed to cost $\$ 100,000$ to purchase. The estimated maintenance costs are inflated $25 \%$.

The following table summarizes the performance requirements of rental tools when $\$ 13,200$ is used as the daily cost for conventional rotary technology. Requirements assuming a $\$ 19,100$ daily cost are given in the following sections. 


\section{Summary of ROP Requirements}

$(\$ 13,200$ daily cost for a conventional rotary rig)

\begin{tabular}{l|c|c|c}
\hline & Soft & Medium & Hard \\
\hline Fully integrated coiled-tubing rig & $1.5-3.5$ & $1.4-2.3$ & $1.4-2.1$ \\
Jet-assist & & & \\
$\quad$ Surface pressure generation & $>3.4$ & $2.2-5.0$ & $1.9-3.4$ \\
$\quad$ Positive-displacement DHP & $1.7-2.0$ & $1.6-1.9$ & $1.6-1.9$ \\
$\quad$ Centrifugal DHP & $1.6-1.8$ & $1.5-1.7$ & $1.5-1.7$ \\
Projectile-assist & $2.2-3.2$ & $2.0-2.5$ & $1.9-2.3$ \\
Microwave-assist & $?$ & $?$ & $?$ \\
Mud hammer & $1.4-1.6$ & $1.3-1.5$ & $1.3-1.5$ \\
Thermal spallation & & & \\
$\quad$ Downhole separation & $1.1-1.4$ & $1.1-1.3$ & $1.1-1.2$ \\
Spark drill & $?$ & $?$ & $?$ \\
Explosive drill & $?$ & $?$ & $?$ \\
Pulse laser-water jet (3,500-hr life) & $\sim 2.5$ & $\sim 1.7$ & $\sim 1.5$ \\
Rock melters & $?$ & $?$ & $?$ \\
\hline \hline
\end{tabular}




\section{COILED-TUBING DRILL RIG}

The estimated costs to build and field a coiled tubing drilling system are compared to a similar-size conventional rig in the following table. Both rigs are designed to be capable of drilling to 18,000 feet. Coiled tubing is currently used in drilling operations; however, these rigs are not capable of drilling full hole to 18,000 feet.

\begin{tabular}{|c|c|c|}
\hline \multicolumn{3}{|c|}{ Drilling System Cost Comparison } \\
\hline Coiled & Tubing Drill Rig & Conventional Rig \\
\hline Sub-System & Cost (thousands) & Cost (thousands) \\
\hline Mast \& substructure & $\$ 180$ & $\$ 973$ \\
\hline Power generation equipment & $\$ 1,233$ & $\$ 1,233$ \\
\hline Drawworks & -- & $\$ 782$ \\
\hline Hydraulic jack & $\$ 280$ & --- \\
\hline Coiled tubing drive unit & $\$ 250$ & --- \\
\hline Mud pumps \& high-pressure equipment & $\$ 1,002$ & $\$ 1,008$ \\
\hline Mud conditioning equipment & $\$ 349$ & $\$ 349$ \\
\hline BOP equipment & $\$ 875$ & $\$ 875$ \\
\hline Rotating equipment & -- & $\$ 92$ \\
\hline Traveling \& pipe handling equipment & $\$ 182$ & $\$ 625$ \\
\hline Instrumentation & $\$ 72$ & $\$ 77$ \\
\hline Miscellaneous equipment & $\$ 360$ & $\$ 409$ \\
\hline Tubing \&BHA & $\$ 299$ & $\$ 975$ \\
\hline Rig assembly \& test & $\$ 480$ & $\$ 680$ \\
\hline Sub-total & $\$ 5,562$ & $\$ 8,078$ \\
\hline Contingency $(5 \%)$ & $\$ 278$ & $\$ 404$ \\
\hline Taxes $(8 \%)$ & $\$ 467$ & $\$ 679$ \\
\hline Total & $\$ 6,307$ & $\$ 9,161$ \\
\hline
\end{tabular}

The coiled tubing rig will have significantly lower capital cost than a conventional drill rig. In the $\$ 6.3$-million total for the coiled tubing rig, there are $\$ 4.9$ million in capital equipment and $\$ 500$ thousand in expendable materials and equipment. The remaining costs are taxes and assembly. 


\section{Cost \& Performance/CT Drill Rig}

The daily operating costs for the coiled tubing rig are compared to the daily operating costs for the conventional rig in the following table. The assumptions employed in these estimates are discussed in Appendix C.

\begin{tabular}{|c|c|c|}
\hline & Comparison of Daily Operating Costs & $=$ \\
\hline & Coiled Tubing Rig & Conventional Rig \\
\hline Long-term debt & $\$ 2,600$ & $\$ 3,400$ \\
\hline Short-term debt & $\$ 2,300$ & $\$ 2,700$ \\
\hline Maintenance & $\$ 1,200$ & $\$ 1,700$ \\
\hline Labor & $\$ 2,300$ & $\$ 2,700$ \\
\hline Office support & $\$ 500$ & $\$ 500$ \\
\hline Insurance & $\$ 200$ & $\$ 300$ \\
\hline Fuel & $\$ 1,200$ & $\$ 1,600$ \\
\hline Total & $\$ 10,300$ & $\$ 12,900$ \\
\hline
\end{tabular}

When compared to the conventional system, the coiled tubing system has lower costs for long-term debt, short-term debt, and maintenance. These are due to the lower cost of both capital and expendable equipment. The reduced labor costs are due to the use of one less rig hand on the coiled tubing rig. The lower insurance cost reflects the decreased capital investment.

The coiled tubing rig would also have the drill-site charges of $\$ 6,200$ per day discussed in Appendix $C$. This brings the total operating cost to $\$ 16,500$ per day.

\section{Performance Requirements}

Assuming technical problems concerning fatigue strength and flow capacity of the tubing can be solved, we predict that a coiled tubing rig would reduce operating costs by about $\$ 2,500$ per day. However, these costs do not include drilling motors which currently rent for between $\$ 230$ to $\$ 400$ per hour depending on size and design. The addition of a drilling motor can easily absorb the savings in daily operating costs.

Based on the projected operating costs and assuming $\$ 270$ per hour for a drilling motor, the following table gives estimates of the performance requirements for the coiled tubing rig when compared to conventional rotary technology based on both current rig rates and on our estimates of operating costs for a rig built from new materials and equipment. 


\begin{tabular}{lcc}
\hline \multicolumn{3}{c}{ Coiled Tubing Rig Performance Requirements } \\
\hline Operating cost for comparison & $\$ 13,200$ per day & $\$ 19,100$ per day \\
\hline Soft rock & $1.5-3.5$ & $0.9-1.6$ \\
Medium-hard rock & $1.4-2.3$ & $=1.0-1.5$ \\
Hard rock & $1.4-2.1$ & $1.0-1.4$ \\
\hline \hline
\end{tabular}

There is no particular reason to believe that a coiled-tubing rig should be able to drill faster than a conventional rig. The coiled tubing rig makes sense primarily if the costs of drilling motors can be reduced such that drilling with coiled tubing is cheaper than drilling with a conventional rig. The ability to run a wireline inside coiled tubing does open the possibility of using electric motors which may be cheaper than current turbines or positive-displacement motors. 


\section{JET-ASSISTED DRILLING}

\section{TeleJet Technologies System Costs}

The estimated costs to build and field the TeleJet Technologies (MultiCon ${ }^{\mathrm{TM}}$ ) system (Schuh 1995) are compared to our estimates of the costs to build and field a similar-size conventional rig in the following table.

\begin{tabular}{|c|c|c|}
\hline \multicolumn{3}{|c|}{ Drilling System Cost Comparison } \\
\hline TeleJet Tech & nologies System ${ }^{1}$ & Conventional Rig \\
\hline Sub-System & Cost (thousands) & Cost (thousands) \\
\hline Mast \& substructure & $\$ 1,145$ & $\$ 973$ \\
\hline Power generation equipment & $\$ 2,756$ & $\$ 1,233$ \\
\hline Drawworks & $\$ 1,153$ & $\$ 782$ \\
\hline Mud pumps \& high-pressure equipment & $\$ 2,264$ & $\$ 1,008$ \\
\hline Annular fluid system & $\$ 476$ & --- \\
\hline Return fluid system & $\$ 703$ & $\$ 349$ \\
\hline MultiCon fluid system & $\$ 160$ & -- \\
\hline BOP equipment & $\$ 725$ & $\$ 875$ \\
\hline Rotating equipment & $\$ 1,040$ & $\$ 92$ \\
\hline Traveling \& pipe handling equipment & $\$ 2,432$ & $\$ 625$ \\
\hline Instrumentation & $\$ 264$ & $\$ 77$ \\
\hline Miscellaneous equipment & $\$ 507$ & $\$ 409$ \\
\hline Tubing \&BHA & $\$ 2,145$ & $\$ 975$ \\
\hline Rig assembly \& test & $\$ 300$ & $\$ 680$ \\
\hline Sub-total & $\$ 16,070$ & $\$ 8,078$ \\
\hline Contingency $(5 \%)$ & --- & $\$ 404$ \\
\hline Taxes $(8 \%)$ & $\$ 1,286$ & $\$ 679$ \\
\hline Total & $\$ 17,356$ & $\$ 9,161$ \\
\hline
\end{tabular}

The MultiCon ${ }^{\mathrm{TM}}$ rig will have significantly higher capital cost than a conventional drill rig. In the \$17.4-million total for the MultiCon ${ }^{\mathrm{TM}}$ rig, there are $\$ 13.1$ million in capital equipment and \$2.7 million in expendable materials and equipment. The remaining costs are taxes and assembly. 
The daily operating costs for the MultiCon ${ }^{\mathrm{TM}}$ rig are compared to the daily operating costs for conventional rig in the following table. These estimates are those of the authors. They were neither made nor endorsed by either TeleJet Technologies or Drilling Technology. The assumptions employed in these estimates are discussed in Appendix C.

\begin{tabular}{lrr}
\hline \multicolumn{3}{c}{ Comparison of Daily Operating Costs } \\
\hline & TeleJet Technologies Rig & Conventional Rig \\
\hline Long-term debt & $\$ 7,200$ & $\$ 3,400$ \\
Short-term debt & $\$ 5,800$ & $\$ 2,700$ \\
Maintenance & $\$ 3,600$ & $\$ 1,700$ \\
Labor & $\$ 2,700$ & $\$ 2,700$ \\
Office support & $\$ 500$ & $\$ 500$ \\
Insurance & $\$ 600$ & $\$ 300$ \\
Fuel & $\$ 3,600$ & $\$ 1,600$ \\
\hline Total & $\$ 24,000$ & $\$ 12,900$ \\
\hline \hline
\end{tabular}

Compared to the conventional system, the MultiCon ${ }^{\mathrm{TM}}$ system has significantly higher costs for long-term debt, short-term debt, and maintenance. These are due to the higher cost of both capital and expendable equipment. Labor and overhead are unchanged. The increase in insurance reflects the increased capital investment. The increased fuel costs, when compared to the baseline rig, are primarily due to the increased horsepower needed for the high-pressure pumps.

The MultiCon ${ }^{\mathrm{TM}}$ rig would also have the drill-site charges of $\$ 6,200$ per day discussed in Appendix C. This brings the total estimated operating cost to $\$ 30,200$ per day.

\section{MultiCon ${ }^{T M}$ Rig Performance Requirements}

Using the estimated operating costs above, the following table gives estimates of the performance requirements for the MultiCon ${ }^{\mathrm{TM}}$ rig when compared to conventional rotary technology both for current rig rates and for our estimates of operating costs of a rig built from new materials and equipment. 


\begin{tabular}{lcc}
\hline \multicolumn{3}{c}{ MultiCon $^{\mathrm{TM}}$ Rig Performance Requirements } \\
\hline Operating cost for comparison & $\$ 13,200$ per day & $\$ 19,100$ per day \\
\hline Soft rock & $>3.4$ & $1.5-6.3$ \\
Medium-hard rock & $2.2-5.0$ & $=1.4-2.7$ \\
Hard rock & $1.9-3.4$ & $1.3-2.2$ \\
\hline \hline
\end{tabular}

Our calculations indicate that the MultiCon ${ }^{\mathrm{TM}}$ system would need to increase penetration rate by a factor of 3.4 or greater to compete with current rig rates in soft rock. This would require penetration rates in excess of 130 feet per hour. The indicated requirements in medium and hard rock are not as stringent as in soft rock. When compared to the predicted operating cost for a new rig, the performance requirements for the MultiCon ${ }^{\mathrm{TM}}$ rig are significantly reduced.

Schuh makes penetration-rate predictions based on extrapolation of current data to expected system performance (Schuh 1995). He gives currently available data in the region from about one to ten hydraulic horsepower per square inch and predicts performance in the region of twenty-five to thirty hydraulic horsepower per square inch. Making assumptions concerning the effects of cavitation coupled with both linear and exponential curve fits, ROP's an order-ofmagnitude faster than currently possible are indicated. Based on these numbers, Schuh predicts $20 \%$ to $40 \%$ reductions in drilling costs. As shown in the above table, our calculations indicate that an order of magnitude increase in penetration rate would be more than adequate to make the MultiCon ${ }^{\mathrm{TM}}$ system competitive.

\section{TeleJet Technologies' Estimates}

Schuh estimates dayrates for the MultiCon ${ }^{\mathrm{TM}}$ system as well as for current and new conventional rigs (Schuh 1995). These estimates are given in the following table.

\begin{tabular}{lc}
\hline \multicolumn{2}{c}{ TeleJet Technologies Dayrate Estimates ${ }^{1}$} \\
\hline Current 18,000-foot conventional rig & $\$ 5,723$ \\
New conventional rig & $\$ 8,493$ \\
MultiCon ${ }^{\mathrm{TM}}$ rig & \\
High-pressure drilling $^{\text {Other operations }}$ & $\$ 16,436$ \\
\hline${ }^{\prime}$ Frank J. Schuh, Drilling Technology, Inc., MultiCon ${ }^{T M}$ Drilling System Economics, January 1995 \\
\hline \hline
\end{tabular}


Schuh specifies different rates depending on whether or not high-pressure operations are in progress. The primary differences between Schuh's high-pressure estimate and our estimate are in maintenance costs and the way equipment costs and replacement are treated. Schuh argues that mud costs for the MultiCon ${ }^{\mathrm{TM}}$ rig would be reduced by $80 \%$ when compared to a conventional rig (Schuh correspondence). Using Schuh's numbers would result in reduced performance requirements.

The feasibility of the TeleJet Technologies system depends on increased rate of penetration. Schuh's performance estimates exceed the necessary increases, whether our cost estimates or Schuh's cost estimates, are used.

\section{Positive Displacement Downhole Intensifier Costs}

Estimated costs for a positive displacement downhole intensifier are given below. These estimates are based on a qualitative analysis of the device and were neither made nor endorsed by FlowDril.

\begin{tabular}{lr}
\hline \multicolumn{2}{c}{ Estimated Costs - Positive Displacement Downhole Intensifier } \\
\hline Initial cost & $\$ 80,000$ \\
General repair cost & $\$ 7,500$ \\
Mean time between repair & 80 hours \\
Repair time & 10 days \\
Useful life & 40 repair cycles \\
\hline \hline
\end{tabular}

Based on these numbers, we estimate that the pump would rent for about $\$ 310$ per hour. The standby charge would be about $\$ 30$ per hour. Using these estimates and a $\$ 26,000$ bit cost; the performance requirements for a positive-displacement downhole intensifier are given in the following table.

\begin{tabular}{lcc}
\hline \hline \multicolumn{2}{c}{ Performance Requirements - Positive Displacement Downhole Intensifier } \\
\hline operating cost & $\$ 13,200$ per day & $\$ 19,100$ per day \\
\hline soft rock & $1.7-2.0$ & $1.5-1.7$ \\
medium-hard rock & $1.6-1.9$ & $1.4-1.7$ \\
hard rock & $1.6-1.9$ & $1.4-1.6$ \\
\hline \hline
\end{tabular}




\section{Cost \& Performance/Jet Drilling}

We predict that a $60 \%$ to $90 \%$ increase in the penetration rate would be necessary for a positive displacement downhole pump to be cost effective at current operating rates.

\section{Centrifugal Downhole Intensifier Costs}

Estimated costs for a centrifugal downhole intensifier are given below. These estimates are based on a qualitative analysis of the device and were neither made nor endorsed by Maurer Engineering.

\begin{tabular}{lr}
\hline \hline \multicolumn{2}{c}{ Estimated Costs - Centrifugal Downhole Intensifier } \\
\hline Initial cost & $\$ 50,000$ \\
General repair cost & $\$ 6,000$ \\
Mean time between repair & 80 hours \\
Repair time & 10 days \\
Useful life & 40 repair cycles \\
\hline \hline
\end{tabular}

Based on these estimates, we estimate that the pump would rent for about $\$ 250$ per hour. The standby charge would be about $\$ 20$ per hour. Using these estimates and a $\$ 26,000$ bit cost, the required performance for a centrifugal downhole intensifier is given in the following table.

\begin{tabular}{lcc}
\hline \hline \multicolumn{2}{c}{ Performance Requirements - Centrifugal Downhole Intensifier } \\
\hline operating cost & $\$ 13,200$ per day & $\$ 19,100$ per day \\
\hline soft rock & $1.6-1.8$ & $1.4-1.6$ \\
medium-hard rock & $1.5-1.7$ & $1.4-1.5$ \\
hard rock & $1.5-1.7$ & $1.4-1.5$ \\
\hline \hline
\end{tabular}

We predict that a $50 \%$ to $80 \%$ increase in penetration rate would be necessary for a centrifugal downhole pump to be cost effective at current daily costs.

\section{Intensifier Requirements as a Capital Item}

We also considered the performance requirements of downhole intensifiers if purchased, instead of rented. Figures 4 through 9 show the projected performance requirements in soft, medium-hard, and hard rock. The upper curve in each of the figures assumes a basic operating cost of $\$ 13,200$ per day. The lower curve assumes a basic operating cost of $\$ 19,100$ per day. 
These curves indicate performance requirements that are comparable to the lower bound for the requirements of the tools when considered rental items. As was found in the analysis as rental tools, lower rig rates result in higher performance requirements for the downhole pumps to be competitive.

The relationship between device life and performance requirements is apparent in the figures. Judging from these curves, it is important for the devices to attain a life on the order of 1,500 hours to 2,000 hours or longer in order to reduce the penetration rate requirements.

In general, the centrifugal pump has slightly lower requirements than the positive displacement pump. This is a reflection of the difference in the estimated costs. Based on currently anticipated output pressures and flow rates, the positive-displacement pump should be capable of higher performance than the centrifugal pump. 


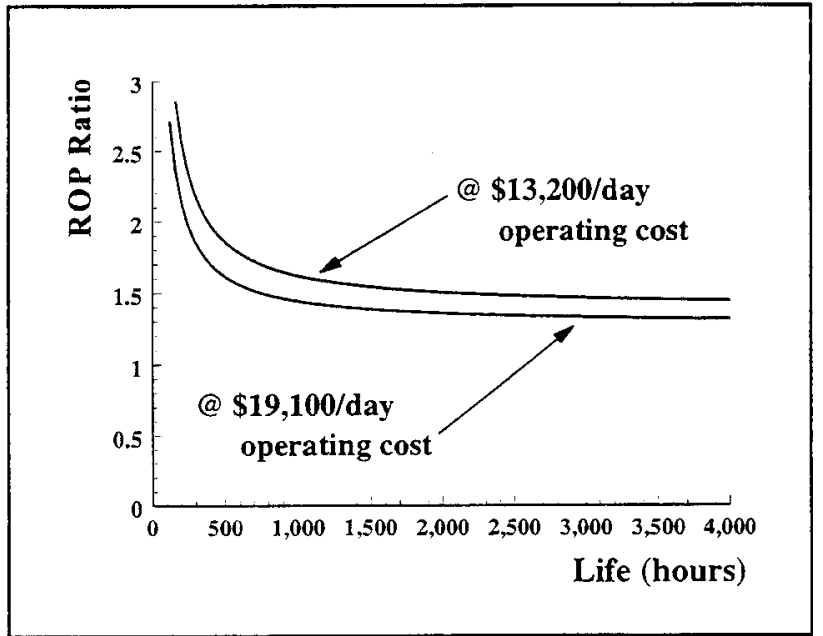

Figure 4: Positive-Displacement DHP Soft Rock

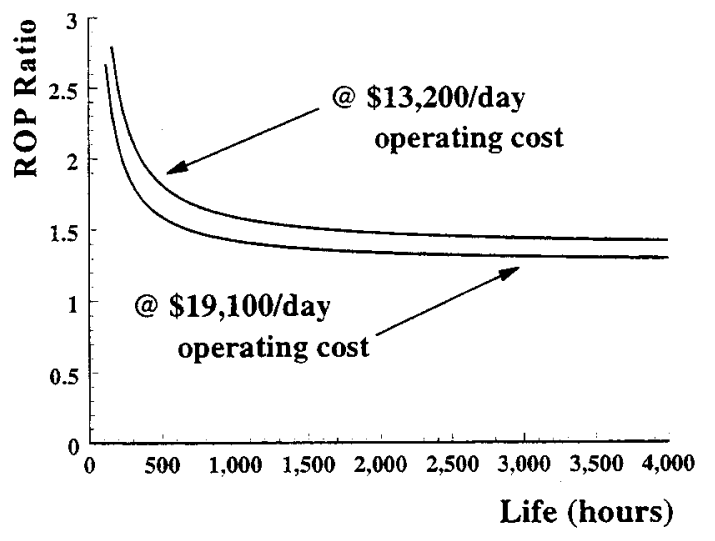

Figure 6: Positive Displacement DHP Medium-Hard Rock

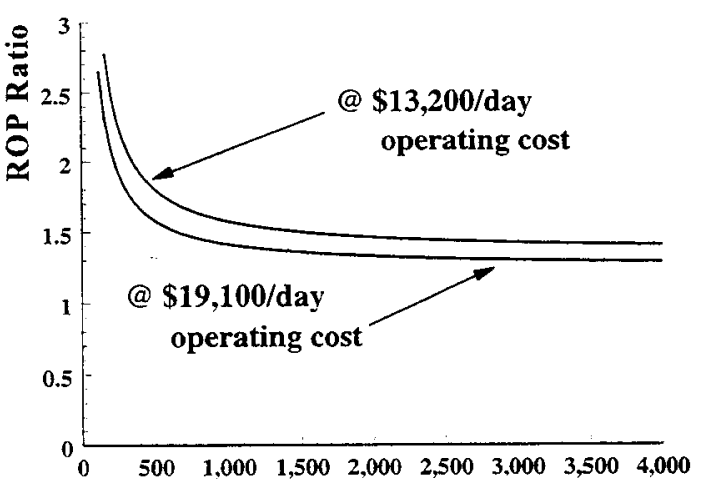

Life (hours)

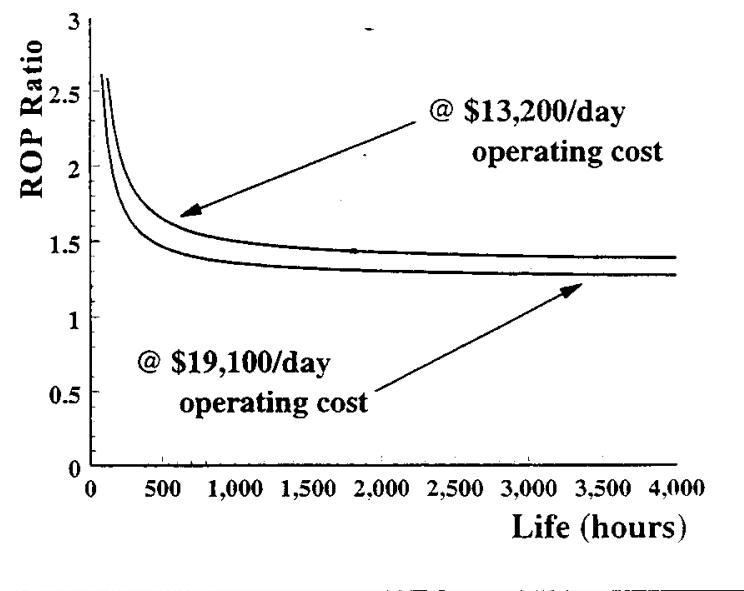

Figure 5: Centrifugal DHP Soft Rock

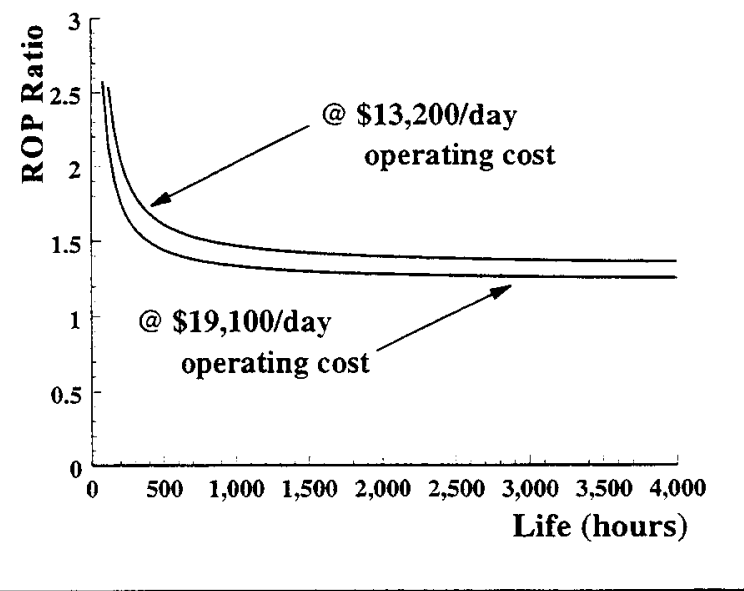

Figure 7: Centrifugal DHP

Medium-Hard Rock

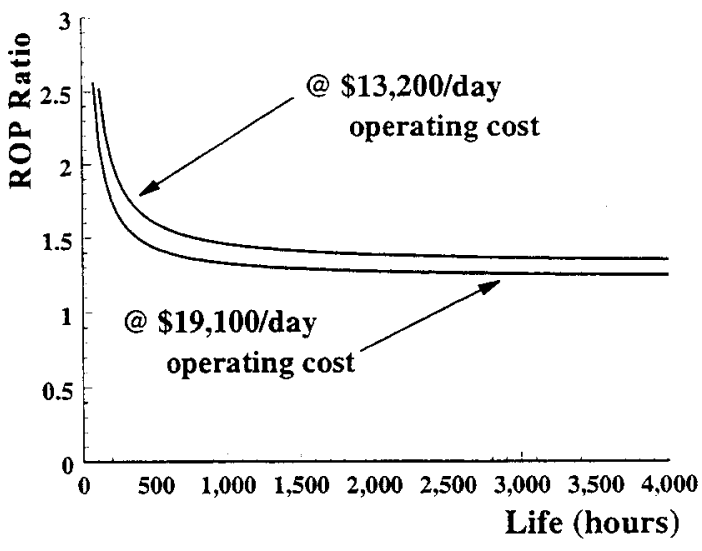

Figure 9: Centrifugal DHP Hard Rock 


\section{PROJECTILE-ASSISTED DRILLING}

Estimated costs for the Tround system are given the following table. These estimates are based on a qualitative analysis of the system and were neither made nor endorsed by Tround International.

\begin{tabular}{lr}
\hline \hline \multicolumn{2}{c}{ Projectile Drilling Costs and Characteristics } \\
\hline Initial cost & $\$ 150,000$ \\
Maintenance & $\$ 1,000$ per well \\
& plus $\$ 75,000$ each 1,000 hours \\
Useful life & 2,000 hours \\
Cartridge cost & $50 \downarrow$ each \\
Firing rate & 1 per minute \\
\hline \hline
\end{tabular}

\section{Performance Requirements as a Rental Device}

We estimate that the tool would rent for about $\$ 370$ per hour. The standby charge would be about $\$ 80$ per hour. Because the Tround system cannot operate in a liquid environment, it was evaluated against general air-drilling operations.

Using a $\$ 370$ per hour rental charge, an $\$ 80$ per hour standby charge, and a $\$ 26,000$ bit cost; the performance requirements for a projectile-assist drilling system are given in the following table.

\begin{tabular}{lcc}
\hline \hline \multicolumn{3}{c}{ Performance Requirements - Projectile Assisted Drilling } \\
\hline base operating cost & $\$ 13,200$ per day & $\$ 19,100$ per day \\
\hline soft rock & $2.2-3.2$ & $1.9-2.5$ \\
medium-hard rock & $2.0-2.5$ & $1.7-2.1$ \\
hard rock & $1.9-2.3$ & $1.6-2.0$ \\
\hline \hline
\end{tabular}

The first column in the table assumes a base operating cost of $\$ 13,200$ per day. In soft rock, we estimate that the Tround system must increase performance by a factor of two to three in order to compete with current technology. This would require penetration rates on the order of $150 \mathrm{fph}$ to $250 \mathrm{fph}$. In medium rock, the Tround system would have to drill about two to two and a half times faster than current technology and, in hard rock about twice as fast. The second 
column in the table uses an operating cost of $\$ 19,100$ per day. As shown in this column, increasing the operating cost reduces the performance requirements.

\section{Performance Requirements as a Capital Item}

We also estimated the performance requirements of a projectile-assisted system if purchased, instead of rented. Figures 10 through 12 show the projected performance requirements in soft, medium-hard, and hard rock respectively. The upper curve in each of the figures assumes a basic operating cost of $\$ 13,200$ per day. The lower curve assumes a basic operating cost of $\$ 19,100$ per day. As was found in the analysis as a rental, lower rig rates result in higher performance requirements for the tool to be competitive.

These figures indicate that a useful life of 1,500 hours to 2,000 hours is necessary to minimize performance requirements. Assuming an adequate tool life, the predicted performance requirements in these figures are generally lower than those predicted when the device was considered a rental tool.

Based on the data provided by Tround and included in the description of the Tround System, this system appears to be capable of meeting performance requirements as either a rental tool or capital equipment. 


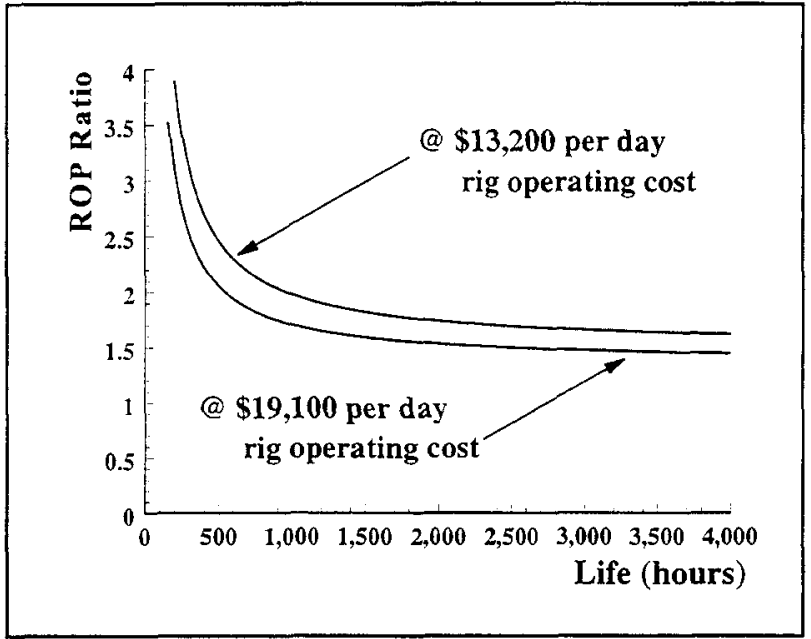

Figure 10: Tround Performance Requirements in Soft Rock

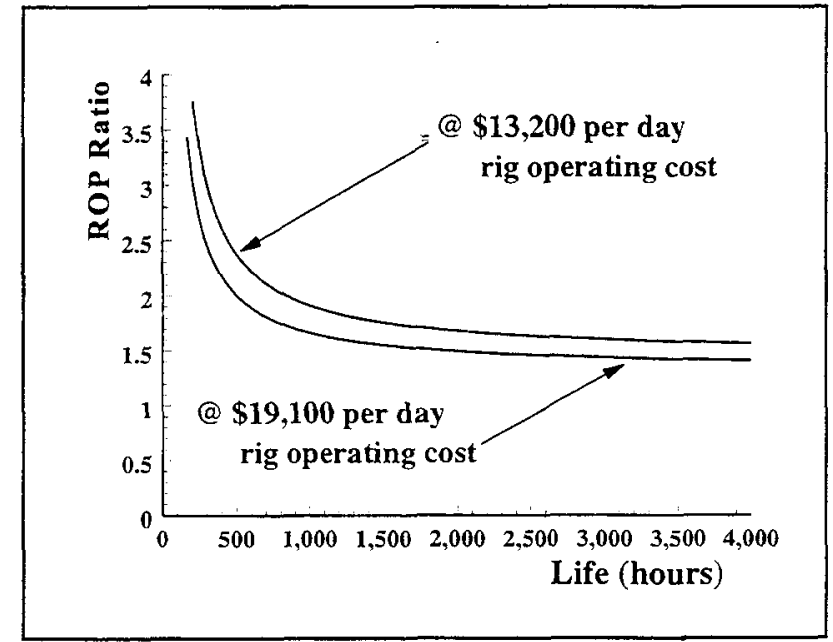

Figure 11: Tround Performance Requirements in Medium-Hard Rock

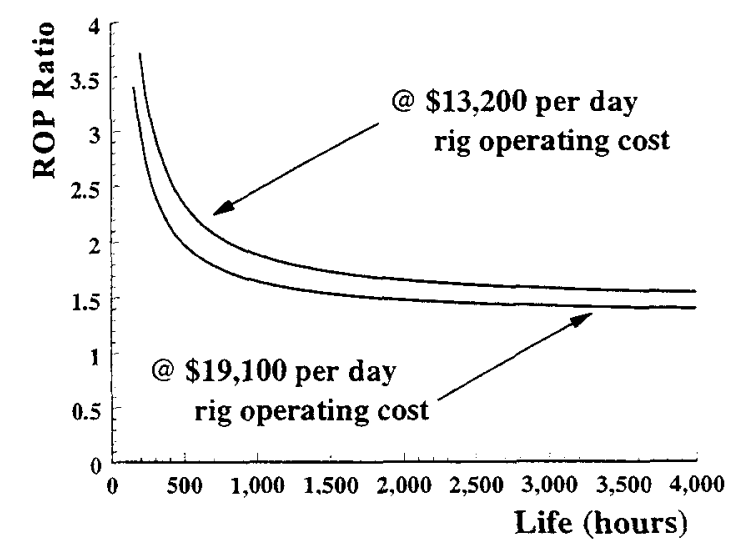

Figure 12: Tround Performance

Requirements in Hard Rock 


\section{Tround Response}

Personnel at Tround International reviewed a draft of this section and responded with the following points (Juliana):

1. Manufacturing cost of $\$ 150 \mathrm{k}$ is very conservative to build a projectile-assisted drilling system. Initial cost would approach $\$ 250 \mathrm{k}$ to $\$ 300 \mathrm{k}$. Production buys of 100 plus units would significantly reduce the costs.

2. Maintenance costs of $\$ 1,000$ per well are reasonable. The interior mechanism was designed to handle 200-300,000 rounds before failure which equates to 5,000 hours of use. If the gun mechanism required replacement, the cost would be no more than $\$ 20,000$. Repairs could be done within three days.

3. Cartridge costs were estimated by Tround to be less than $\$ 1.00$. However, more design studies are necessary to generate confidence in the cost. The Bureau of Alcohol, Tobacco and Firearms has ruled that the Tround Drill is an industrial tool and not a firearm. The ammunition is Class $\mathrm{C}$ and requires no special permits for transportation. There are no toxic products of combustion in the plastic materials used in the cartridge case.

4. Tround's 16-inch bit assemblies cost about $\$ 12,000$. The cost is a direct function of borehole size.

5. Whenever the word projectile is used the word ceramic should precede it.

6. You may want to comment on the straightness of the bore that is achievable using the Tround projectile-assisted drilling technology and, also, the ability to obtain seismic feedback for determining strata conditions and bit location.

In regular production, Tround expects the cost of the system to be about $\$ 100,000$. Using this value yields an estimated rental charge of $\$ 320$ per hour and a standby charge of $\$ 55$ per hour. Using a 5,000-hour life, yields a $\$ 280$ per hour rental charge and a $\$ 35$ per hour standby charge. The average of these estimates is a $\$ 300$ per hour rental charge and a $\$ 45$ per hour standby charge. The predicted performance requirements using these values are given in the following table. 


\begin{tabular}{lcc}
\hline \hline \multicolumn{3}{c}{$\begin{array}{c}\text { Performance Requirements - Projectile Assisted Drilling } \\
(\mathbf{3 0 0 / h r} \text { rental } \mathbf{8} \mathbf{\$ 4 5 / h r} \text { stand-by })\end{array}$} \\
\hline base operating cost & $\$ 13,200$ per day & $\$ 19,100$ per day \\
\hline soft rock & $1.9-2.5$ & $1.7-2.0$ \\
medium-hard rock & $1.8-2.1$ & $1.6-1.8$ \\
hard rock & $1.8-2.1$ & $1.5-1.8$ \\
\hline \hline
\end{tabular}

The performance requirements given in the above table are lower than those developed using our estimates of system costs. 


\section{Cost \& Performance/Thermal-Assisted Drilling}

\section{THERMAL-ASSISTED ROTARY DRILLING}

\section{Energy Requirements}

If the initial and final temperatures are specified, rough estimates of the power requirements for the microwave transmitter can be made. Maurer gives estimates of thermal properties for a number of materials and types of rock (Maurer 1968). Based on Maurer's data, the values in the following table are considered typical.

\begin{tabular}{lr}
\hline \hline \multicolumn{2}{c}{ Typical Thermal Properties of Rock } \\
\hline Specific gravity & $2.6 \mathrm{~g} / \mathrm{cm}^{3}$ \\
Specific heat & $0.24 \mathrm{cal} / \mathrm{g}^{\circ} \mathrm{C}$ \\
Melting temperature & $1300^{\circ} \mathrm{C}$ \\
\hline \hline
\end{tabular}

The work at the Bureau of Mines investigated effects for temperatures up to about $1100^{\circ} \mathrm{C}$. Assuming an initial temperature of $50^{\circ} \mathrm{C}$ and using the data in the above table, then a $121 / 4$-inch hole requires about $18 \mathrm{~kW} / \mathrm{fph}$ penetration rate.

\section{Equipment}

The primary equipment additions necessary for microwave-assisted drilling are the microwave generator and the transmission line. The microwave generator will contain a magnetron. It is doubtful that currently available magnetrons could withstand the shock and vibration environment of the bottom-hole assembly in drilling. If a more rugged magnetron cannot be developed, the microwave generator would need to be located on the surface. The following table gives output power and approximate costs for various microwave generators. These units are complete generators including the magnetron and power supply. The largest unit given in the table, $60 \mathrm{~kW}$, would be adequate for drilling at about three feet per hour.

\begin{tabular}{cc}
\hline \hline \multicolumn{2}{c}{ Commercially Available Microwave Generators } \\
\hline Output Power & Cost \\
\hline $1 \mathrm{~kW}$ & $\$ 200$ to $\$ 2,000$ \\
$3 \mathrm{~kW}$ & $\$ 10,000$ \\
$8 \mathrm{~kW}$ & $\$ 30,000$ \\
$60 \mathrm{~kW}$ & $\$ 70,000$ to $\$ 80,000$ \\
\hline \hline
\end{tabular}


If the generator is located on the surface, the microwave energy would need to be transmitted downhole either through a waveguide or a co-axial transmission line Both square and round waveguide are available. The approximate cost of waveguide and co-axial transmission line are given in the following table.

\begin{tabular}{lr}
\hline \multicolumn{2}{c}{ Transmission Line Characteristics and Costs } \\
\hline Co-axial transmission line: \\
- Size & 4 -inch nominal \\
$\quad$ Power rating & $2 \mathrm{MW}$ peak / $25 \mathrm{~kW}$ average \\
Cost & $\$ 45$ per linear foot \\
- Size & 3 -inch nominal \\
Power rating & 1 MW peak / $12 \mathrm{~kW}$ average \\
Cost & $\$ 35$ per linear foot \\
Waveguide: & \\
Size & 9.75 -inch by 4.875 -inch \\
Frequency range & $750 \mathrm{MHZ}$ to $1.12 \mathrm{Ghz}$ \\
Cost & $\$ 40$ per linear foot \\
Size & 7.7 -inch by 3.8 -inch \\
Frequency range & $960 \mathrm{MHZ}$ to $1.45 \mathrm{MHZ}$ \\
Cost & $\$ 40$ per linear foot \\
\hline \hline
\end{tabular}

Exceeding the maximum rating of the co-axial line will result in dielectric breakdown. Exceeding the average rating for an extended period will result in excessive heating. As shown, even the four-inch co-axial line has only adequate power capacity for about one foot-per-hour. The waveguide would have no problems even at power levels of $500 \mathrm{~kW}$. However, even if the waveguide were flexible and rugged enough, the dimensions given in the above table would make it difficult to use for power transmission in drilling.

The transmission of microwave energy in drilling will encounter problems in capacity and/or size. Additionally, the $\$ 35 /$ foot to $\$ 45 /$ foot would add significant cost to the operation. Ideally, drill pipe or coiled tubing might work as the transmission line. But any irregularities on the inner surface would result in reflected energy. Special pipe or tubing would be necessary; and the cost of such pipe is not known.

Microwave-assisted rock cutting may be practical where an open surface exists on which to work. However, this concept faces a number of challenging technical problems before it can be applied in a downhole drilling system. 


\section{MUD HAMMER}

Estimated costs for a downhole mud hammer are given below. These estimates are based on a qualitative analysis of the device and were neither made nor endorsed by Novatek. Based on the these numbers, we estimate that the hammer would rent for about $\$ 230$ per hour. The standby charge would be about $\$ 40$ per hour.

\begin{tabular}{lr}
\hline \hline \multicolumn{2}{c}{ Estimated Mud Motor Costs and Operating Characteristics } \\
\hline Initial investment & $\$ 30,000$ \\
General repair cost & $\$ 7,200$ \\
Mean time between repair & 120 hours \\
Repair time & 10 days \\
Useful life & 6 repair cycles \\
\hline \hline
\end{tabular}

\section{Performance as a Rental Tool}

Using a \$230-per-hour rental charge and a \$40-per-hour standby charge, the required performance for a mud hammer is given in the following table.

\begin{tabular}{lcc}
\hline \multicolumn{3}{c}{ Mud Hammer Performance Requirements } \\
\hline Daily operating cost & $\$ 13,200$ per day & $\$ 19,100$ per day \\
\hline Soft rock & $1.4-1.6$ & $1.3-1.4$ \\
Medium-hard rock & $1.3-1.5$ & $1.2-1.4$ \\
Hard rock & $1.3-1.5$ & $1.2-1.4$ \\
\hline \hline
\end{tabular}

The effect of rig rate on performance requirements is evident in the estimates. At current rates $(\$ 13.2 \mathrm{k} /$ day), a $50 \%$ increase in penetration rate would be necessary for the hammer to be competitive with conventional drilling in soft rock. The performance requirements are reduced in medium-hard and hard rock. We gave the hammer no credit for increased bit life which would reduce the performance requirements.

\section{Performance Requirements as a Capital Item}

We also considered the performance requirements of a downhole mud hammer if purchased instead of rented. Figures 13 through 15 show the projected performance requirements in soft, medium-hard, and hard rock respectively. The upper curve in each of the-figures assumes a daily 
operating cost of $\$ 13.2 \mathrm{k}$ per day. The lower curve assumes an operating cost of $\$ 19.1 \mathrm{k}$ per day. As was found in the analysis of the mud hammer as a rental tool, lower rig rates result in higher performance requirements to be competitive.

Our estimate of the useful life of the mud hammer is 720 hours ( 6 cycles, 120 hours each). Based on Figures 13 through 15, the hammer needs to attain a life of 500 hours to 1000 hours to operate on the flat portion of the curve. Assuming a sufficiently long life, these curves predict lower performance requirements than when the hammer was analyzed as a rental tool. 


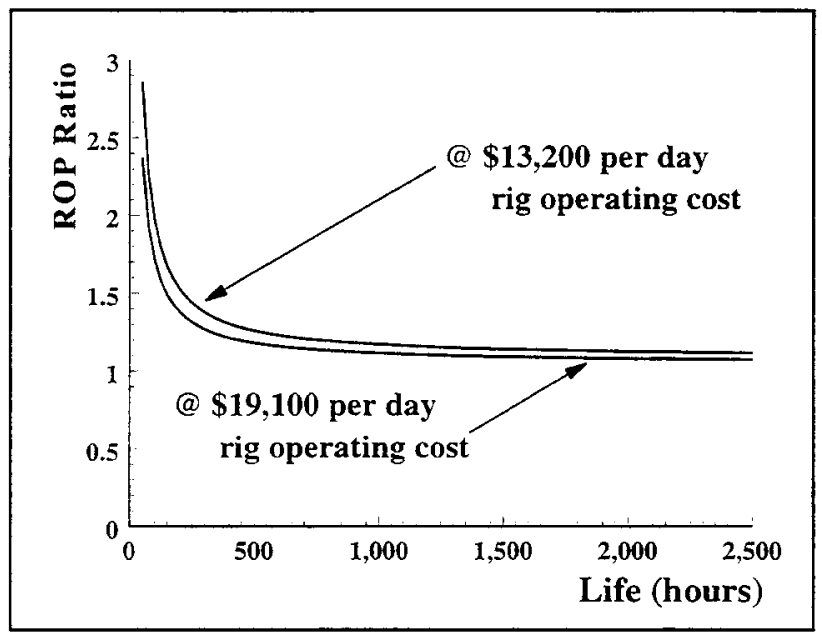

Figure 13: Mud Hammer Performance Requirements in Soft Rock

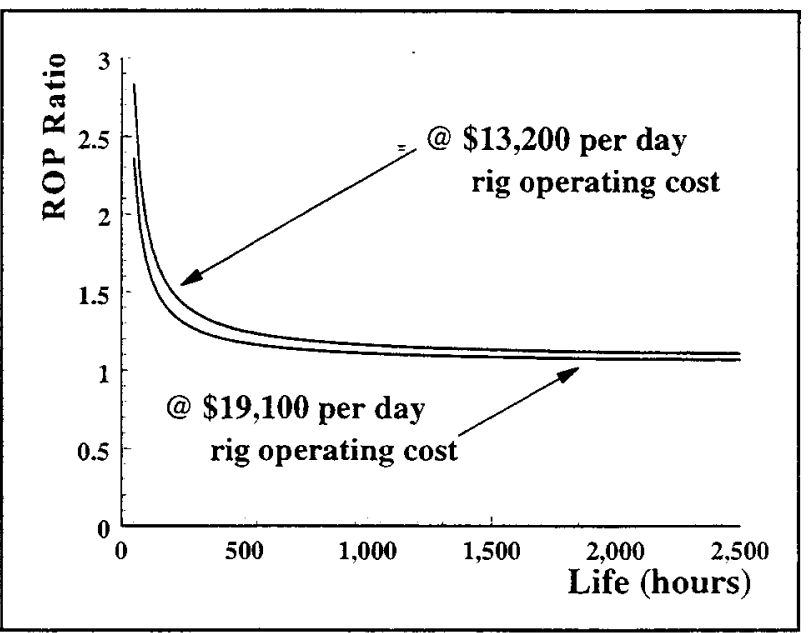

Figure 14: Mud Hammer Performance Requirements in Medium-Hard Rock

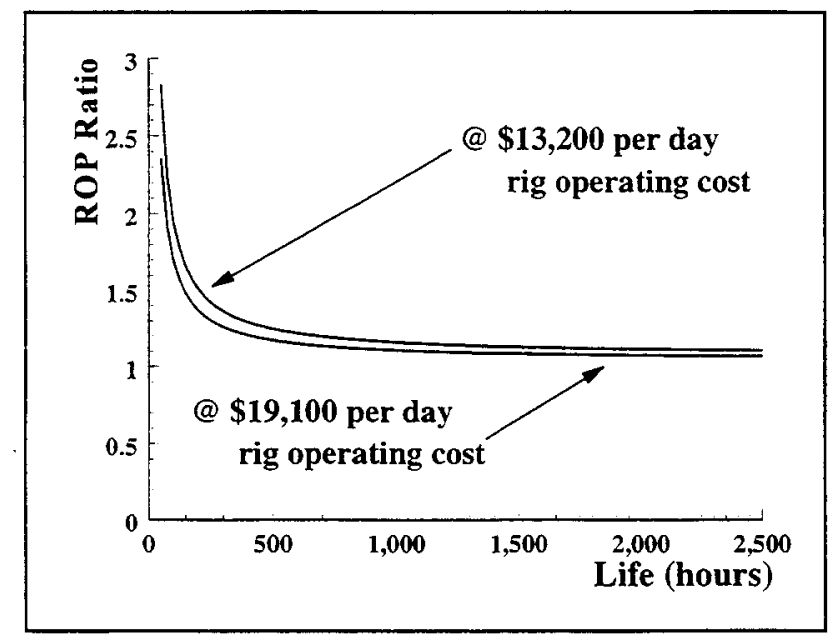

Figure 15: Mud Hammer

Performance Requirements in Hard Rock 


\section{THERMAL SPALLATION - DOWNHOLE SEPARATOR}

\section{Estimated Manufacture and Maintenance Costs}

The following table gives our estimates of the costs associated with downhole separation and thermal spallation. The estimates for the downhole unit are broken out. The surface unit includes pipes, valves, mixing, flow control, fuel storage, and pumps.

\begin{tabular}{cr}
\hline \hline \multicolumn{2}{c}{ Cost Estimates - Downhole Separation System } \\
\hline Downhole unit \\
Main body and bearings \\
Centrifugal separation unit & $\$ 20,000$ \\
Downhole storage and burner & $\$ 45,000$ \\
Turbine and ignition system & $\$ 30,000$ \\
Miscellaneous valves and piping & $\$ 20,000$ \\
Total downhole unit & $\$ 15,000$ \\
Maintenance $\quad$ Useful life & $\$ 130,000$ \\
General maintenance costs & \\
Mean time between repair & $\$ 20,000$ \\
Surface system & 500 hours \\
Mixing and flow control & 20 cycles \\
Fuel tanks and pumps & \\
General maintenance costs & $\$ 40,000$ \\
Maintenance frequency & $\$ 15,000$ \\
Maintenance $\quad$ & 10 years \\
\hline \hline
\end{tabular}

A downhole ignition system is desirable for restart and also to eliminate the necessity of tripping a burning torch. A system that provides ignition spark periodically is attractive to eliminate the need for communication with the surface. The turbine is preferred over a battery system on the basis of life.

The maintenance estimate for the downhole unit is based on comparison to drilling motors. Maintenance on motors is around $\$ 10,000$ every 150 hours to 200 hours for bearings and seals. The thermal spallation unit is significantly more complex and has more moving parts than a 
drilling motor. However, it does not operate in the abrasive environment of drilling mud and it would not be required to carry the axial load of a motor. Thus, the maintenance costs would be expected to be higher, but the mean time between repairs should be longer.

\section{Performance as a Rental Tool}

Based on the estimated costs, we predict that a downhole separation unit would rent for about $\$ 125$ per hour and the stand-by charge would be about $\$ 15$ per hour. This rate is sensitive to the estimated mean-time-between-repair. The rental charge for the surface system, including flow control, fuel tanks, and pumps is estimated to be $\$ 20$ per hour.

Thermal spallation requires air and fuel. Two 1,000 psi, 1,200 scfm compressors are generally brought on site for air drilling operations. We assumed that this capacity could supply air not only for debris lift but also for burning. Kerosene currently costs about $\$ 0.95$ per gallon. Maurer estimates fuel usage in thermal spallation between twenty-five and fifty gallons per hour (Maurer 1980). Rinaldi estimated fuel usage at forty gallons per hour. Using forty gallons of kerosene per hour yields $\$ 38$ per hour for fuel.

Using a total $\$ 145$ per hour rental charge, a $\$ 38$ per hour fuel charge, and a $\$ 15$ per hour standby charge, the required performance for the downhole separation system is given in the following table.

\begin{tabular}{lcc}
\hline \hline \multicolumn{3}{c}{ Performance Requirements - Downhole Separation Tool } \\
\hline Daily operating cost & $\$ 13,200$ per day & $\$ 19,100$ per day \\
\hline Soft rock & $1.1-1.4$ & $1.1-1.3$ \\
Medium-hard rock & $1.1-1.3$ & $1.1-1.2$ \\
Hard rock & $1.1-1.2$ & $1.1-1.2$ \\
\hline \hline
\end{tabular}

These estimates assume that the system can drill from casing-point to casing-point without tripping. In hard rock, little improvement over conventional technology is needed for the downhole separation system to be cost effective. Based on reported performance characteristics, there is little doubt a thermal spallation system could meet these requirements in at least some formations.

\section{Performance Requirements as a Capital Item}

We also considered the performance requirements of a thermal spallation system employing downhole separation if purchased, instead of rented. Figures 16 through 18 show the projected 
performance requirements in soft, medium-hard, and hard rock respectively. The upper curve in each of the figures assumes a basic operating cost of $\$ 13,200$ per day. The lower curve assumes a basic operating cost of $\$ 19,100$ per day. As was found in the analysis as a rental tool, lower rig rates result in higher performance requirements for the thermal spallation system to be competitive.

The requirements shown in Figures 16 through 18 are comparable to those found when the downhole separation unit was considered a rental system. The predicted life of the system is 10,000 hours ( 20 cycles at 500 hours/cycle). As shown in the figures, so long as the system achieves a life on the order of 3,000 hours or longer, it is working against a fairly flat portion of the required-performance curves. 


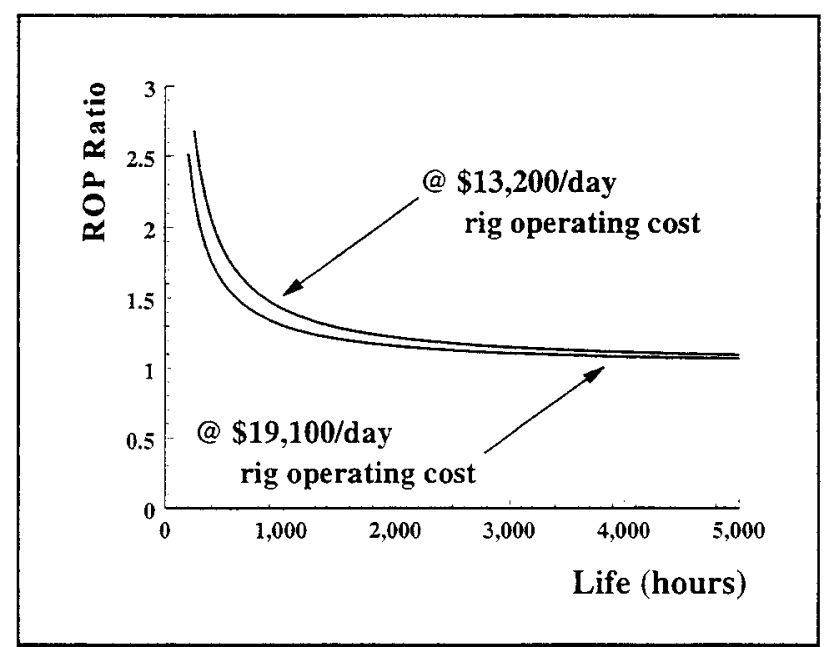

Figure 16: Performance Requirements Downhole Separator / Soft Rock

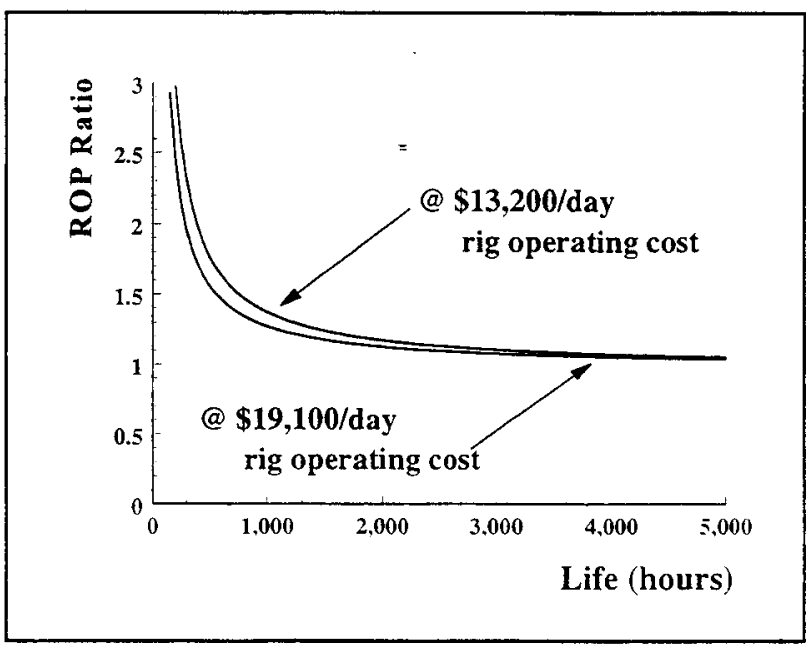

Figure 17: Performance Requirements Downhole Separator / Medium-Hard Rock

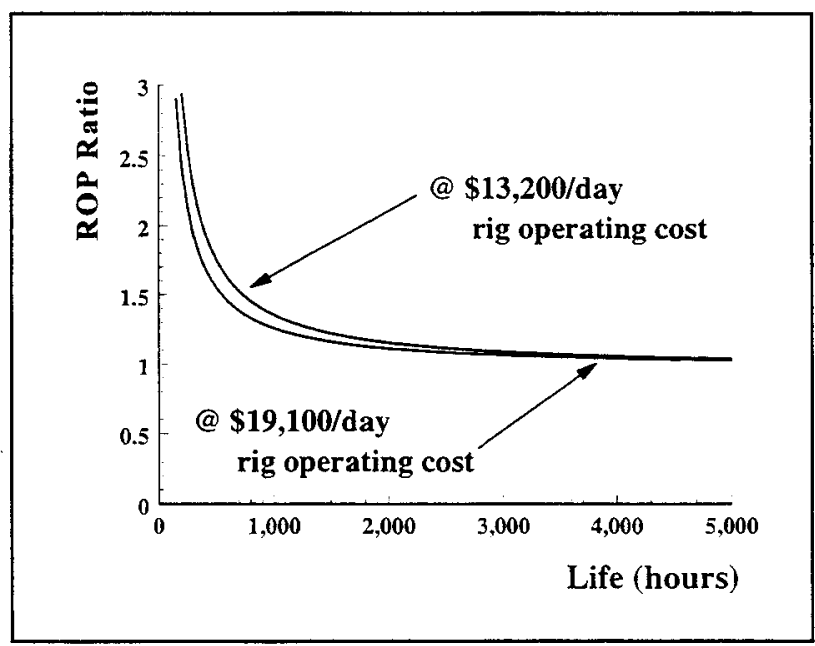

Figure 18: Performance Requirements Downhole Separator / Hard Rock 


\section{SPARK DRILL - TETRA COST ESTIMATES}

Because of the rise times and current levels involved with a spark-drill, ordinary power supplies and transmission lines will not suffice with a spark drilling system. Because of our inability to define these components in sufficient detail, we were unable to make reasonable estimates of their costs. This precludes making assessments of performance requirements.

Moeny gives the following information concerning the expected cost of the system (Moeny correspondence):

- Estimated production cost: about $\$ 1.5$ million

- Lifetime between overhauls: $100-150$ holes $1 \mathrm{~km}$ deep depending on rock properties

- Cost per overhaul: $\$ 100-150 \mathrm{k}$

- Maintenance cost per hole (electrode servicing): $\$ 1-2 \mathrm{k}$

- Drilling rate: 30 meters/hour in hard granite

- Topside power requirements: $1 \mathrm{MW}$

Tetra estimates it will take about $\$ 10 \mathrm{M}$ to develop the first prototype drill, based on research they have conducted to date. 


\section{EXPLOSIVE DRILL}

Costs associated with an explosive drill system were not considered in more than a qualitative manner. These costs include the following:

- the explosives,

- $\quad$ a system to introduce the explosives into the drill string,

- storage and handling facilities,

- an assembly to eject or position the explosives at the hole bottom, and

- $\quad$ additional instrumentation to monitor explosive input and ignition.

There may be a need for the development of a reamer to work behind the explosive system to assure hole gauge. It is also probable that some precautions would be necessary for shock isolation.

The explosives are expected to be relatively expensive. Maurer confirms these expectations with a statement that the high cost could limit application of the system (Maurer 1980). It is also expected that the explosive handling and introductory system would be relatively expensive. Robinson proposed a magazine just above the swivel. This magazine would be reloaded periodically and would alternately inject shape and gauge charges at timed intervals.

In a system designed for the explosive to assist rotary drilling, special bits would be required. In a pure explosive drill system, the bit and at least some of the drill collars could be eliminated, but it may be necessary to include a reamer to assure maintenance of hole gauge.

An explosive drilling system would need all or nearly all of the current surface system. Mud pumps and a mud cleaning system would be necessary. The mast, substructure, drawworks, and hoisting system would be necessary for handling drill pipe and casing. Diesel-electric generators would be needed to drive the surface system. It is not likely that an explosive system would result in lower capital or operating costs than conventional technology. 


\section{ROCK MELTERS - PERFORMANCE REQUIREMENTS}

\section{Energy Consumption}

Regardless of the technology employed, the energy required to melt a given rock is constant. The calculation of this energy yields basic requirements for all rock melting systems. Maurer gives estimates of thermal properties for a number of materials and types of rock (Maurer 1968). Based on Maurer's data, the values in the following table are considered typical.

\begin{tabular}{lr}
\hline \hline \multicolumn{2}{c}{ Representative Thermal Properties of Rock } \\
\hline Specific gravity & $2.6 \mathrm{~g} / \mathrm{cm}^{3}$ \\
Specific heat & $0.24 \mathrm{cal} / \mathrm{g}^{\circ} \mathrm{C}$ \\
Melting temperature & $1300^{\circ} \mathrm{C}$ \\
Latent heat of fusion & $80 \mathrm{cal} / \mathrm{g}$ \\
\hline \hline
\end{tabular}

While the data in the above table can be considered representative of most rock, there are significant exceptions. The melting temperature of sandstone $\left(1650^{\circ} \mathrm{C}\right)$ is $25 \%$ higher, and the heat of fusion of basalt $(100 \mathrm{cal} / \mathrm{gm})$ is $25 \%$ larger, than the values given above. Limestone decomposes to calcium oxide and carbon dioxide, at $895^{\circ} \mathrm{C}$ requiring $425 \mathrm{cal} / \mathrm{g}$. The total energy requirements for melting limestone would be significantly underestimated if no account is made for this decomposition.

If the initial temperature and hole size are specified, the general rock properties can be used to estimate the rate at which energy must be input to the rock to attain a given rate-of-penetration.

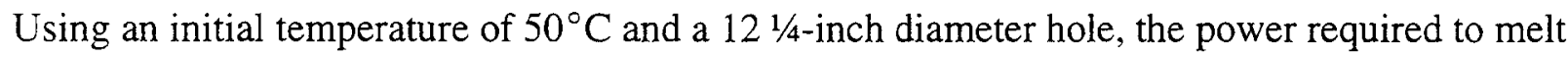
one foot of rock in one hour is about $27 \mathrm{~kW}$. Maurer gives $4,000 \mathrm{~J} / \mathrm{cm}^{3}$ to $5,000 \mathrm{~J} / \mathrm{cm}^{3}$ as the specific energy required to fuse rock (Maurer 1968 / Maurer GRI). The 27-kW power requirement to drill one foot per hour in a $12 \mathrm{~s} / 4$-inch hole translates to $4,200 \mathrm{~J} / \mathrm{cm}^{3}$. The necessary power to melt rock is directly proportional to the rate of melting. If we assume $50 \%$ efficiency in delivering heat to the rock, in excess of $50 \mathrm{~kW}$ of thermal energy must be delivered to the hole bottom for every foot-per-hour of penetration rate we hope to achieve. This value is at the lower end of the necessary energy requirements predicted in the ARPA-Bureau of Mines study (Olson).

Using a 12 1/4-inch diameter borehole as the basis for comparison does not favor rock melting devices. The energy requirements for rock melting vary linearly with penetration rate but by the square of the diameter. Thus a six-inch rock melter would require only a fourth of the energy for 
a given penetration rate as a twelve-inch device $(13 \mathrm{~kW} / \mathrm{fph}$ as opposed to $51 \mathrm{~kW} / \mathrm{fph}$ at $50 \%$ efficiency) and a three-inch device would only require a sixteenth as much energy ( $3.2 \mathrm{~kW} / \mathrm{fph})$.

\section{General Rock Melter Drilling Rig}

Rock melting systems do not need to rotate. Thus, these systems can employ a coiled tubing drilling system without the financial penalty associated with drilling motors. The operating cost of a rig developed specifically to support rock melter systems is estimated to be $\$ 14,600$ per day. The development of the operating cost for the rock melter drilling rig is given in Appendix $C$. All comparisons of rock melting systems were performed against a conventional rig drilling with air at a daily cost of $\$ 18,500$ ( $\$ 12,900$ rig rate, $\$ 2,400$ for compressor rental, and $\$ 6,200$ operator charges less $\$ 3,000$ for mud).

\section{Plasma Arc Drilling System}

We found no reference to work on the use of plasma arc torches for cutting rock since the Bureau of Mines completed a study for ARPA about 20 years ago (Olson). Nevertheless, the cost and operational characteristics presented here reflect current technology.

Plasma arc torches are available with input ratings from thirty kilowatts to around six megawatts. The cost of current devices is about $\$ 1,000 / \mathrm{kW}$. The cost per kilowatt will be slightly higher for smaller units and slightly lower for larger devices. Maintenance, from changing out o-rings to machining and replacing electrodes, is necessary every fifty to fivehundred hours depending on the operating environment. For a non-transfer torch in an enclosed environment, relatively frequent maintenance would be expected. Maintenance on a $50-\mathrm{kW}$ device averages $\$ 2,500$ to $\$ 3,000$ in materials in addition to four to eight hours labor. Maintenance costs will increase with size, but not proportionally. Estimated costs and characteristics for a $50-\mathrm{kW}$ plasma-arc torch are summarized in the following table.

\begin{tabular}{lr}
\hline \multicolumn{2}{c}{ 50-kW Plasma Arc Torch Costs and Characteristics } \\
\hline Initial cost & $\$ 50,000$ \\
Maintenance & $\$ 2,500$ to $\$ 3,000$ materials \\
& and 4 to 8 hours labor every 50 hours \\
Useful life & 1,000 hours \\
\hline \hline
\end{tabular}

We previously estimated that rock melting would require at least $50 \mathrm{~kW} / \mathrm{fph}$. Electric losses of $20 \%$ and thermal losses to the cooling water of $45 \%$ are not unusual for plasma arc torches. 
Using these values yields an estimate of $110 \mathrm{~kW}$ input to the torch for each foot-per-hour of penetration rate. Fuel costs to generate $110 \mathrm{~kW}$ are estimated at $\$ 8$ per hoür.

In addition to the previously discussed assumptions concerning the cost of a drill rig, the performance requirements for a plasma arc drilling system were estimated under the following conditions:

- Two 1000-psi, 1,200 scfm air compressors can supply adequate plasma gas and any additional air needed for debris lift,

- Torch capital costs are $\$ 1,000$ per $\mathrm{kW}$ input capacity,

- Energy requirements are $110 \mathrm{~kW}$ per foot-per-hour penetration rate,

- Fuel costs to generate $110 \mathrm{~kW}$ are $\$ 8$ per hour,

- The torch can drill from casing-point to casing-point, and

- Maintenance costs average $\$ 70$ per hour of operation.

Under these assumptions, no plasma arc drilling system with a torch life less than 4,000 hours was found to be competitive with rotary drilling in hard rock. In soft and medium-hard rock, no plasma arc system with a torch with less than 6-megawatt capacity and less than 10,000 hours life was found to be competitive. Torch life longer than 10,000 hours was not investigated.

At 3,000-hour operational life, it was predicted that a 3.6-megawatt torch could compete with conventional rotary technology (at $\$ 19.1 \mathrm{k}$ per day) if it could improve the penetration rate in hard rock by $130 \%$. At increasingly longer operational life, torch size and ROP requirements are predicted to decrease. The results for torch life up to 10,000 hours are summarized below.

\begin{tabular}{ccc}
\hline \hline \multicolumn{2}{c}{ Plasma Arc Torch - Performance Requirements in Hard Rock } \\
\hline Life (hours) & Size (MW) & ROP Ratio \\
\hline$<3,000$ & - & -- \\
3,000 & $3.6 \mathrm{MW}$ & 2.3 \\
4,000 & $2.5 \mathrm{MW}$ & 1.6 \\
5,000 & $2.1 \mathrm{MW}$ & 1.4 \\
6,000 & $1.9 \mathrm{MW}$ & 1.2 \\
7,000 & $1.8 \mathrm{MW}$ & 1.1 \\
8,000 & $1.7 \mathrm{MW}$ & 1.1 \\
$9,000-10,000$ & $1.6 \mathrm{MW}$ & 1.0 \\
\hline \hline
\end{tabular}




\section{Cost \& Performance/Rock Melters}

\section{Laser-Thermal and E-Beam Drilling Systems}

No cost estimates were made for either laser-thermal or e-beam drilling systems.

\section{Electric Heater Drilling System Costs}

Los Alamos National Laboratory has performed a significant amount of research on the use of electric heaters for drilling (Altseimer 1974 / Altseimer 1976). Altseimer gives a system description and compares costs of drilling with rock melting devices to the costs of wells drilled with conventional technology. Estimated bit cost and life are given below.

\begin{tabular}{lr}
\hline \hline & Electric Heater Bit Cost and Life \\
\hline Extruding bit cost & $\$ 28,000$ \\
Bit life & 1,500 hours \\
\hline
\end{tabular}

Altseimer gives a relationship between the cost and size of rock-melting bits (Altseimer 1976). This relationship predicts a cost of about $\$ 14,000$ for a twelve-inch bit. To allow for general inflation since 1976, we used a cost of $\$ 28,000$. Altseimer states that bit life up to 100 hours had been achieved with experimental bits. It is doubtful that much consideration was given to improving bit life in a development program. Thus, it is likely that bit life could be extended significantly beyond this value. We used 1,500 hours for bit life.

We previously estimated that rock melting would require at least $50 \mathrm{~kW} / \mathrm{fph}$. Assuming additional electric and thermal losses of $50 \%$ yields $100 \mathrm{~kW}$ input to the rock melter for each foot-per-hour of penetration rate. Fuel costs to generate $100 \mathrm{~kW}$ are estimated at $\$ 7$ per hour.

Because of corrosion problems, nitrogen is used for the drilling fluid with the rock melter. The following table gives the costs associated with the use of nitrogen.

\begin{tabular}{lr}
\hline \hline \multicolumn{2}{c}{ Nitrogen and Equipment Costs } \\
\hline Equipment delivery & $\sim \$ 1$ per mile \\
Equipment rental & $\$ 250$ per day \\
Field support & $\$ 15$ per hour per person \\
Nitrogen & $65 \mathrm{~d}$ per $100 \mathrm{ft}^{3}$ \\
\hline \hline
\end{tabular}

In evaluating the electric heater system, we made no charge for equipment delivery. Some distributors stated that they prefer two people with the equipment, but we assumed one person for field support. Wholesale costs for nitrogen run from $49 \mathrm{~d} / 100 \mathrm{ft}^{3}$ to $60 \mathrm{~d} / 100 \mathrm{ft}^{3}$, depending on 
purity. The retail price for nitrogen in the above table $\left(65 \mathrm{~d} / 100 \mathrm{ft}^{3}\right)$ assumes the purchase of large quantities of other than top grade material.

At $65 \mathrm{~d} / 100 \mathrm{ft}^{3}, 1,000 \mathrm{scfm}$ of nitrogen will cost $\$ 390$ per hour. Charges of this magnitude could support the investigation of methods to use the exhaust from the generators, instead of nitrogen, for drilling fluid. The exhaust should be relatively free of oxygen though it may require filtering for other elements (particularly $\mathrm{CO}_{2}$ ) and it would not be low temperature.

To estimate performance requirements, we used the rock melter rig cost discussed previously with $23 / 8$-inch by $3 / 16$-inch tubing would be adequate. This reduced tubing size reduces rig operating costs by $\$ 500$ per day.

Based on these assumptions, at current day rates ( $\$ 13.2 \mathrm{k}$ per day) the rock melting bits are not competitive in soft or medium-hard rock under any condition and they needed to more than double current penetration rates to be competitive in hard rock drilling. At $\$ 19.1 \mathrm{k}$ per day for conventional drilling, this system is still not competitive in soft rock. At this same cost for conventional technology, the electric heater would need to increase penetration rates by $60 \%$ in medium-hard rock and by $30 \%$ in hard rock. 
A plasma arc drilling system will require multi-channel conduit. One channel is needed for cooling liquid and another for plasma gas. A third fluid conduit to carry air may also be necessary if the combined volumes of cooling liquid and plasma gas are not adequate to lift material from the hole. At least two electric lines are required to maintain the torch. Additional lines for command and control may also be needed.

The plasma arc torch will need mechanical support in the hole. For essentially vertical holes, this may be accomplished with a simple rolling or bow-spring support system. A more elaborate thruster-retractor-director would be required for high angle drilling and may be desirable for all drilling. Either support system should provide a means of aiming the torch as maintenance and control of direction will be accomplished in this manner. The operational environment for the torch mount would include exceptionally high temperatures.

A plasma arc torch can definitely generate sufficient output to melt rock. It may also be possible to use the torch as a spallation device by operating at a greater stand off. Since the torch would not be in contact with the rock, a method of measuring and controlling stand-off distance would be needed. The only way to avoid vaporizing rock is for the flow of the plasma gas to lift the melted rock off the bottom. If this occurs, the molten rock may then solidify and be lifted from the hole by the plasma gas in combination with the ejected cooling fluid. Additional air flow may also be required. 


\section{PULSED-LASER WATER-JET}

Sellar performed an economic analysis of the pulsed-laser water-jet system for EPRI (Sellar EPRI). The costs in the following table are based primarily on that study.

\begin{tabular}{lr}
\hline \hline \multicolumn{2}{c}{ Pulsed-Laser Water-Jet System Costs and Characteristics $^{2}$} \\
\hline Basic system $^{*}$ & $\$ 900,000$ \\
Rating $^{*}$ & $8 \mathrm{~kW}$ \\
Efficiency $^{*}$ & $10 \%$ \\
Maintenance & $\$ 45,000$ per year \\
Fiber optic cable & $39 \pm$ per meter \\
\hline$* \quad$ John G. Sellar, Rock Excavation Using a Pulsing Laser-Water Jet, EPRI Center for \\
Materials Production, Pittsburgh, PA, CMP Report Number 93-7, November 1993 \\
\hline \hline
\end{tabular}

The system described by Sellar employs an 8-kW, neodymium based laser, hosted in a yttrium, aluminum, garnet crystal (Nd:YAG). Sellar gives $\$ 900,000$ as the cost of the system. This is extrapolated from the cost of a 2-kW continuous wave laser and includes 500 feet of fiber optic cable. Sellar also allowed $\$ 3,000$ for water pumps that we did not include. This amount is lost in the uncertainty in the estimate of the overall cost; and, in any event, drill rigs are not generally lacking for pump capacity.

Sellar gave no estimates of maintenance costs. The $\$ 45,000$ per year given in the table is based on $5 \%$ of initial cost per year. Based on general experience, this is probably an underestimate. We assumed the system could be set up in a building equivalent to a generator house and run from the rig floor. No special provisions for environmental controls were made.

Sellar gives $10 \%$ as the power efficiency of the system. The $80-\mathrm{kW}$ load is smaller than needed for turning drill pipe. This can be handled by the standard rig power system and will cost about $\$ 6$ per hour in fuel charges.

Additional fiber-optic cable is needed for a drilling system. Coated fiber-optic cable to work in the 1,300-nm wavelength range can be purchased for $39 \mathrm{~d}$ per meter or about a penny per inch. Two cables are needed: one for the pulsed laser and another for the monitoring laser.

Since rotation is not required, the pulsed-laser water-jet system can employ a coiled tubing rig without the additional cost for drilling motors. Two fluid conduits are needed: one conduit for clear water and a second for drilling mud or air to lift debris. We assumed dual-conduit coiled tubing with an inner $13 / 8$-inch tube to carry fresh water. The fiber-optic cables would be

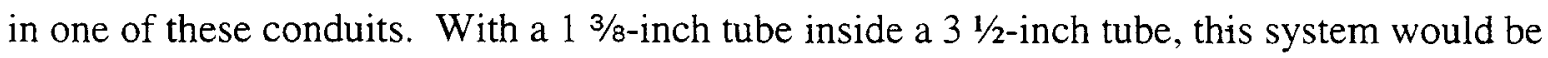


limited for flow capacity. The additional tubing, the fiber-optic cables, and the fuel charges increase the estimated cost for the coiled tubing rig by $\$ 600$ per day.

Based on the above discussion of costs, Figures 19 illustrates the performance requirements for the pulsed-laser water-jet system in soft rock, Figure 20 in medium-hard rock, and Figure 21 in hard rock. The upper curve in each figure gives the performance requirements to be competitive with a conventional rig operating at $\$ 13,200$ per day. The lower curve gives the requirements to be competitive with a conventional rig operating at $\$ 19,100$ per day.

As shown in Figures 19 through 21, the pulsed-laser-water jet needs a system life on the order of 3,000 hours or longer to reduce penetration rate requirements. 


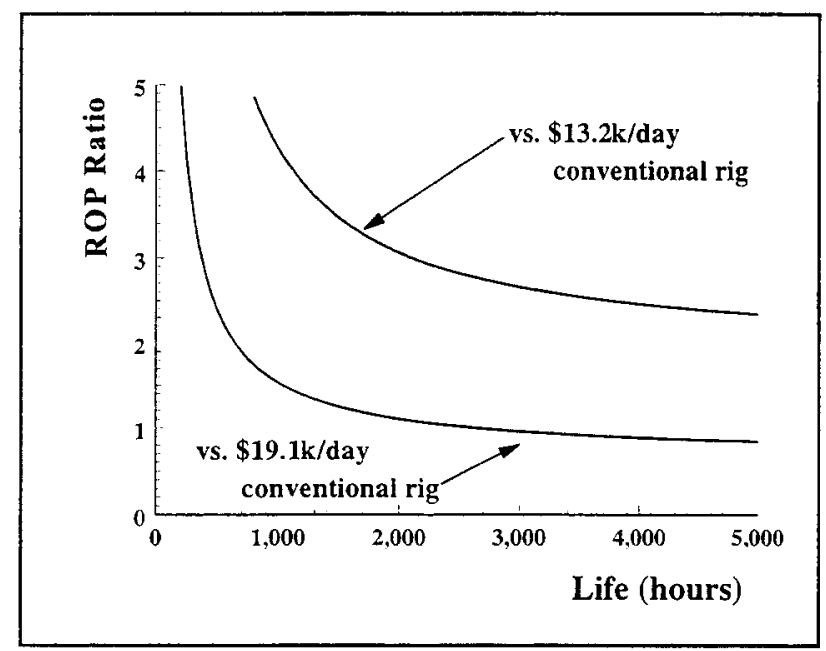

Figure 19: Pulsed-Laser Water-Jet

Performance Requirements in Soft Rock

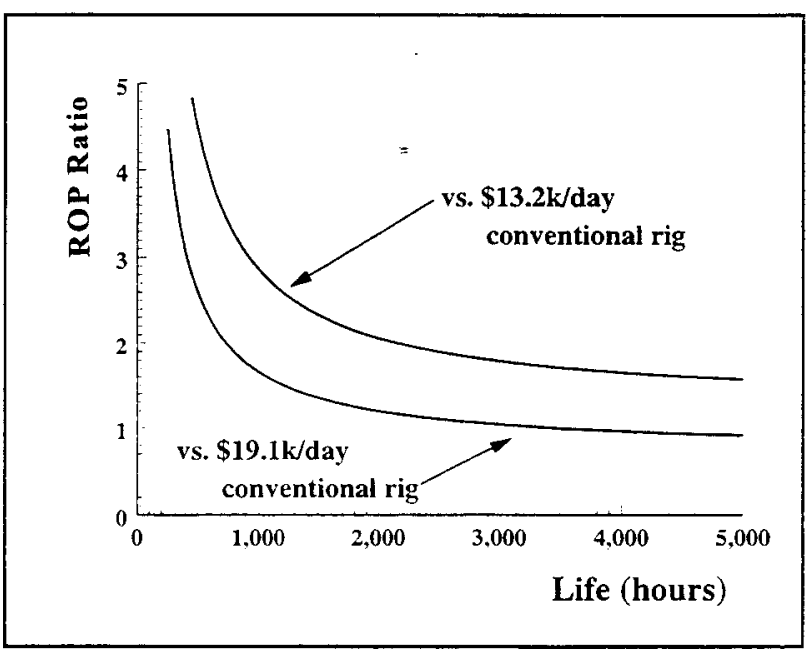

Figure 20: Pulsed-Laser Water-Jet

Performance Requirements in Medium-Hard Rock

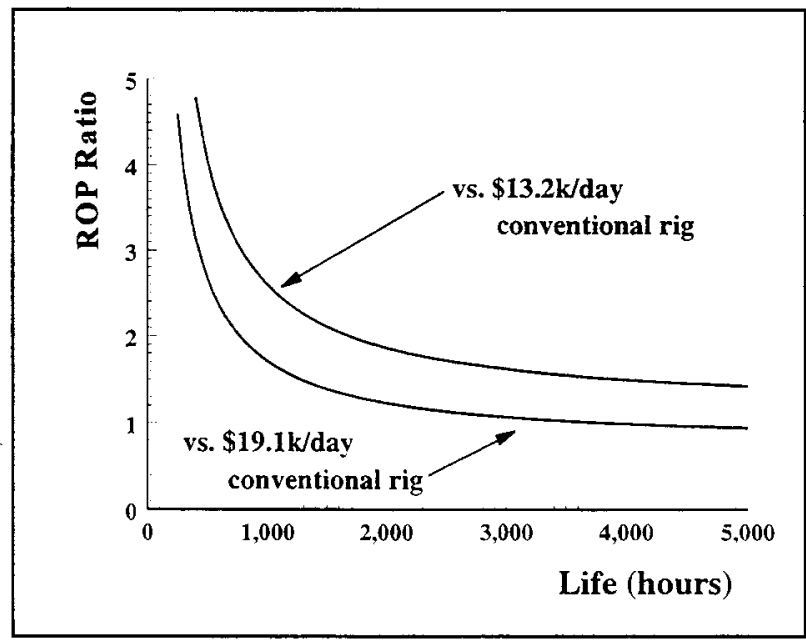

Figure 21: Pulsed-Laser Water-Jet

Performance Requirements in Hard Rock 
Cost \& Performance/Pulsed-Laser Water-Jet

page V-44 


\section{DEVELOPMENT STATUS}

In the remaining pages of this report, we group various concepts and systems according to the technical difficulty of building and testing a unit. The groupings are not meant to be a statement concerning commercial or technical potential; they are meant only as an indication of the relative difficulty of building a given system or developing a concept and preparing for field testing.

\section{Difficulty of Technical Development}

\section{Group I}

Jet-assisted / positive displacement downhole intensifier

Mud hammer

Rock melter - electric heater

Projectile-assisted drilling

General thermal spallation

Jet-assisted / dual-channel pipe

Jet or jet-assisted - full pressurization

\section{Group II}

Jet-assisted / centrifugal downhole intensifier

Jet assisted / multi-channel conduit

Fully-integrated coiled tubing drill rig

Explosive capsule drill

Explosive shape and gage charges

Explosive-assisted rotary drilling

\section{Group III}

Thermal spallation - downhole separator

Spark drill

Pulse laser-water jet

Rock melter - laser thermal

Liquid explosive drill

Rock melter - e-beam and plasma arc torch

Thermally-assisted drilling - microwaves

Thermal spallation - super critical liquid 


\section{GROUP I}

The systems and concepts in Group I are considered closest to technical feasibility. In general either (1) these systems and concepts are currently close to, or in, field testing; (2) these systems and concepts have previously been tested and are considered relatively easy to revive; or (3) it would be possible to order most if not all of the parts and subsystems necessary to build and test the system.

\section{Jet-Assisted / Positive Displacement Downhole Intensifier}

FlowDril has developed a positive displacement downhole intensifier that is currently being tested. Information concerning this device can be obtained from:

FlowDril Corporation

$21414-68^{\text {th }}$ Avenue South

Kent, WA 98032

\section{Mud Hammer}

There have been a number of mud hammers developed and tested including efforts by Bassinger and Amoco. Novatek has developed a mud hammer that is currently being tested. Information concerning the Novatek device can be obtained from:

Novatek

2185 South Larsen Pkwy

Provo, UT 84606

\section{Rock Melting - Electric Heater}

Scientists at Los Alamos National Laboratory (LANL) developed an electric-heater drill at least to the stage of lab tests in the 1970's. The infrastructure necessary to build and test an electric heater is still essentially in place and there is a renewed effort directed toward small-hole environmental drilling using this technology. Information concerning this effort can be obtained from: 
Los Alamos National Laboratory

Earth and Environmental Sciences Division

Mail Stop H-865

Los Alamos, NM 87545

\title{
Projectile Assisted Drilling
}

Tround International developed and tested a projectile-assisted drill in the 1970's and early 1980 's. There is no current activity by this company, but it is not believed that it would be difficult to revive this effort. Information concerning the Tround system can be obtained from:

\section{Tround International \\ 1899 L Street NW Suite 500 \\ Washington, DC 20036}

\section{General Thermal Spallation}

Included in this category are thermal spallation systems similar to those developed by Linde and Browning. Most of the commercial activity by Linde was terminated by the mid-1970's and Linde officially dropped this line of business in 1983. Browning Engineering is no longer active in the marketing of thermal spallation drills. However, these systems were fully developed and used commercially. It would not be exceedingly difficult to build and test a spallation system of this type. General information concerning thermal spallation systems can be obtained from:

Los Alamos National Laboratory

Mail Stop D443

Los Alamos, NM 87545

or

\author{
MIT Energy Laboratory \\ Massachusetts Institute of Technology \\ 77 Massachusetts Avenue \\ Room E40-455 \\ Cambridge, MA 02139-4307
}

\section{Jet-Assisted / Dual-Channel Pipe}

FlowDril developed and tested a jet-assisted drilling system employing high-pressure surface pumps and a parallel high-pressure flow path from the swivel to the bit. This system was fully 
tested and demonstrated increased productivity. FlowDril is not currently pursuing development of this system, but their past efforts demonstrate engineering and technical feasibility.

Information concerning the FlowDril system can be obtained from:

\author{
FlowDril Corporation \\ $21414-68^{\text {th }}$ Avenue South \\ Kent, WA 98032
}

\title{
Jet-Assisted or Jet Drilling - Full Pressurization
}

Both FlowDril and Exxon, among others, have investigated pressurizing the entire mud stream for high-pressure jet drilling. Exxon took a system to field test and demonstrated increased productivity at least to depths of 6,000 feet. The authors know of no company or individual currently attempting to employ full pressurization as the primary cutting mechanism in full-sized holes. However, building and testing such a system should not present too great an obstacle. Haliburton has the necessary pumps. The major problem would be finding or building a swivel to handle the high-pressure flow. This technology could be particularly useful for drilling short radius turns.

\section{GROUP II}

When compared to the systems in Group I, the systems and concepts in Group II will require some additional technical development and engineering design before build and test. Some of these systems are in conceptual design; while others have been tested, but it is not certain that the necessary expertise and materials to revive the systems can be easily obtained.

\section{Jet-Assisted / Centrifugal Downhole Intensifier}

Maurer Engineering has taken this concept through engineering design and analyses, but no hardware has been produced. Information concerning this system can be obtained from:

Maurer Engineering, Inc.

2916 West T.C. Jester

Houston, TX 77018-7098

\section{Jet-Assisted / Multi-Channel Conduit}


This is the MultiCon ${ }^{\mathrm{TM}}$ system. With the exception of the bottom-hole assembly, engineering design is fairly complete. FlowDril's experience with the dual-channel system has demonstrated the general concept, however, the non-symmetrical nature of the flow paths and the use of reverse circulation in the MultiCon ${ }^{\mathrm{TM}}$ system could present unforseen difficulties. Information concerning this system can be obtained from:

TeleJet Technologies, Inc.

3030 LBJ Freeway Suite 1210

Dallas, TX 75234

or

Drilling Technology, Inc.

5808 Wavertree Suite 1000

Plano, TX 75093-4513

\title{
Fully-Integrated Coiled-Tubing Drill Rig
}

Newman has proposed a hybrid rig employing coiled tubing (Newman and Doremus). This concept might possibly be classified in Group I. The authors have discussed a fully-integrated coiled tubing rig that employs hydraulic jacks for handling casing. This concept needs overall design and definition, and the system to handle casing needs to be developed. This system is Group II so long as the authors' assumption of $4 \frac{1}{1 / 2}$-inch tubing is not considered. The development of composite materials to prevent plastic deformation of tubing is a Group III project. Information concerning coiled-tubing drilling and drill rigs can be obtained from:

\author{
CTES \\ 9870 Pozos Lane \\ Conroe, TX 77305-2178
}

\section{Explosive Capsule, Shape and Gage Charges, and Explosive-Assisted Rotary}

Systems employing explosive capsules, shape and gage charges, and explosive-assisted rotary concepts were all developed and tested in the 1960's and 1970's. Maurer describes each in previous publications (Maurer 1968 and 1980). There have been no serious efforts in explosive drilling since that time. While the use of explosives for drilling has been demonstrated, it would require significant effort to revive this concept.

\section{GROUP III}




\title{
Development Status
}

The systems and concepts in Group III would require significant definition, research, and development before they could begin field testing. There may be some level of effort with some of these systems or advocates may be active.

\section{Thermal Spallation - Downhole Separator}

This system is a step toward making thermal spallation compatible with current drilling equipment. At least two concepts for achieving separation, vortex and centrifugal, are possible. Worldrill has applied for a European patent on a device employing vortex separation. To the authors' knowledge, no hardware has been built and no tests have been performed. Information concerning the use of downhole separation in thermal spallation can be obtained from either of the sources listed previously for general thermal spallation or from the following:

\author{
Worldrill, England \\ Contact: \\ Newport Financial Limited \\ 2811 McKinney Avenue Suite 208 \\ Dallas, TX 75204
}

\section{Spark Drill}

The use of electric arcs underwater to generate a high-pressure pulse to break rock has been demonstrated. Sandia National Laboratories investigated the use of this concept as a drilling system in the 1970's and found significant problems in energy transmission, arc over, and cutting ability at depth. Tetra Corporation has a patent on a system that is claimed to have overcome these problems. Information concerning this effort can be obtained from:

Tetra Corporation

3701 Hawkins St. NE

Albuquerque, NM 87109-4512

\section{Pulse Laser-Water Jet}

This system has been proposed and the ability to break rock with a relatively low power laser pulse has been demonstrated. Rock destruction has been shown to be magnified by the presence of water on the rock face. Resonance of a rock face has been demonstrated and measured. However, transmission of the laser through a laminar flow stream combined with the 
simultaneous measurement of resonance and tuning of the pulse laser has not been demonstrated. Information concerning this system can be obtained from:

PowerPulse Systems, Inc.

6045 W. Evans Place

Lakewood, CO 80227

\section{Rock Melter - Laser Thermal}

Both Maurer (Maurer 1968, Maurer 1980) and the Bureau of Mines (Olson and Olson) discuss the use of lasers in cutting kerfs. There has been a proposed project at WestinghouseHanford to develop a laser drilling system for small-hole environmental applications. Information concerning this effort can be obtained from:

Westinghouse Hanford Co.

PO Box 1970

MSIN H6-32

Richland, WA 99352

\section{Liquid Explosive Drill}

Maurer discusses the development of liquid explosives in drilling (Maurer 1968 and 1980). Fundamental and serious problems with removal of the debris were encountered.

\section{Rock Melter E-Beam and Plasma Arc Torch}

Maurer discusses the use of e-beam guns and plasma arc torches in drilling (Maurer 1968 and 1980). An ARPA sponsored project in tunneling that employed an e-beam gun fell short of field tests in the 1970's (Olson and Olson). Problems with beam scattering have been encountered in past efforts. Tests of plasma torches to cut kerfs have been performed (Olson and Olson). Neither the plasma arc torch nor the e-beam gun have advanced beyond bench tests.

\section{Thermally-Assisted Drilling - Microwave}

The Bureau of Mines has experimented with the use of microwave energy to precondition rock before cutting (Lindroth). However, this concept has not been developed as a downhole drilling tool. Significant engineering problems exist in either generating the microwave energy downhole or in surface generation and transmission downhole. 
Development Status

\section{Thermal Spallation - Super Critical Liquid}

This concept has been discussed but, to the authors' knowledge, there have been no serious efforts to define the system. 


\section{CONCLUSIONS}

In the course of this study, we investigated the history, costs, technological characteristics and performance requirements for a wide variety of advanced drilling concepts and systems as well as current rotary drilling technology.

\section{COMMON PROBLEMS}

By taking a systems approach, we identified a number of problems common to a variety of drilling systems, including rotary technology. These problems include the need for multi-channel conduit and electrical transmission downhole, maintenance of the borehole gauge, control of stand-off distance, drilling trajectory control, well control and wellbore stability in the absence of drilling mud, and reduced drilling effectiveness with depth. A solution to any one of these problems could help a number of concepts.

\section{SYSTEM COSTS}

The investment necessary to build a land-based rig capable of drilling to 18,000 feet from all new materials and equipment is over nine-million dollars with the vast majority of this expenditure in the surface system. The size, cost, and complexity of the rig's surface system is little affected by the way we cut rock.

The sizes and specifications for the mast, substructure, and drawworks are determined by the need to handle casing. The requirements of the mud pumps, pits, and mud-cleaning equipment are determined by the size of the cuttings and the rate at which they are produced. About the only equipment that depends directly on how we cut rock is the bottom hole assembly. It is doubtful that any novel rock cutting mechanism will cost less than drill collars, stabilizers, and bits. Overall, it is unlikely that significant savings in materials and equipment can be achieved by simply changing the way we cut rock.

Similar conclusions are reached when daily operational costs are considered. The numbers and skills of the crew are determined by the surface equipment. Rig insurance is determined by capital investment; liability insurance and workman's compensation costs are proportional to payroll. While turning on bottom, the power delivered to the rotary table or top drive is generally less than $30 \%$ of the total power usage on the rig. And, in any event, all rock-cutting mechanisms require energy delivery in some form. 


\section{Conclusions}

Reduction of drilling costs can occur only by changing the nature of the drilling system or by increasing the rate of penetration. Neither capital investment nor daily operational costs appear to be significantly affected by the way rock is cut. Any increase in capital or operating costs must be offset by a commensurate increase in penetration rate. Unconventional rock-cutting mechanisms can reduce costs only if they can increase ROP.

\section{PERFORMANCE REQUIREMENTS}

Analyses of advanced cutting concepts indicate that many can be competitive with current technology if they increase the penetration rate by factors ranging from just over one to about five. Based on published data, this performance is within reach of some systems, particularly mud hammers, jet-assisted drilling, projectile-assisted drilling, and thermal spallation. There have been considerable development efforts aimed at each of these systems, but none has attained widespread commercial success.

Based on current daily drilling charges, a mud hammer needs to increase the penetration rate by $30 \%$ to $60 \%$ to offset the initial capital investment and costs of periodic maintenance. Published data indicate that both the Bassinger hammer (Brown 1950) and the hammer developed by Pan American Petroleum Corporation (Vincent and Wilder 1969) were capable of meeting or exceeding these performance requirements.

Jet-assisted drilling encompasses a wide variety of systems and concepts ranging from downhole tools to be added to a conventional rotary system to the use of surface pressure intensifiers with a parallel high pressure flow path to completely new rigs designed specifically for jet-assisted drilling. Depending on the configuration, penetration rate increases ranging from $50 \%$ to about five times are necessary for these systems to compete economically with conventional rotary technology. Work performed by FlowDril has demonstrated $100 \%$ increases in penetration rate for jet-assisted systems to depths of 10,000 feet (Cure 1991; Veenhuizen 1993).

Tround has completed a major development in projectile-assisted drilling. We estimate that this system would need to increase penetration rate by about $100 \%$ to be competitive with conventional rotary technology. Tround has published data indicating that their system can meet and exceed these requirements (Juliana; Mining Journal 1984).

Both the Linde Division of Union Carbide and Browning Engineering have developed thermal spallation drilling systems. We estimate that a thermal spallation system based on a downhole separator would need to increase the penetration rate by $10 \%$ to $40 \%$ to be economically competitive with current rotary technology. Concurrent work at Los Alamos 
National Laboratory and at Browning Engineering Corporation indicated that thermal spallation was capable of penetration rates four to eight times faster than conventional rotary technology (Williams 1985).

The discussion of performance requirements in the previous paragraphs is based on the break-even cost for the advanced systems. Because of risk, simply matching the performance of rotary technology will not likely be sufficient for any system to gain a share of the drilling market. Analysis indicates that the possible savings due to faster penetration rate are significantly increased in regions where current technology can not drill faster than fifteen or twenty feet-per-hour. This hard-rock drilling is a particularly attractive target for systems whose primary advantage is higher penetration rates. 
Conclusions

page VII-4 


\section{REFERENCES}

1. John H. Altseimer, Geothermal Well Technology and Potential Applications of Subterrene Devices - A Status Review, Los Alamos National Laboratory, LA-5689-MS, August 1974

2. John H. Altseimer, Technical and Cost Analysis of Rock-Melting Systems for Producing Geothermal Wells, Los Alamos National Laboratory, LA-6555-MS, November 1976

3. Ross Bassinger, Rotary Percussion Drilling ... a Review and a Prediction, The Oil and Gas Journal, pgs. 111 and 112, October 12, 1950

4. Robinson Brown, The Bassinger Rotary Percussion Drill, The Petroleum Engineer, December 1950

5. A. T. Burgoyne, Jr., K. K. Milheim, M. E. Chenevert, and F. S. Young, Jr., Applied Drilling Engineering, Society of Petroleum Engineers, 1986

6. T. Butler, P. Fontana, and R. Otta, FlowDril Corp., A Method for Combined Jet and Mechanical Drilling, SPE paper 20460, September 1990

7. Joe Calaman, Linde Air Division/Union Carbide retired, personal correspondence

8. G. L. Chahine, P. F. Genoux, V. E. Johnson, G. S. Frederick, Analytical and Experimental Study of the Acoustics and the Flow Field Characteristics of Cavitating Self-Resonating Water Jets, Sandia Report SAND84-7142, September 1984

9. John H. Cohen, Gefei Liu, and Curtis E. Leitko, Maurer Engineering, John Aslakson, Gas Research Institute, Steve Kennedy and Lawrence Lee, REDA Pump Company, HighPressure Pump for Jet-Assisted Drilling, ASME, PG-Vol. 65 Drilling Technology, Book No. H00920-1995

10. Mike Cure, Grace Drilling Co., and Pete Fontana, FlowDril Corp., Jet-Assisted Drilling Nears Commercial Use, Oil \& Gas Journal, March 11, 1991

11. I. M. Daniel, R. E. Rowlands, and T. J. Labus, IIT Research Institute, Chicago, IL, Photoelastic Study of Water Jet Impact, Second International Symposium on Jet Cutting Technology, Cambridge, April, 1974

12. F. H. Deily and J. K. Heilhecker, Exxon Production Research Co., W. C. Maurer, Maurer Engineering, and W. W. Love, Brandt Co., Five Wells Test High-Pressure Drilling, The Oil and Gas Journal, July 4, 1977

13. U. Deutsch, C. Marx, and H. Rischmüller, Evaluation of Hammerdrill-Potential for KTB, K. Fuchs, ed. Springer-Verlag, Berlin 


\section{References}

14. Drilling Research Division, Drilling Research on the Electrical Detonation and Subsequent Cavitation in a Liquid Technique (Spark Drilling), Sandia Laboratories Energy Report, SAND76-0086, April 1976

15. R. Feenstra, A. C. Pols, and J. van Stevenick, Rock Cutting by Jets, Mining Engineering, pages 41-47, June 1974

16. R. Feenstra, A. C. Pols, and J. Stevenick, Rock Cutting by Jets: A Promising Method of Oil Well Drilling, 1974 SPE paper \# 4923

17. M. Friedman, J. Handin, N. G. Higgs, J. R. Lantz, and S. J. Bauer, Strength and Ductility of Room-Dry and Water-Saturated Igneous Rocks at Low Pressures and Temperatures to Patrial Melting, Sandia Report SAND80-7159, November 1980

18. Carl Gatlin, Petroleum Engineering: Drilling and Well Completions, Prentice-Hall, Inc. 1960

19. Sue J. Goff, Gilles Y. Bussod, Kenneth Wohletz, Aaron Dick, and John C. Rowley, Rock Melting: A Specialty Drilling System for Improved Hole Stability in Geothermal Wells, Los Alamos National Laboratory

20. John T. Finger, Sandia National Laboratories, Investigation of Percussion Drills for Geothermal Applications, Journal of Petroleum Technology, December 1984

21. David E. Fogelson, Twin Cities Mining Research Center, U.S. Bureau of Mines, Advanced Fragmentation Techniques

22. S. E. Forman and G. A. Secor, Bell Laboratories, The Mechanics of Rock Failure Due to Water Jet Impingement, SPE Journal, February 1974

23. David A. Glowka, Development of a Method for Predicting the Performance and Wear of PDC Drill Bits, Sandia Report SAND86-1745, September 1987

24. Bernie Hill, Dardick's Machine Gun Design Modified to Drill Rock, The Gun Report, December 1983

25. D. W. Holm, MND Drilling Corp., Economics of the U.S. Onshore Contract Drilling Industry, 1989 SPE paper \# 18645

26. D. W. Holm, MND Drilling Corp., The Economics and Related Factors Involved in the Replacement of Land Drilling Rigs, 1992 SPE paper 23864

27. Allen Howland, Machine Gun Bit Speeds Air Drilling, Drilling Technology, August 1984

28. James N. Juliana, Tround International, personal correspondence 
29. H. A. Kendall and W. C. Goins, Jr., Gulf Research and Development Co., Design and Operation of Jet-Bit Programs for Maximum Hydraulic Horsepower, Impact Force or Jet Velocity, presented at the $34^{\text {th }}$ Annual Fall Meeting of the SPE, October 1959

30. Mike Killalea, editor, High Pressure Drilling System Triples ROPS, Stymies Bit Wear, Drilling, March/April, 1989

31. J. J. Kolle, QUEST Integrated Inc., and R. Otta and D. L. Stang, FlowDril Corp., Laboratory and Field Testing of an Ultra-High-Pressure, Jet-Assisted Drilling System, SPE paper 22000, March 1991

32. D. P. Lindroth, W. R. Berglund, R. J. Morrell, and J. R. Blair, U. S. Bureau of Mines, Twin Cities Research Center, Microwave-Assisted Drilling in Hard Rock, Mining Engineering, September 1992

33. Jeff Littleton, editor, Jet Drilling Technology Advances, Drilling, November/December 1987

34. Pamela McClintock, A Marriage of Guns and Geology, Washington Times, February 20, 1984

35. Michael C. McDonald, James M. Reichman, Kenneth J. Theimer, Flow Technology Company, Evaluation of High Pressure Drilling Fluid Supply Systems, Sandia National Laboratories Contractor Report SAND81-7142

36. Rich McNally, associate editor, Increasing Penetration Rates with High-Pressure Mud, Petroleum Engineer International, December 1987

37. W. C. Maurer, Jersey Production Research Co., The "Perfect-Cleaning" Theory of Rotary Drilling, Journal of Petroleum Technology, November 1962

38. William C. Maurer, Novel Drilling Techniques, Pergamon Press, Library of Congress No. 6817738,1968

39. William C. Maurer, Advanced Drilling Techniques, Petroleum Publishing Company, Tulsa, OK, ISBN 0-87814-117-0, 1980

40. William C. Maurer, Eric Anderson, Michael Hood, George Cooper, and Neville Cook, Deep Drilling Basic Research, Gas Research Institute, Chicago, Il, GRI-90/0265

41. William C. Maurer and Joe K. Heilhecker, Esso Production Research, Houston, TX, Hydraulic Jet Drilling, SPE Paper 2434, 1969

42. W. C. Maurer, Joe K. Heilhecker, and William W. Love, Esso Production Research Co., High-Pressure Drilling, 1973 SPE paper \# 3988 
43. William J. McDonald, Maurer Engineering, Four Different Systems Used for MWD, The Oil and Gas Journal, April, 3, 1978

44. Mining Journal, Methods and Machines: Hard Rock rotary Drill of Novel Design, July 27, 1984

45. William M. Moeny, Tetra Corporation, personal correspondence

46. William M. Moeny and James G. Small, Tetra Corporation, Focused Shock Spark Discharge Drill Using Multiple Electrodes, U. S. Patent number 4,741,405, May 1988

47. Preston L. Moore, Drilling Practices Manual, PennWell Books, 1974

48. K. R. Newman, CTES, Coiled Tubing and Its Applications, SPE Short Course, October 1995

49. K. R. Newman, Drexel Oilfield Services, Inc., and D. M. Doremus, Schlumberger Dowell, Hybrid Coiled Tubing/Snubbing Drilling and Completion System, SPE paper 28300 , September 1994

50. M. M. Newson and R. L. Alvis, Sandia National Laboratories, and David Dardick, Tround International, The Terra-Drill Program: A Progress Report and Program Plan, Sandia Laboratories Report, SAND76-0228, June 1976

51. James J. Olson and Keith S. Olson, Twin Cities Mining Research Center, ARPA-Bureau of Mines Rock Mechanics and Rapid Excavation Program, A Research Project Summary, U.S. Bureau of Mines, Information Circular 8674, 1975

52. David S. Pixton, Yu Xiangnuang, Vance Fryer, Steven Payne, and David Hall, A New Generation Mud Driven Rotary Percussion Tool: Summary of Current Research and Development Efforts, Novatek, Provo, UT, February 1990

53. J. W. Pritchett and T. D. Riney, Analysis of Dynamic Stresses Imposed on Rocks by Water Jet Impact, Second International Symposium on Jet Cutting Technology, Cambridge, April, 1974

54. R. M. Rauenzahn and J. W. Tester, Flame-Jet Induced Thermal Spallation as a Method of Rapid Drilling and Cavity Formation, 1985 SPE paper 14331

55. Robert J. Regan, Mining Cannon is a Real Rockbuster, Iron Age, June 24, 1983

56. Wang Renjie, Hydro-Percussive-Rotary (Hydro-Hammer) Drilling

57. Roger Rinaldi, Resource Technology, Inc., A Technical and Economic Evaluation of Thermal Spallation Drilling Technology, July 1984 
58. Roger Rinaldi, Resource Technology, Inc., A Technical and Economic Evaluation of Thermal Spallation Drilling Technology Volume IV, October 1984

59. L. H. Robinson, Humble Oil and Refining, Co., Experimental Tests of a Method for Drilling with Explosives, 1965 SPE paper 1001

60. Frank J. Schuh, Drilling Technology, Inc., MultiCon ${ }^{\mathrm{TM}}$ Drilling System Potential, February 1994

61. Frank J. Schuh, Drilling Technology, Inc., MultiCon ${ }^{\mathrm{TM}}$ Drilling System Economics, January 1995

62. Frank J. Schuh, Drilling Technology, Inc., personal correspondence

63. John G. Sellar, Rock Excavation Using a Pulsing Laser-Water Jet, EPRI Center for Materials Production, Pittsburgh, PA, CMP Report Number 93-7, November 1993

64. John G. Sellar, Lakeland, CO, Hard Rock Excavation Using a Pulsing Laser, March 1993

65. David A. Summers, University of Missouri-Rolla, Waterjetting Technology, Chapman and Hall, 1995, ISBN 0419196609

66. David A. Summers and Almed A. El-Saie, Progress in the Water Jet Assisted Drilling of Rock

67. David A. Summers and Richard L. Henry, University of Missouri Rolla, Water Jet Cutting of Sedimentary Rock, 1972 SPE paper \# 3533

68. Jefferson W. Tester, Robert M. Potter, Carl R. Peterson, Howard J. Herzog, Massachusetts Institute of Technology, John North, Worldrill, and John E. Mock, Geothermal Division U.S. DOE, Advanced Drilling and Its Impact on Heat Mining

69. J. R. Thiery, IFP, Rueil-Malmaison, France, Flexodrill Monitors Borehole Continuously, The Oil and Gas Journal, May 15, 1978

70. Bernard V. Traynor, Jr., General Electric Co., Electrodril Demonstration Program Shows Promise, The Oil and Gas Journal, April 17, 1978

71. Scott D. Veenhuizen and John B. Cheung, Flow Industries, Kent, WA, Parameters for Waterjet Drilling of Small-Diameter Holes, The Energy Technology Conference and Exhibition, Houston, TX, September 1977 
72. S. D. Veenhuizen, T. J. Butler, and D. P. Kelley, FlowDril Corporation, Jet-Assisted Mechanical Drilling of Oil and Gas Wells, Seventh American Water Jet Conference, Seattle, WA, August, 1993

73. R. Price Vincent and L. B. Wilder, Pan American Petroleum Corporation, Tool Boosts Drilling in Hard Formations, Oil and Gas Journal, March 31, 1969

74. M. R. Wells, Amoco Production Co., Dynamic Rock Chip Removal by Turbulent Jetting, 1985 SPE paper 14218

75. M. A. Wilkinson and J. W. Tester, Experimental Measurement of Surface Temperatures During Flame-Jet Induced Thermal Spallation, Rock Mechanics and Rock Engineering, 1993

76. R. Edward Williams, Los Alamos National Laboratory, Thermal Spallation Drilling, Transactions of the Geothermal Resources Council, Volume 9, Part I, August, 1985

77. R. Edward Williams, Thomas Dey, Rick Rauenzahn, Robert Kranz, Robert Potter, and Hugh Murphy, Los Alamos National Laboratory and Jefferson Tester, Massachusetts Institute of Technology, Advancements in Thermal Spallation Drilling Technology, Los Alamos National Laboratory Report LA-11391-MS, September 1988

78. Worldrill Corporation, Improvements in or Relating to Drilling with Centrifuge/Vortex Combustion Jet Spallation, British and Foreign Patent Application PCT/GB94/00515 


\section{APPENDIX A: DRILLING PERFORMANCE CURVES}

\section{DRILLING INTERVAL COSTS}

The costs of drilling from casing point to casing point in a well are summarized in Table a.1. The interval begins and ends with drilling out cement. For systems that affect the end-of-interval activities, costs of current technology need to be estimated as a benchmark.

\begin{tabular}{|c|c|}
\hline & Table a.1: Drilling Interval Costs \\
\hline Activity & Cost Basis \\
\hline 1. drilling & (cost per foot) $x$ (interval length) \\
\hline \multicolumn{2}{|c|}{ End-of-interval activities: } \\
\hline 2. hole conditioning & (operating cost) $\mathrm{x}$ (circulation time) \\
\hline 3. logging & (operating cost) $\mathrm{x}$ (logging time) + logging charges \\
\hline 4. casing & (operating cost) $\times$ (casing time) + casing costs + casing crew \\
\hline 5. cement & (operating cost) $\mathrm{x}$ (cementing time) + cement costs \\
\hline 6. wait-on-cement & (operating cost) $\mathrm{x}$ (waiting time) \\
\hline 7. test cement & (operating cost) $\mathrm{x}$ (test time) \\
\hline 8. change BOP & (operating cost) $\mathrm{x}$ (installation time) \\
\hline
\end{tabular}

The cost of the first activity in Table a.1

(drilling) can be estimated from Equation a.1.

$$
C_{d}=C_{e} / n+\left(C_{o}+C_{r}\right)\left(t_{d}+t_{t}\right)
$$

where: $C_{d}$ is the interval drilling cost,

$C_{e}$ is the cost of downhole expendable equipment,

$n$ is the number of intervals that can drilled by the equipment,

$C_{o}$ is the rig operating cost per unit time,

$C_{r}$ is the charge for any drilling tools per unit time,

$t_{d}$ is the drilling time, and

$t_{t}$ is the tripping time.

The factor $\boldsymbol{n}$ in Equation a.1 apportions the cost of downhole expendable equipment over the number of intervals that can be drilled by the equipment.

The cost of the activities 2 through 8 in Table a.1 can be estimated from Equation a.2.

$$
C_{a}=C_{o} t_{s}+C_{s}
$$




\section{Appendix A: Drilling Performance Curves}

where: $\quad C_{a}$ is the total cost of activities 2 through 8 ;

$t_{s}$ is the sum of the circulation time, the logging time, the casing time, the cementing time, the wait-on-cement time, the test-cement time, and the time to change the blow-outpreventer; and

$C_{s}$ is the sum of the logging charges, the casing costs, the casing crew, and the cement costs.

Combining Equations a.1 and a. 2 yields Equation a. 3 for the

$$
C_{i}=C_{e} / n+\left(C_{o}+C_{r}\right)\left(t_{d}+t_{t}\right)+C_{o} t_{s}+C_{s}
$$
interval cost.

where: $C_{i}$ is the total cost of the interval.

The life of the downhole expendable materials can be introduced into Equation a.3 through the number of drilling intervals $(n)$. The life of the downhole expendable materials, given by Equation a.4, is $\quad \boldsymbol{t}_{\boldsymbol{L}}=\boldsymbol{n} * \boldsymbol{t}_{d}$ the number of intervals times the drilling time.

where: $t_{L}$ is the life of the downhole expendable equipment.

Solving Equation a.4 for the number of drilling

$$
C_{i}=C_{e}\left(t_{d} / t_{L}\right)+\left(C_{o}+C_{r}\right)\left(t_{d}+t_{t}\right)+C_{o} t_{s}+C_{s}
$$

intervals and substituting it into Equation a.3 yields Equation a.5 for the cost of the drilling interval as a function of the life of the downhole equipment. In substituting Equation a.4 into Equation a.5, there is an implicit assumption that downhole expendable equipment will be employed until it wears out. In terms of current technology, this assumes that if a bit is used for 90 hours of it's 100-hour life in one interval, it would then be used in another interval for the remaining 10 hours of life. This is not the general practice. The other extreme would be to assume that once a bit is used it is discarded regardless of drilling time. The difference in the interval costs predicted by these two approaches is generally on the order of $1 \%$ or less. This difference is smaller than the uncertainty in the parameter estimates.

Equation a.5 gives the cost of a drilling interval as a function of the cost and serviceable life of downhole expendable materials $\left(C_{e}\right.$ and $\left.t_{L}\right)$, the drilling time $\left(t_{d}\right)$, the tripping time $\left(t_{t}\right)$, the rig operating cost $\left(C_{o}\right)$, the cost of rental equipment $\left(C_{r}\right)$, and the time and cost of end of interval activities $\left(\boldsymbol{t}_{s}\right.$ and $\left.\boldsymbol{C}_{s}\right)$. By defining a drilling interval according the depth, hole size, and rock type, 
we can estimate all variables in Equation a. 5 for current technology and, thus, estimate the cost of the drilling interval.

\section{Rate-of-Penetration}

The average rate-of-penetration is the interval length divided by the drilling time $\left(t_{d}\right)$. Solving Equation a.5 for $1 / t_{d}$ and multiplying by the interval length yields Equation a.6.

$$
\frac{L_{i}}{t_{d}}=R O P=\frac{\left(C_{o}+C_{r}\right) * L_{i}}{C_{i}-\left(C_{o}+C_{r}\right) t_{t}-C_{o} t_{s}-C_{s}}+\left\{\frac{C_{e} * L_{i}}{C_{i}-\left(C_{o}+C_{r}\right) t_{t}-C_{o} t_{s}-C_{s}}\right\} * \frac{1}{t_{L}}
$$

where: $\boldsymbol{L}_{i}$ is the interval length and

$R O P$ is the average rate-of-penetration over the interval.

\section{Performance Evaluation}

Equations a.5 and a.6 yield a method to estimate the required performance characteristics of various drilling technologies such that the cost is equivalent to that possible with current technology. The first step in the evaluation of performance requirements is to estimate interval costs for current technology using Equation a.5. As mentioned previously this can be done if we specify the interval characteristics of depth, hole size, and general rock type.

For the advanced drilling concepts, we can estimate operating costs $\left(C_{o}\right)$ as well as the costs of downhole expendable materials and equipment $\left(\boldsymbol{C}_{e}\right)$. The tripping time $\left(\boldsymbol{t}_{t}\right)$ will depend on whether coiled tubing or drill pipe is employed. The number of trips will depend on the interval length, the rate-of-penetration, and the serviceable life of the downhole equipment. Any variations in the costs and times associated with services ( $\boldsymbol{C}_{s}$ and $\boldsymbol{t}_{s}$ respectively) can also be estimated. Then using these estimates for an advanced technology, along with the estimated interval costs for current technology from Equation a.5, Equation a.6 will yield a relationship between rate-of-penetration $\left(\boldsymbol{R} O P\right.$ ) and serviceable life $\left(t_{L}\right)$ for the advanced technology such that the resultant interval cost is equivalent to what can be accomplished with current technology. At any combination of $\boldsymbol{R} \boldsymbol{O P}$ and $\boldsymbol{t}_{L}$ above the curve defined by Equation a.6, the advanced technology is predicted to cost less than current technology.

If the life of the downhole equipment is such that it will not last from casing-point to casingpoint, then Equation a. 6 requires an iterative solution. This occurs because of the trips, and consequently the tripping time, necessary to change the equipment. 


\section{INTERPRETATION}

It is informative to examine the terms in Equation a. 6 with respect to our purposes. The denominator is the amount of money allocated to drilling. This value is derived by starting with the cost of drilling from casing-point to casing-point with current technology $-C_{i}$. The costs of end-of-interval materials and services $-C_{s}$ - are subtracted. The operating costs accrued while completing end-of-interval activities $-C_{o} t_{s}$ - are also deducted. Finally, the operating costs accrued while tripping $-\left(C_{o}+C_{r}\right) t_{t}$ - are subtracted. What is left is the amount of money that can be spent drilling if the advanced technology is to be competitive with current practices. If we divided this amount by the rate that must be paid to operate $-\left(C_{o}+C_{r}\right)$, we would get the maximum time that can be spent drilling. Finally, if we divide this time into the length that we have to drill $-\boldsymbol{L}_{i}$, we arrive at the minimum average rate-of-penetration such that the advanced technology will cost no more than current operations. This is the first term in Equation a.6. The second term in Equation a.6 accounts for the rate at which downhole equipment and materials are expended $-C_{e} / t_{L}$ - and has a similar interpretation.

Equation a.6 describes a

hyperbola. The vertical asymptote $\quad \boldsymbol{R O P}_{\min }=\frac{\left(C_{o}+C_{r}\right) * L_{i}}{C_{i}-\left(C_{o}+C_{r}\right) t_{t}-C_{o} t_{s}-C_{s}}$
is the ROP-axis. The horizontal

asymptote can be found by letting

the life $\left(t_{L}\right)$ become large. The result is given by Equation a.7. Equation a.7 defines a minimum rate-of-penetration that must be achieved by an advanced technology if it is to be competitive with current drilling practices. While Equation a.7 does predict a minimum requirement, it is not particularly informative since it assumes an infinite life. Thus, Equation a. 7 is an adequate performance requirement for new technology only if the equipment associated with that technology will never wear out.

\section{Equation Characteristics}

Most advanced technology systems increase the operating cost when compared to conventional drilling. The increased operating cost can be due to a rental charge, increased maintenance, increased debt, and/or increased energy usage.

Equation a. 6 is used to predict

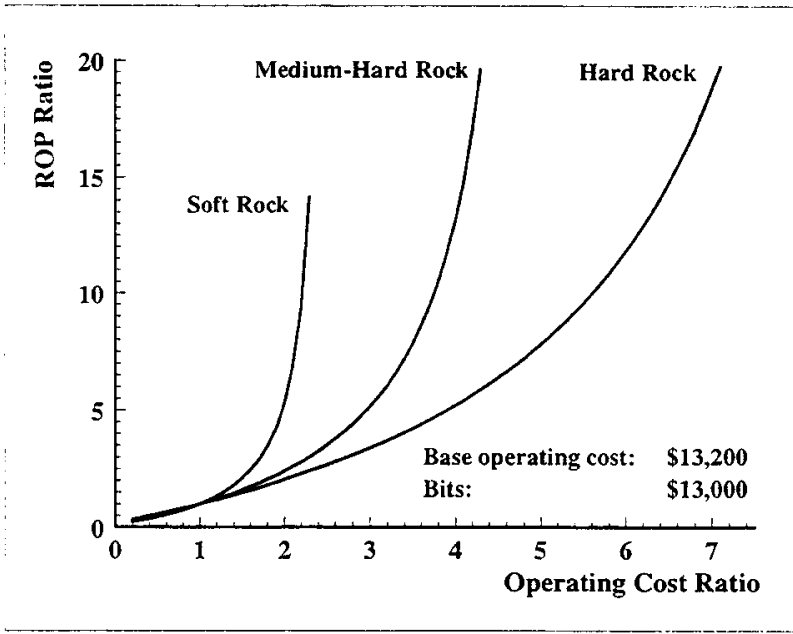

Figure a.1: The Effect of Operation cost on Performance Requirements 
performance requirements. This equation is linear with respect to the cost of expendable equipment $\left(C_{e}\right)$; however, it is not linear with respect to either operating cost $\left(C_{o}\right)$ or rental cost $\left(C_{r}\right)$. Figure a.1 shows the relationship between the required ROP ratio and the ratio of the advanced technology operating cost to the current operating cost. The definitions of soft, medium-hard, and hard rock are given in Appendix B.

Equation a. 6 was derived to estimate performance requirements such that the cost of an advanced technology is no higher than the cost of performing the same task with current drilling technology. As is apparent in the figure, this equation becomes unbounded under certain conditions. These conditions occur when the advanced technology operating cost is such that the charges for tripping and end-of-interval activities are larger than the total interval charges with conventional technology. Under these conditions, the advanced technology cannot be competitive under any combination of penetration rate and equipment life.

If the operating cost associated with a system is near the asymptote, relatively high performance requirements will be indicated. In this region, a small error in cost estimation can result in a large error in the predicted requirement. This region can also be considered a region of opportunity. In this area a small reduction in cost can result in a large reduction in performance requirements.

Rental costs charged only during drilling activities $\left(\boldsymbol{C}_{r}\right)$ have the same general effect on performance requirements as increasing operating costs. However, because these costs are not charged on end-of-interval activities, the affects are significantly delayed. In soft rock, Equation a. 6 does not become unbounded until the rental costs exceed thirty times the daily operating costs; in medium-hard rock, it is eighty times; and in hard rock, it is one-hundred eighty times. This is far beyond the region of interest in drilling operations.

For rental rates of interest, the increased performance requirements necessary to offset increased rental costs are essentially linear with bit cost determining the slope of the line. This is shown for three bit costs in Figure a.2. The bit cost affects the slope of the line in the region of interest. The important parameter in determining the slope is the bit-cost-todaily-cost ratio. The three curves in Figure a. 2 are for ratios of one-tenth, one, and five. While the slope is a monotonically decreasing function of bit cost, it is not a linear function.

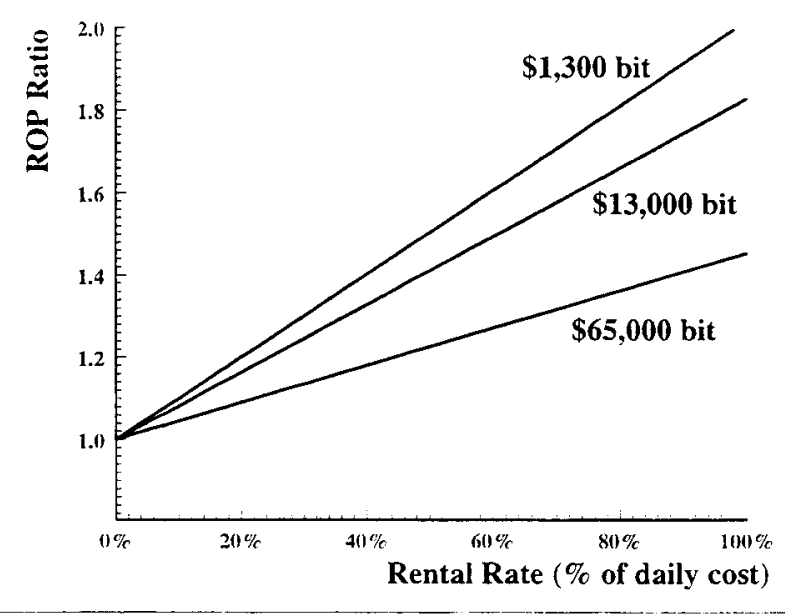

Figure a.2: Sensitivity to Rental Rates 
Appendix A: Drilling Performance Curves

page IX-6 


\section{APPENDIX B: INTERVAL DEFINITION AND COSTS}

For the purpose of evaluating drilling performance, we defined the following five general rock types classified primarily by hardness:

\section{Rock Classifications and Characteristics}

Very Soft This is IADC series 4xx. These formations can be drilled by either roller cone or PDC bits with penetration rates in excess of $70 \mathrm{fph}$. The largest problem in this type of formation is not cutting rock, but removing the cuttings. Specific formations types include gumbo, soft shale, and halite. Commonly employed bits include Security S82F, Hughes J-11 or J-05, and Smith F1.

Soft This is IADC series $51 \mathrm{x}$ and $52 \mathrm{x}$. Roller cone bits will drill these formations at 25 fph to $35 \mathrm{fph}$; with PDC bits at higher penetration rates. Removing the cuttings can still be a problem. Typical formation types include chalk, claystone, siltstone, and unconsolidated sands. Commonly employed bit types include Security S84F or S86F, Hughes J-22, and Smith F2 or F27.

Medium This is IADC series 53x through 61x. Roller cone bits will drill these formations with penetration rates of $15 \mathrm{fph}$ to $25 \mathrm{fph}$. PDC bits begin to fail in this region.

Removing cuttings is less of a problem than in softer formations, but good hydraulics are essential. Typical formation types are sandstone, limestone, anhydrite, and the softer dolomites. Commonly employed bits include Security S86F to S88F or M84F, Hughes ATJ-33 or ATJ-44, and Smith F3, F37, or F4.

Hard This is IADC series $62 x$ through $74 x$. PDC bits are not used. This lithology will challenge the bits. If the formations are also abrasive, there will be significant problems with gage wear. Penetration rates range from $7 \mathrm{fph}$ to $10 \mathrm{fph}$, but can be as slow as $5 \mathrm{fph}$. Typical formation types are cemented sandstone, hard limestone, dolomite, dense shales, diorite, and quartz. Commonly employed bits include Security M89T, H87F, or H88F; Hughes ATJ-55 or ATJ-77; and Smith F57 to F7.

Very Hard This is IADC series $8 \mathrm{xx}$. These formations are extremely hard and abrasive. Penetration rates on the order of $2 \mathrm{fph}$ to $3 \mathrm{fph}$ are common and gage wear is a significant problem. Typical formations are quartzite, quartzitic sands, cherts, and basalt. Possible bits are Security H99F or H100F, Hughes ATJ-99 or ATJ99A, and Smith F9. 


\section{PENETRATION RATES}

For comparison of advanced technologies to current practices, we have excluded consideration of both the very soft and the very hard categories. In the very soft category, rock cutting is not a problem; the major impediment to higher penetration rates is removal of

\begin{tabular}{|c|c|c|}
\hline \multicolumn{3}{|c|}{ Table b.1: Bit Performance } \\
\hline & ROP & Life \\
\hline Soft & $40 \mathrm{fph}$ & $90 \mathrm{hr}$ \\
\hline Medium-hard & $15 \mathrm{fph}$ & $90 \mathrm{hr}$ \\
\hline Hard & $7 \mathrm{fph}$ & $90 \mathrm{hr}$ \\
\hline
\end{tabular}
the cuttings. On the other extreme, there is very little drilling in what we classified as very hard rock. For the remaining classifications, the penetration rates and bit lives used in performance evaluation are given in Table b.1.

As discussed in Appendix A, there are a number of times and costs, in addition to bit performance

\section{Table b.2: Drilling Interval Parameters} characteristics, that must be estimated in order to determine interval costs. The parameter values employed are given in Table b. 2 .

\section{SAMPLE CALCULATION}

Cement

Interval

Hole conditioning

Logging

Casing

L- 80 buttress

$95 / 8$ inch

$47 \mathrm{lb} /$ foot $\$ 35.50 /$ foot

As indicated in Table b.2, the interval has a length of 4000 feet. The hole has a $121 / 4$-inch diameter and $95 / 8$-inch casing is run. Casing was charged from the surface to total depth plus 200 feet extra.
Change BOP

Bits $\quad 12 \frac{1}{4}$ inch TCI

Tripping time (per $1000 \mathrm{ft}$ roundtrip) start 4000 feet

end 8000 feet

4 hours

time 16 hours

charge $\$ 80,000$

cost $\$ 291,100$

set up 3 hours

run casing 20 hours

crew charges $\$ 14,000$

cost $\$ 85,000$

set-up 3 hours

run cement 8 hours

wait-on-cement 6 hours

test 4 hours

18 hours

$\$ 13,000$

0.7 hours

Summing the end-of-interval charges in the table yields:

$$
C_{s}=\$ 80,000+\$ 291,100+\$ 14,000+\$ 85,000=\$ 470,100 \text {. }
$$

The total time necessary for end-of-interval activities is:

$$
t_{s}=82 \text { hours. }
$$


The cost of downhole expendable materials is:

$C_{e}=\$ 13,000$ per bit.

The determination of the operating cost is discussed in Appendix C. The estimated operating cost for a rig built from new equipment and materials is:

$C_{o}=\$ 19,100$ per day $=\$ 796$ per hour.

Assuming no tools other than those supplied with the rig are required, tool rental charges are zero:

$$
C_{r}=0
$$

To estimate tripping time $\left(t_{t}\right)$, the drilling interval is charged for half of a roundtrip at the beginning, half of a roundtrip at the end, and any necessary trips within the interval. Based on the data in Table b.1, a single bit in soft rock will drill ( $40 \mathrm{ft} / \mathrm{hr})(90 \mathrm{hr})=3,600$ feet. Thus, a trip to change bits will be required at 7,600 feet. Then the total tripping time is estimated to be:

$$
t_{t}=(0.0007 \mathrm{hr} / \mathrm{ft})(4,000 \mathrm{ft} / 2+7,600 \mathrm{ft}+8,000 \mathrm{ft} / 2)=9.52 \mathrm{hr}
$$

The drilling time is estimated from the rate-of-penetration and the interval length as:

$$
t_{d}=(4000 \mathrm{ft}) /(40 \mathrm{ft} / \mathrm{hr})=100 \text { hours }
$$

Using these values, the cost for the drilling interval is estimated from Equation a.5:

$$
\begin{aligned}
C_{i}= & C_{e}\left(t_{d} / t_{L}\right)+\left(C_{o}+C_{r}\right)\left(t_{d}+t_{t}\right)+C_{o} t_{s}+C s \\
= & (\$ 13,000)(100 \mathrm{hr} / 90 \mathrm{hr})+(\$ 796 / \mathrm{hr}+0)(100 \mathrm{hr}+9.52 \mathrm{hr})+ \\
& (\$ 796 / \mathrm{hr})(82 \mathrm{hr})+\$ 470,100 \\
= & \$ 637,000
\end{aligned}
$$

Analogous calculations can be performed for medium and hard rock. The calculations for using both our estimate of the cost of a rig built from all new materials and equipment and our estimate of current daily costs are summarized in the following table. These are the baseline 
interval costs used in estimating the required performance characteristics for the various advanced technologies when compared to the cost of drilling with a rig built from new materials and equipment.

\begin{tabular}{lcc}
\hline & Table b.3 Drilling Interval Costs & \multicolumn{1}{l}{} \\
\hline & Current Rig & New Rig \\
\cline { 2 - 3 } Soft rock & $\$ 590,000$ & $\$ 637,000$ \\
Medium-hard rock & $\$ 707,000$ & $\$ 796,000$ \\
Hard rock & $\$ 929,000$ & $\$ 1,097,000$ \\
\hline \hline
\end{tabular}

Some of the advanced concepts cannot operate in a full liquid environment. As a basis of comparison for these systems, we added the cost of renting two 1000-psi, 1200-scfm air compressors to the base operating cost. These compressors currently rent for about $\$ 1,200$ each per day. Since mud is not needed, the drill-site charges are reduced by $\$ 3,000$ per day. This yields an estimated daily operating cost of $\$ 18,500$ for a rig built from all new materials and $\$ 12,600$ for currently available rigs.

We assumed that current technology will drill twice as fast with air as with mud. This doubles the rates-of-penetration given in Table b.1. Under this set of assumptions, the interval costs used for current technology when drilling on air are given in the following table.

Table b.4 Drilling Interval Costs / Air Drilling

\begin{tabular}{lcc}
\hline & Current Rig & New Rig \\
\cline { 2 - 3 } Soft rock & $\$ 549,000$ & $\$ 582,000$ \\
Medium-hard rock & $\$ 607,000$ & $\$ 662,000$ \\
Hard rock & $\$ 714,000$ & $\$ 809,000$ \\
\hline \hline
\end{tabular}




\section{SMALLER HOLE}

We also investigated the effect of hole size. Table b.5 gives the parameters for an $8 \frac{1}{1} 2$-inch hole completed with 7-inch casing.

The ROP's for the smaller hole were not changed, however, the bit lives were reduced to 75 hours due to reduced bearing sizes.

Table b.5: Drilling Interval Parameters

( 8 3/4-inch hole)

Interval

Hole conditioning

Logging

Casing

Cement

Change BOP

Bits $83 / 4$-inch TCI

Tripping time (per $1000 \mathrm{ft}$ roundtrip) start 4000 feet end 8000 feet 4 hours time 16 hours charge $\$ 80,000$ cost $\$ 159,900$ set up 3 hours $\begin{array}{lrr}26 \mathrm{lb} / \text { foot } & \text { run casing } & 20 \text { hours } \\ \$ 19.50 / \text { foot } & \text { crew charges } & \$ 11,300\end{array}$ cost $\$ 52,000$ set-up 3 hours run cement 8 hours wait-on-cement 6 hours test 4 hours 18 hours $\$ 6,000$

0.7 hours 


\section{APPENDIX C: OPERATING COSTS}

One objective of this study is to estimate the capital and operating costs for advanced drilling systems. These estimates are compared to similar costs for current drilling technology to develop performance requirements such that the cost of a well drilled with the advanced technology is no higher than the cost would be with conventional rotary technology. However, due to excess equipment and low demand, rig rates today are artificially low. Thus, it is necessary to estimate the costs of a conventional rotary drilling system built from all new equipment and materials as a basis for equitable comparisons to the expected costs of other systems.

\section{RIG COSTS}

The estimated costs to build and field a drill rig from all new equipment are given in Table c.1. The rig priced in this table is designed to be capable of drilling to 18,000 feet. In the $\$ 9.2$ million total, there are $\$ 6.5$ million in capital equipment and $\$ 1.3$ million in expendable materials and equipment. The remaining costs are taxes and assembly.

The costs in Table c. 1 are derived from estimates of the costs of individual components and materials. Where possible, the costs of individual pieces were taken from manufacturer's price lists or from discussions with suppliers. A given piece of equipment may cost more than our estimate or it may be possible to obtain it at discount. We do

\section{Table c.1: Drilling System Costs}

Sub-System Cost (000)

Mast \& Substructure

$\$ 973$

Power Generation Equipment \$1,233

Drawworks

$\$ 782$

Mud Pumps \& High Pressure Equipment $\$ 1,008$

Mud Conditioning Equipment \$349

BOP Equipment $\$ 875$

Rotating Equipment $\$ 92$

Traveling \& Pipe Handling Equipment \$625

Instrumentation $\quad \$ 77$

Miscellaneous Equipment $\quad \$ 409$

Drill String \& BHA $\$ 975$

Assembly Costs $\quad \$ 680$

Sub-Total

Contingency (5\%) $\$ 404$

Taxes $(8 \%) \quad \lcm{\$ 679}$

Total not maintain that the costs in Table c. 1 are exact; they are only meant to be representative of the costs for new equipment and materials today.

The Dreco mast is specified at 132 feet with a 30 -foot substructure and a 500-ton lifting capacity. The power generation equipment include three 1615-hp, $1030 \mathrm{~kW} \mathrm{CAT} \mathrm{model} 3512$ diesel-electric generators; an SCR system; plus associated equipment, generator houses, and starters. The drawworks is a 2,000-hp Continental Emsco C-2-II and includes type 37 and type 
24 catheads. Two GE 752AR electric motors are used to drive the drawworks. Included with in the drawworks category are a Baylor 7040 brake, controls, and cooling system; an Emsco rotary

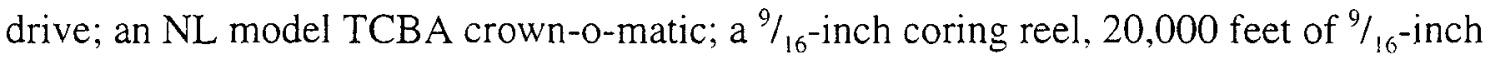
sandline, and a spooler.

Two Emsco FB 1600 triplex mud pumps, each driven by two GE 752AR electric motors, are specified. Also included in the mud pumps category are Mission Magnum charge pumps with 100-hp drive motors, Hydril K20 and I-F dampners, Cameron relief valves and gauges, and various other valves, hoses, belts, a 3-hp lubricator, and safety clamps. The return mud system consists of three 500-bbl mud pits, Brandt MA15 and MA7.5 agitators, bottom guns, top guns, a shale shaker, a desander, a desilter, a degasser, various pumps, motors, mixers, and a Swaco mud hopper.

The BOP equipment includes Schaffer 13 5/8-inch, 5,000-psi and 211/4-inch, 2,000 psi annular blow-out preventers, Cameron 10,000-psi blind and pipe rams, a choke manifold, a 10,000 psi drilling spool, a Koomey controller, and various ram sets, gasket sets, and armored hose. The rotary equipment include and Emsco T-2750 rotary table and Varco master and kelly bushings. A Dreco 500-ton traveling block, a BJ-5500 hook, 13/8-inch drilling line, and an LTV/CE LB-650 swivel form the basis of the traveling equipment. This category also includes an AR-3000 iron roughneck, BJ elevators, Varco slips, tongs, clamps, and a spinning wrench. Instrumentation includes a Martin Decker Type E weight indicator, a satellite driller, as well as the standard pressure and pump gauges, torque and RPM indicators, the driller's console, and a rig intercom system.

Miscellaneous equipment includes a utility room, a tool room, a fuel tank, a water tank, associated pumps, air tools, and rig lighting. The drill string and bottom-hole assembly includes 21,000 feet of 5-inch drill pipe, 20 joints of heavy-weight drill pipe, twelve 8 -inch drill collars, $2461 / 2$-inch drill collars, a 5 1/4-inch kelly, upper and lower valves, crossover subs, bit subs, and protectors. The assembly costs include labor, testing, and transportation necessary to build the rig.

\section{Basic Assumptions}

In order to translate the total costs in Table $c .1$ to an operating cost for the rig, a number of assumptions must be made. The main assumptions are given in Table c.2. The same discount rate $(12 \%)$ was applied to both long-term and short-term debt. Utilization is

\begin{tabular}{lr}
\hline \hline \multicolumn{1}{c}{ Table c.2: General Assumptions } \\
Interest rate & $12 \%$ \\
Rig utilization & $75 \%$ \\
Labor costs: & \\
Tool pusher & $\$ 6,000 /$ month \\
Crew & 5 men/shift \\
wage rate & $\$ 15 / \mathrm{hr}$ \\
Labor load & $37 \%$ \\
Drill pipe life & $300,000 \mathrm{feet}$ \\
Diesel fuel & $\$ 1.10 / \mathrm{gal}$ \\
\hline \hline
\end{tabular}

page IX-13 


\section{Appendix C: Operating Costs}

the proportion of time that the rig is in use (or the percentage of time for which a rig rate is being collected). We assumed twelve-hour shifts, thus requiring two five-man crews plus a two-man relief crew. The wage rate ( $\$ 15 /$ hour) is an average for the crew. The loaded wage rate (37\%) includes holidays, vacation, FICA, medical insurance, workman's compensation, and unemployment insurance. Indirect support (i.e. main office staff) is estimated separately. The cost of indirect support was based on a requirement for both engineering and clerical support for the rig. The estimated serviceable life of capital equipment ranges from five years to thirty years depending on the device. The life of non-capital equipment and materials generally ranges from less than a year to three years. Salvage was included for all major pieces of equipment and material.

\section{Daily Costs}

Based on the discussion in the previous paragraph, the costs in Table c.1, and the assumptions in Table c. 2 , the daily operating costs for the rig given in Table c. 3 were determined using standard business practices. Long-term debt is the total necessary payment to replace capital equipment as it wears out. Capital equipment includes such pieces as the mast and substructure, the diesel-electric

Table c.3: Daily Operating Cost Long-term debt $\$ 3,400$ Short-term debt $\$ 2,700$ Maintenance Labor $\$ 1,700$ Office support $\$ 2,700$ Insurance $\$ 500$ Fuel Total
$\$ 300$

$\$ 1,600$ generators, and the mud pumps. Short-term debt covers the cost of expendable materials and equipment, primarily the drill string. The short term debt is reduced for salvage. Maintenance covers equipment upkeep. The maintenance cost was estimated by summing the expected maintenance expense of the individual components (mast and substructure, mud pumps, diesel electric generators, rig lighting system, etc.). The bases for the labor and fuel costs were discussed previously. The insurance was estimated to cover capital equipment and five-million dollars of liability protection.

The cost of short-term and long-term debt given in Table c. 3 can be interpreted in more than one way. If the drilling contractor borrows the money both to build the rig and to purchase the initial supply of expendable materials and equipment, then the long-term and short-term debt are the necessary cash flow to make the payments on the loans. If the contractor uses personal or internal company funds to finance building the rig and the purchase of expendable materials and equipment, then the long-term and short-term debt are the return necessary to recover this 
investment. If the investment is not repaid, then eventually the equipment will wear out and there will be no money to replace it.

One might argue that in the second case (self-financing), the contractor would not have to pay interest on the money. This would be a zero-interest loan. Why should the contractor invest several million dollars in a drill rig at zero interest when the same money could be invested in a large multitude of other ventures and receive a return?

An intermediate case where the contractor finances a portion of cost of building the rig and borrows the remainder is the most realistic scenario. But even in this case the results are the same as the two cases discussed in previous paragraphs.

If we assume the contractor is required to cover taxes and manufacturer plus $30 \%$ of equipment and materials, the total outlay will be $\$ 3.7$ million. Assuming a $40 \%$ tax rate, we estimate that charging $\$ 12,900$ per day will yield between $12 \%$ and $13 \%$ average return on this investment over 30 years. This is not unreasonable.

In our model, the only cash income above expenses to the contractor is the return on invested capital. A large part of the contractor's net income is equity in equipment. We did not perform a cash-flow analysis, so it is not clear that the $\$ 12,900$-rate would provide sufficient cash to maintain operations. Additional working-capital loans or a higher rate may be necessary to sustain the business.

Currently, rigs capable of drilling to 18,000 feet rent for around $\$ 7,000$ per day. The estimated cost in Table c.3, is nearly twice as high as current rig rates. There are a number of reasons for this difference. The costs given in Table c. 3 are based on the purchase of all new materials and equipment. There are few (if any) such rigs being built. There is still a supply of surplus equipment manufactured in the late 1970's. Also, the estimates in Table c. 3 are based on costs; however, prices are not determined by costs. The active rig count has been declining since the early 1980 's. Drilling contractors with rigs to rent are taking the best price they can obtain in a buyer's market. 


\section{Appendix C: Operating Costs}

\section{Additional Drill-Site Charges}

There are a number of costs associated with drilling that are not included in the calcu-lations of the previous section. These are costs generally born by the operator. In some cases, the rig contractor will incur these costs and pass them through to the operator. In others, the operator will pick them up directly. Estimates of these additional drill-site costs are given in Table c. 4 .

The largest single charge in Table c. 4 is for drilling mud. It is common to lose from $1 \%$ to $2 \%$ of the drilling mud in the mud conditioning system. For a 12 1/4-inch hole, these losses would be on the order of five to ten gallons per minute, or upwards from 300 gallons-per-hour while drilling. Mud will also have to be added as the hole deepens. At a cost of $\$ 8$ to $\$ 20$ per barrel, $\$ 3,000$ per day is a reasonable estimate.

Rig supervision is the operator's

\begin{tabular}{lr}
\hline \multicolumn{2}{c}{ Table c.4: Operator-Incurred } \\
Drill-Site Costs \\
Rig monitoring \\
Rig supervision \\
Mud logging & $\$ 800$ \\
Drilling fluid expenses & $\$ 1,000$ \\
Drilling fluids & \\
Mud engineer & $\$ 3,000$ \\
Rental tools and services & $\$ 400$ \\
Stabilizers, reamers & \\
Monel collar & $\$ 200$ \\
Single shot survey & $\$ 50$ \\
Fishing tool standby & $\$ 80$ \\
Other services & $\$ 50$ \\
Transportation & \\
Water supply & $\$ 300$ \\
Inspection & $\$ 100$ \\
Welding and repair & $\$ 40$ \\
Waste disposal & $\$ 100$ \\
Total & $\$ 100$ \\
\hline \hline
\end{tabular}

representative at the drill site. The mud logger has general responsibility for data monitoring on the rig. The mud engineer is self explanatory. The stabilizers, reamers, and monel collar are bottom-hole tools not generally supplied with the rig. We have included transportation as an operator-supplied service. Although we have not included it, it is not unusual for there to be a transportation charge as part of rig rental also. Inspection is not a daily activity - the cost is meant to represent an average. Waste disposal includes site waste, cuttings, and mud.

For the purpose of estimating drilling costs, the costs detailed in Table c. 4 are in addition to those in Table c.3. The estimated total daily costs for an 18,000-foot land rig built from new equipment and materials is $\$ 19,100$.

\section{AIR DRILLING}

In operations using air as the drilling fluid, compressors have to be brought onto the drill site. Two 1,000-psi, 1,200-scfm air compressors, at a daily rate of $\$ 1,200$ each, are generally used. This increases the daily drill-site charges by $\$ 100$ per hour. However, air drilling operations do not require the drilling fluids charged in Table c.4. This reduces the site-related costs by $\$ 3,000$ 
per day, or $\$ 125$ per hour. The net difference is estimated to be $\$ 600$ per day lower drill-site related costs during air drilling operations.

\section{COILED TUBING RIG}

Work on jointless tubing began in World War II. The use of coiled tubing in well field operations today is a $\$ 650$ million industry; however, $75 \%$ to $85 \%$ of the use of coiled tubing is for logging, clean out, and well maintenance activities. The use of coiled tubing in drilling has grown from 3 jobs in 1991 to 150 in 1994 and 350 were planned in 1995 . Coiled tubing has been used to drill a $121 / 4$-inch hole in Lake Maricaibo; but, in general, coiled-tubing drilling is constrained by flow and torque limitations to diameters below eight inches. The current record for the longest vertical section drilled with coiled tubing is 5,200 feet and the longest horizontal section is 3,200 feet (Newman 1995). Currently available coiled-tubing drill rigs have a lifting capacity on the order of 75 tons to 80 tons. This is a capacity of about six-thousand feet with seven-inch casing.

For land-based operations, the necessary investment to build a conventional rig capable of drilling to 18,000 feet is on the order of nine-million dollars. Well over seven-million dollars of that investment is spent on the surface system. In an attempt to find a way to reduce this expense, we investigated the cost of building a fully-integrated coiled-tubing rig capable of drilling to 18,000 feet. To reduce the size of the mast, a hydraulic system, essentially modified casing jacks, is employed to handle casing. Newman and Doremus describe a drilling rig similar to this, but it is not capable of drilling to 18,000 feet (Newman 1994).

The estimated costs to build and field the coiled-tubing rig described in the previous paragraph are given in Table c.5. In the \$6.3-million total, there are $\$ 4.9$ million in capital equipment and $\$ 500$ thousand in

Table c.5: Coiled Tubing System Costs

Sub-System Cost (000)

Mast \& Substructure $\$ 180$

Power Generation Equipment

$\$ 1,233$

Hydraulic Jack

$\$ 280$

Coiled Tubing Drive Unit

$\$ 250$

Mud Pumps \& High Pressure Equipment \$1,002

Mud Conditioning Equipment

BOP Equipment

$\$ 349$

Pipe Handling Equipment

Instrumentation

$\$ 875$

$\$ 182$

$\$ 72$

Miscellaneous Equipment

$\$ 360$

$31 / 2$-inch Tubing \& BHA

$\$ 299$

Assembly Cost $\$ 480$

Sub-Total

$\$ 5,562$

Contingency (5\%)

$\$ 278$

Taxes (8\%) $\$ 467$

Total

$\$ 6,307$ 


\section{Appendix C: Operating Costs}

expendable materials and equipment. When compared to the standard rig described previously, the coiled-tubing rig reduces the investment in capital equipment by $25 \%$, the investment in expendable materials and equipment by over $60 \%$, and the overall investment by $30 \%$.

A comparison of the two systems reveals the source of these savings. The mast of the coiled tubing rig is significantly reduced since its primary use is drill collar make-up, and it is not required to handle either drill pipe or casing. The drawworks is replaced by the hydraulic casing jack and tubing drive units; though a general purpose winch is included. Since both systems are expected to have the same depth capacity, the power generation and mud pump requirements are unchanged. The estimated costs for mud conditioning and BOP equipment are also unchanged. Another major source of savings is the reductions in pipe handling equipment. Instrumentation is reduced slightly since rotary rate and torque are not measured on the coiled-tubing rig. The tubing is cheaper than drill pipe. There is also no longer a need for the kelly or kelly valves.

\section{Tubing Sizes and Characteristics}

Coiled tubing sizes to $4 \frac{1}{1 / 2}$-inch OD are currently available in the U. S. and to $6 \frac{5}{8}-$ inch OD in Europe. However, because of fatigue strength limitations, coiled tubing used in lieu of drill pipe is currently restricted to $23 / 8$-inch OD. This size limits fluid flow and results in the need for a centrifuge in the mud conditioning equipment at a cost of about $\$ 120,000$. We have assumed that $31 / 2$-inch tubing with $1 / 4$-inch wall is available for drilling, thus reducing the need for a centrifuge. Even $31 / 2$-inch tubing would reduce flow and hole-cleaning ability when compared to 5-inch drill pipe.

We did not address the problem of transportation for $3 \frac{1}{2}$-inch tubing. On an eight-foot drum, 18,000 feet of $31 / 2$-inch by $1 / 4$-inch tubing would result in a eighteen-foot diameter load weighing 80 tons. To say the least, problems could be encountered attempting to move such a load down the highway. The use of significant lengths of large-diameter tubing will require the development of methods to join tubing rolls on site without introducing residual stresses.

The basic assumptions concerning interest rates, labor rates, rig utilization, and fuel costs are unchanged for the coiled tubing rig when compared to the conventional rig previously described (Table c.2). Because of the elimination of handling drill pipe, the coiled-tubing rig should be able to operate with a four-man crew instead of the five-man crew employed on a conventional rig.

Another major difference between the two systems relates to drill string life. We assumed that drill pipe would last for 300,000 feet of drilling. For the coiled tubing rig, we assumed that the tubing has to be salvaged every three wells. 
Current practice results in plastic deformation of the tubing once as it comes off the reel and twice as it goes over the guide arch and into the well. Fatigue damage to the tubing depends on the severity of the deformation and the internal pressure. As a general rule, current coiled tubing will withstand about thirty round trips before failure. This is roughly equivalent to drilling one well. The use of a larger radius could reduce or eliminate the plastic deformation of the tubing as it goes over the guide arch. Since the most severe deformation is at the reel, eliminating the plastic deformation at the guide arch would not reduce the fatigue damage by $2 / 3$; however, we have assumed that it would extend the tubing life from one well to three.

\section{Operational Costs}

Based on the discussion in the previous paragraphs, the operating costs for the coiledtubing rig given in Table c. 6 were determined using standard business practices.

Comparison of these estimates to those for a conventional rig reveals that long-term debt, short-term debt, maintenance, labor, insurance, and fuel costs are reduced; while rentals, transportation, and office support are unchanged.

\begin{tabular}{lr}
\hline \multicolumn{2}{c}{$\begin{array}{c}\text { Table c.6: Coiled-Tubing Rig } \\
\text { Operating Cost }\end{array}$} \\
Long-term debt & $\$ 2,600$ \\
Short-term debt & $\$ 2,300$ \\
Maintenance & $\$ 1,200$ \\
Labor & $\$ 2,300$ \\
Office support & $\$ 500$ \\
Insurance & $\$ 200$ \\
Fuel $\quad$ & $\$ 1.200$ \\
$\quad$ Total & $\$ 10,300$ \\
\hline \hline
\end{tabular}

The reduced labor costs are due to the use of four-man crews. Insurance costs are reduced for two reasons: reduced crew size and reduced capital investment. The reductions in long-term debt and maintenance costs for the coiled-tubing rig are due to the smaller overall rig and lower initial investment.

The fuel costs in Table c. 6 are primarily for the fuel necessary to produce power to drive the mud pumps. The reduced fuel costs for the coiled tubing rig reflect the reduced energy needs due to elimination of the necessity to rotate a drill string. However, not reflected in Table c.6, are the costs of the downhole motor necessary with coiled tubing. Motor rental will increase operating costs by $\$ 4,000$ to $\$ 6,000$ per day in addition to the estimates in the table. When motor costs are considered, the coiled tubing rig is higher cost than the standard rig.

It would seem that the mud pumps would have to work harder to drive the downhole motor and this should increase fuel costs. However, current motor technology limits the maximum hydraulic pressure difference across the motor. Consequently, pump drive characteristics (pressure and flow) are generally the same when a downhole motor is used as when turning from 
the surface. The motor thus limits the pressure drop across the bit nozzles and possibly reduces cleaning ability.

It was previously noted that expendable materials for the coiled-tubing rig were reduced by over $60 \%$ when compared to a conventional drill rig. Yet, the estimate of short-term debt is reduced by only $\$ 300$ per day (about $12 \%$ ). The short-term debt for the coiled tubing rig is dominated by tubing costs. In arriving at the estimate of short-term debt, we assumed that tubing life could be extended from one well to three wells by reducing the deformation at the guide arch. If tubing life is reduced to a single well, then the short-term debt (minus salvage) will more than double from $\$ 2,300$ to $\$ 4,800$. This would make the estimate of the operating cost of the coiled tubing rig, without drilling motor rental, essentially the same as a standard rig.

If we assume the contractor is required to cover taxes and manufacturer plus $30 \%$ of equipment and materials, the total outlay for the coiled tubing rig will be $\$ 2.6$ million. Assuming a $40 \%$ tax rate, we estimate that charging $\$ 10,300$ per day will result in between $12 \%$ and $13 \%$ average return on this investment over 30 years. This is comparable to the return on investment estimated for a conventional drill rig. The previous discussion concerning the necessary cash flow for maintaining operations of a conventional rig also applies to the coiled tubing rig.

Drilling with a coiled tubing rig would incur all of the additional operator costs previously estimated. Including these charges results in an estimate of $\$ 16,500$ for the total daily operating costs.

\section{Motor and Tubing Costs}

Overall, it doesn't appear that a specifically designed coiled-tubing rig would drill at lower operating cost than a similar size conventional drill rig. The cost of drilling with coiled tubing is exacerbated by two factors: the necessity of running a downhole motor and the cost of the tubing. If tubing life was comparable to drill pipe (300,000 feet), the estimate of short term debt in Table c. 6 would be reduced to $\$ 1,200$ and the estimate of operating cost would be reduced to $\$ 9,200$.

We performed a brief analysis, based on cash flow, of the factors effecting the cost of drilling motors. The assumptions used in this analysis are given in Table c.7. Our analysis predicts that reducing the capital investment by half would reduce operating costs by $10 \%$. Doubling the mean time between repair could reduce operating costs by as much as $45 \%$.

\section{Table c.7: Drilling Motor Costs}

Capital investment $\$ 60,000$

Mean time between repair/repair costs: bearings stator rotor 200 hours $/ \$ 10,000$ 400 hours / $\$ 12,000$ 800 hours $/ \$ 8,000$

Life 6 stator repair cycles


Reducing repair costs by half is predicted to reduce operating costs by $25 \%$. Doubling the life reduces costs by $5 \%$. Based on these numbers, motor rental costs appear to be dominated by repair cycle time and costs.

There is one advantage to the use of coiled tubing that has not been discussed: a wireline can be run inside coiled tubing. This is currently accomplished at an installation cost of about $\$ 20,000$ plus the cost of the wire (on the order of $\$ 1.00$ per foot). The tubing is currently uncoiled for installation, however, at least one company is working on a system to install the wire with the tubing on the reel in the hopes of reducing installation costs. In addition to providing signal transmission for downhole sensors, the wireline could be employed to drive an electric motor. The use of electric motors for bit rotation would decouple the motor drive from the bit hydraulics. This would facilitate speed and torque control. It is also possible that electric motors would be cheaper to operate than mud motors.

\section{ROCK MELTER DRILLING SYSTEM}

Rock melting systems do not need to rotate. Thus, these systems can employ a coiled tubing drilling rig without the financial penalty associated with drilling motors. The estimated costs for a rock-melter drilling system built from all new equipment are given in Table c.8. These cost estimates began with the basic coiled tubing system described previously.

Modifications and assumptions associated with the costs in Table c. 8 follow:

\begin{tabular}{lr}
\hline \multicolumn{2}{c}{$\begin{array}{c}\text { Table c.8: Rock Melter Drilling Rig } \\
\text { Sub-System }\end{array}$} \\
\cline { 2 - 2 } Cost (000) \\
Mast \& Substructure & $\$ 180$ \\
Power Generation Equipment & $\$ 1,333$ \\
Hydraulic Jack & $\$ 280$ \\
Coiled Tubing Drive Unit & $\$ 250$ \\
BOP Equipment & $\$ 875$ \\
Instrumentation & $\$ 55$ \\
Miscellaneous Equipment & $\$ 360$ \\
Tubing & $\$ 276$ \\
Assembly & $\$ 480$ \\
& \\
Sub-Total & $\$ 4,089$ \\
Contingency (5\%) & $\$ 204$ \\
Taxes (8\%) & $\$ 344$ \\
Total & \\
\hline \hline
\end{tabular}

- Two air compressors; each rated a $1,000 \mathrm{psi}, 1,200 \mathrm{scfm}$, and 1,200 in in Table c.8. These are considered a rental item and will be included in the daily operating rate. 
- Two diesel generator sets are dedicated to running the rig and air compressors. A third is dedicated to providing power for the drilling head. One generator can provide about one megawatt. If additional power generation is needed, additional generators can be put on the rig for $\$ 430$ per day each. Transformers adequate to step the voltage to between $50 \mathrm{kV}$ and $100 \mathrm{kV}$ are included in the rate for the generators dedicated to powering the drilling head.

- Dual wall coiled tubing is employed. The outer tube is $27 / 8$ inches in diameter and the inner tube is $1 \frac{1 / 4}{4}$ inches. The capability to manufacture dual-wall coiled tubing currently exists. The largest tubing currently used in drilling is $2 \frac{3 / 8}{}$ inches.

- The fuel charge incorporated in the rig rate is adequate for the rig and air compressors. Additional fuel is needed to develop power to drive the rock melter.

- A single multi-strand cable, 0.275 -inch diameter, will carry all necessary signals and power. This cable is run in the coiled tubing for a charge of $\$ 20,000$ plus $\$ 1.30$ per foot.

- No mud pumps or return mud conditioning system are needed or included with the rig.

The costs in Table c. 8 include $\$ 3.4$ million in capital costs and $\$ 430$ thousand in expendable materials and equipment. The remainder of the costs are assembly and taxes.

Based on the same assumptions given previously for a coiled tubing rig, the operating cost for a rock-melter rig are given in Table c.9. The reduction in long-term debt is a direct result of the reduced capital investment. The expense for short-term debt is driven largely by the cost of tubing. Maintenance is reduced due to the reduction in equipment. The fuel charge is to operate the rig and air compressors.

\section{Table c.9: Daily Operating Cost} Long-term debt Short-term debt $\$ 1,800$ Maintenance $\$ 3,300$ Labor $\$ 400$

Office support $\$ 2,300$ Insurance $\$ 500$ Fuel $\$ 200$ $\$ 1,100$ Total 
As with a standard drilling rig, there are additional operator-incurred charges not included in daily operating cost of the rockmelters rig. These costs are summarized in Table c.10. The cost of the air compressors is included in this category. The removal of the mud system reduces the operator incurred costs for the rock melter rig when compared to a standard rig.

Even though there is no drilling mud system on the rock-melter rig, there is a charge for mud logging in Table c.10. The mud logger on a standard drill rig maintains a data record of the drilling activities around the rig. Thus, while it is called mud logging, the task is better described by the category in which it is located: "Rig monitoring". Even without drilling mud, the job of the mud logger must be performed. Similar arguments are made for the items included in the category "Rental tools and services". Whether or not standard services are used, the functions of these services must be maintained.

Combining the costs in Table c. 10 with those in Table c. 9 yields an estimate of $\$ 14,600$ as the daily operating cost for a rock-melter drill rig. This is lower than for either the previously discussed coiled tubing rig or the conventional drill rig. The savings for the rock melter rig came primarily from two sources:

1. Removal of the bottom-hole assembly including drill collars, stabilizers, etc. and

2. Removal of the drilling mud and mud conditioning systems.

Thus while the rock-melter drill rig is lower cost, it is also limited to regions where air drilling is possible. With the way this rig is configured, there are no provisions to combat problems controlling formation fluids or borehole sloughing. If these problems are encountered, there are two possible courses of action: (1) remove the rock-melter rig and replace it with a standard drill rig or (2) plug and abandon the well. 


\section{APPENDIX D: RENTAL RATES}

\section{CASH FLOW MODEL}

Operationally, most of the concepts we investigated could either be provided as rental tools by a service company or could be purchased as a capital item by the operator or drilling contractor. In order to cover both possibilities, we needed to develop a consistent method to estimate rental rates. We used a cash flow model for this purpose. The following factors were considered in this model:

- interest rate - $12 \%$ was employed in all calculations,

- capital investment - the initial cost to build the tool or system,

- repair costs - the cost of expected repairs,

- mean time between repair - the operational time between expected repairs,

- useful life - total operational time expected before the tool is scrapped (no scrap value was incorporated in the model),

- idle time - the expected time after repairs, but before the tool is in use again,

- operational overhead - the cost of maintaining an office and crew for field support, and

- profit margin - add-on percentage of total cost.

Multiple repair cycles were allowed. For example, mud motors require repairs of the bearings, the stator, and the rotor. Each of these has a different expected cost and a different mean-time-between-repairs (mtbr). We assumed that all tools would be idle for ten days after repairs and before being used again.

We used $\$ 120$ per day for operational overhead. This amount is based on maintaining an office with an engineer, a secretary, three field support technicians, and a shop hand. Each of the field support technicians are paid wages plus per diem and are expected to maintain ten tools with an average of five in use. The field support hands, the engineer, and the shop hand were all assumed to have company vehicles.

When the above parameters are input to the model, a cash flow accounting for all income and costs over the life of the tool is performed. The break-even rental rate is determined so that the total income is adequate to cover the total costs. The profit margin is figured as a percentage of the break-even rental rate. Standby charges were estimated by determining the necessary charge to cover the capital investment only.

In practice, rental rates are determined by supply and demand. The owner of a tool will offer it at a given rental rate. If demand is heavy, the rate will be increased; if demand is light, it will be decreased. Costs and cash flow enter the scene only if the rate that can be obtained is 
insufficient to maintain necessary cash flow to support the business and cover costs. The cashflow analysis we employed does not model supply and demand, but it does give a consistent method to estimate rates for different tools and concepts.

In conjunction with the performance curves developed in Appendix A; the cash flow analysis gives estimates of the needed performance for a given tool to be competitive with conventional rotary drilling. The general effect of rental rates on performance requirements is discussed in Appendix A. 
Appendix D: Rental Rates

page IX-26 
DISTRIBUTION:

Mike Akins

Chevron Petroleum Technology

PO Box 4450

Houston, TX 77210

John K. Aslakson

Senior Technology Manager

Gas Research Institute

8600 West Byrn Mawr Avenue

Chicago, IL 60631-3562

Huy D. Bui

Project General Manager

Smith International, Inc.

16740 Hardy Street

Houston, TX 77205-0068

Gilles Bussod

GeoEngineering Group, EES-4

Mail Stop H-865

Los Alamos National Laboratory

Los Alamos, NM 87545

Louis E. Capuano, Jr.

Drilling Engineer

ThermaSource, Inc

725 Farmers Lane

Santa Rosa, CA 95402

John H. Cohen, PE

Vice President

Maurer Engineering, Inc.

2916 West T.C. Jester

Houston, TX 77018-7098

Jim Combs

Geo Hills Associates

27790 Edgerton Road

Los Altos Hills, CA 94022

George A. Cooper

Professor of Petroleum Engineering

Department of Materials Science and

Mineral Engineering

University of California

Berkeley, CA 94720
Aaron Dick

GeoEngineering Group, EES-4

Mail Stop H-865

Los Alamos National Laboratory

Los Alamos, NM 87545

Dave Duchane

Mail Stop D443

Los Alamos National Laboratory

Los Alamos, NM 87545

John R. Duda

Petroleum Engineer

Morgantown Energy Technology Center

PO Box 880

Collins Ferry Road

Morgantown, WV 26507-0880

Daniel Entingh

Senior Scientist

Nova Analytics

3025 Pine Spring Road

Falls Church, VA 22042-1324

Jerry Evanoff

Halliburton Services

PO Box 80118

Bakersfield, CA 93380

Edward B. Fisher

Executive Vice President and $\mathrm{COO}$

Veritay Technology, Inc.

4845 Millersport Highway

East Amherst, NY 14051-0305

Mike Forsha

Barber-Nichols, Inc.

6325 West $55^{\text {th }}$ Street

Arvada, CO 80002

George A. Gazonas

U.S. Army Research Laboratory

Attn: AMSRL-WT-PD

WTD

Aberdeen Proving Ground, MD

21005-5006 
Sue Goff

Team Leader

GeoEngineering Group, EES-4

Mail Stop H-865

Los Alamos National Laboratory

Los Alamos, NM 87545

William J. Gwilliam

Senior Petroleum Geologist

Morgantown Energy Technology Center

PO Box 880

Collins Ferry Road

Morgantown, WV 26507-0880

David R. Hall

Novatek

2185 South Larsen Parkway

Provo, UT 84606

Jerry Hamblin

Unocal / Indonesia

Ratu Plaza Office Tower

3rd to 9th Floors

PO Box 1254

Jakarta, Indonesia 10012

Joe Heilhecker

78 West Golf Place

Pagosa Springs, CO 81147

David W. Holm

Safety Manager

Mitchell Energy Corporation

PO Box 4000

The Woodlands, TX 77387

Allan Jelacic

Geothermal Division EE-122

Energy Efficiency and Renewable Energy

Department of Energy

1000 Independence Avenue S.W.

Washington, DC 20585

James N. Juliana

Public Affairs Advisor

1899 L Street NW

Suite 500

Washington, DC 20036
R. Helene Knowlton

Project Manager

Smith International, Inc.

16740 Hardy Street

Houston, TX 77205-0068

B. J. Livesay (10)

Livesay Consultants = 126 Countrywood Lane

Encinitas, CA 92024

W. C. Maurer

Maurer Engineering, Inc.

2916 West T.C. Jester

Houston, TX 77018-7098

Rand Miller

Westinghouse Hanford Co.

PO Box 1970

MSIN H6-32

Richland, WA 99352

William M. Moeny

Vice President of Research \& Development

Tetra Corporation

3701 Hawkins St. NE

Albuquerque, NM 87109-4512

Ken Nichols

Chief Executive Officer

Barber-Nichols, Inc.

6325 West $55^{\text {th }}$ Street

Arvada, CO 80002

Nic Nickels

Baker Hughes INTEQ

3636 Airway Drive

Santa Rosa, CA 95403

Ken Newman

President

CTES, L.C.

9870 Pozos Lane

Conroe, TX 77305-2178 
Jim O'Connor

FlowDril Corporation

$2141468^{\text {th }}$ Avenue So.

Kent, WA 98032

Susan Petty

Susan Petty Consulting

654 Glenmont Avenue

Solana Beach, CA 92075

Carl Petersen

MIT Energy Lab

E40-455

77 Massachusetts Avenue

Cambridge, MA 02139

Alan C. Pierce

Special Research Associate

Amoco Production Company

Research Center

4502 East $41^{\text {st }}$ Street

Tulsa, OK 74102

David S. Pixton

Novatek

2185 South Larsen Parkway

Provo, UT 84606

Gene Polk

Desert Drilling Fluids

3316 Girard NE

Albuquerque, NM 87107

Bob Potter

EES4 - MS D443

Los Alamos National Laboratory

Los Alamos, NM 87545

D. Stephen Pye

Unocal Geothermal

12th Floor, Citibank Tower

8741 Paseo de Roxas

Makati City, 1226

Philippines
M. Scott Quigley

Vice President

CTES, L.C.

9870 Pozos Lane

Conroe, TX 77305-2178

Mark Rankin

Director of Contracts \& Marketing

Pool Energy Services Co.

PO Box 4271

Houston, TX 77210

Herman H. Rieke

Professor and Head Petroleum Engineering

University of Southern Louisiana

USL Box 44690

Lafayette, LA 70504-4690

Roger E. Rinaldi

Willbros Butler Engineers, Inc.

2087 East $71^{\text {st }}$ Street

Tulsa, OK 74136

John C. Rowley

Earth \& Environmental Sciences Division

Mail Stop D443

Los Alamos National Laboratory

Los Alamos, NM 87545

Jim Ruhle

Scientific Driller

PO Box 4301

Fullerton, CA 92634

Dave Runyon

Western District Manager

STEP, Inc:

13111 East Briarwood Avenue

Suite 250

Englewood, CO 80112

Iraj A. Salehi

Executive Technology Manager

Gas Research Institute

8600 West Byrn Mawr Avenue

Chicago, IL 60631-3562 
Jeffrey C. Savela

Mechanical Engineer

Texaco, Inc.

4800 Fournace

Bellaire, TX 77401

Frank J. Schuh

President

Drilling Technology, Inc.

5808 Wavertree - Suite 1000

Plano, TX 75093-4513

Earl Shanks

Mobile Exploration and Producing

Technical Center

Special Drilling Technologies

PO Box 650232

Dallas, TX 75265-0232

Marc W. Steffen

Cal-Pine Corporation

1160 North Dutton, Suite 200

Santa Rosa, CA 95401

John Sellar

President

PowerPulse Systems, Inc

6045 W. Evans Place

Lakewood, CO 80227

David A. Summers

University of Missouri

Rock Mechanics Department

1006 Kingshighway

Rolla, MO 65401

Jefferson W. Tester

MIT Energy Lab

E40-455

77 Massachusetts Avenue

Cambridge, MA 02139

Gordon Tibbitts

Hughes Christensen

1937 South 300 West

Salt Lake City, UT 84115
Scott D. Veenhuizen

Senior Research Scientist

FlowDril Corporation

$2141468^{\text {th }}$ Avenue So.

Kent, WA 98032

Tommy Warren

Research Supervisor :

Amoco Production Company

Research Center

4502 East $41^{\text {st }}$ Street

Tulsa, OK 74102

W. W. Webster

Mobile Exploration and Producing

Technical Center

Special Drilling Technologies

PO Box 650232

Dallas, TX 75265-0232

Mike W. Weiss

Senior Technology Manager

Gas Research Institute

8600 West Byrn Mawr Avenue

Chicago, IL 60631-3562

Paul A. Wescott

Senior Technology Manager

Gas Research Institute

8600 West Byrn Mawr Avenue

Chicago, Il 60631-3562

John D. Wilson

President and CEO

TeleJet Technologies, Inc.

3030 LBJ Freeway

Suite 1210

Dallas, TX 75234

Geoffrey J. Wilkinson

General Partner

Newport Financial Limited

2811 McKinney Avenue

Suite 208

Dallas, TX 75204 
Jack Wingerter

President

Cobra Industries, Inc.

2021 Aldine Mail Rt. Ste. 202

Houston, TX 77039

Warren J. Winters

Staff Research Engineer

Amoco Production Company

Research Center

4502 East $41^{\text {st }}$ Street

Tulsa, OK 74102

Stephen L. Wolhart

Senior Technology Manager

Gas Research Institute

8600 West Byrn Mawr Avenue

Chicago, IL 60631-3562

Roy M. Wolke

Manager

M-I Air Drilling

3 Greenway Plaza

Suite 2049

Houston, TX 77242

Donald L. Woodford

Project Director

Texaco, Inc.

4800 Fournace

Bellaire, TX 77401

A. B. Yost II

Project Manager

Natural Gas Technology Branch

U. S. Department of Energy

Morgantown Energy Technology Center

PO Box 880

Collins Ferry Road

Morgantown, WV 26507-0880

Internal:

Chuck Carson

MS 0860 - Dept. 2522

Doug Drumheller

MS 1033 - Dept. 6111
Jim Dunn

MS 1033 - Dept. 6111

Rob Easterling

MS 0419 - Dept. 5412

John Finger (10)

MS 1033 - Dept. 6111

Dave Glowka (350)

MS 1033 - Dept. 6111

Dave Northrop

MS 0706 - Dept. 6112

Ken Pierce (10)

MS 0419 - Dept. 5412

Bill Sullivan

MS 1033 - Dept. 6111

Central Technical Files (1)

MS 9018 - Dept. 8523-2

Technical Library (5)

MS 0899 - Dept. 4414

Review \& Approval Desk (2)

MS 0619 - Dept. 12630

For DOE/OSTI 